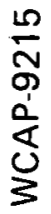

COO-2962-5/UC-78

\title{
IMPROVEMENT OF AVAILABILITY OF PWR NUCLEAR PLANTS THROUGH THE REDUCTION OF THE TIME REQUIRED FOR REFUELING/MAINTENANCE OUTAGES
}

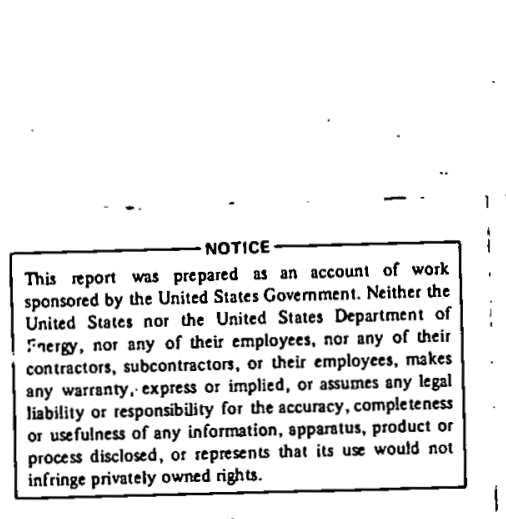

Contract \#EY-76-C-02-2962 - 5

$$
\text { . }
$$

Interim Report

April 1978

Prepared by

Commonwealth Research Corporation

P. O. Box 428

Chicago, Illinois

and

Westinghouse Electric Corporation

PWR Systems Division

P. O. Box 355

Pittsburgh, PA 15230

Principal Investigators

J. B. Mayers (Westinghouse)

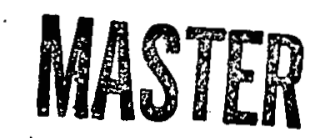

L. G. Soth (Commonwealth Edison)

Prepared for

United States Department of Energy

Program Manager

C. A. Thompson 


\section{DISCLAIMER}

This report was prepared as an account of work sponsored by an agency of the United States Government. Neither the United States Government nor any agency Thereof, nor any of their employees, makes any warranty, express or implied, or assumes any legal liability or responsibility for the accuracy, completeness, or usefulness of any information, apparatus, product, or process disclosed, or represents that its use would not infringe privately owned rights. Reference herein to any specific commercial product, process, or service by trade name, trademark, manufacturer, or otherwise does not necessarily constitute or imply its endorsement, recommendation, or favoring by the United States Government or any agency thereof. The views and opinions of authors expressed herein do not necessarily state or reflect those of the United States Government or any agency thereof. 


\section{DISCLAIMER}

Portions of this document may be illegible in electronic image products. Images are produced from the best available original document. 


\section{LEGAL NOTICE}

This report was prepared as an account of work sponsored by the United States Government. Neither the United States nor the United States Department of Energy, nor any of their employees, nor any of their contractors, subcontractors, or their employees, makes any warranty or representation, express or implied, or assumes any legal liability or responsibility for the accuracy, completeness, or usefulness of any information, apparatus, product or process disclosed, or represents that its use would not infringe privately owned rights. 


\begin{abstract}
The objective of this project, conducted by Commonwealth Research Corporation and Westinghouse Electric Corporation, is to identify improvements in procedures and equipment which will reduce the time required for refueling/maintenance outages at PWR niuclear power plants. The outage of Commonwealth Edison Zion Station Unit 1 in March through May of 1976 was evaluated to identify those items which caused delays and those work activities that offer the potential for significant improvements that could reduce the overall duration of the outage and achieve an improvement in the plant's availability for power production. Modifications in procedures have been developed and were evaluated during one or more outages in. 1977.

Conceptual designs have been developed for equipment modifications to the refueling system that could reduce the time required for the refueling portion of the outage. The purpose of this interim report is to describe those conceptual designs and to assess their impact upon fu-. ture outages. Recommendations are included for the implementation of these equipment im. provements in a continuation of this program as a demonstration of plant availability benefits that can be realized in PWR nuclear plants already in operation or under construction.
\end{abstract}




\section{TABLE OF CONTENTS}

Section

1

2
Title

Page

INTRODUCTION

1.1

2.1

2.1 Phase I

2.1

2.1.1 Task A - Development of an Improved Master Plan for the Refueling/Maintenance Outage:

2.1.2 Task B - Verification of the Improved Master Plan

2.1.3 Task C - Development of Improved Refueling Procedures

2.1

2.1.4 Task D - Verification of Improved Refueling Procedures

2.2

2.1.5 Task E - Phase I Final Report

DESCRIPTION OF. REFUELING EQUIPMENT AND PROCEDURES

3.1 Description of Reactor Components Associated With Refueling

3.1.1 Description of Refueling Operations

3.1.2 Preparation of the Reactor Coolant System

3.1.3 Preparation for Containment Entry

3.1.4 Draining and Venting of the Reactor Coolant System

3.1.5 Reactor Disassembly

3.1.6 Fuel Movement

3.1.7 Component Maintenance Performed Parallel to Core Loading

3.1.8 Reactor Reassembly 


\section{TABLE OF CONTENTS (cont)}

Section

4
Title

Page

EVALUATION OF 1976 REFUELING OF ZION UNIT 1.

4.1

4.1. Introduction

4.1

4.2 Tabulation of Refueling. Data

4.2

4.3 Analyses of Work Time Data

4.2

4.4 Analyses of Refueling Critical Path. Time Data

4.15

CONCEPTUAL DESIGN OF EQUIPMENT MODIFICATIONS TO REDUCE THE TIME REQUIRED FOR REFUELING

5.1

5.1 Integrated Vessel Head Assembly. For One-Lift Operation

5.1.1 Introduction

5.1

5.1.2 Reactor Vessel Head

5.1

5.1.3 Cooling Shroud Structure

5.1

5.1.4 Lifting Rig

5.3

5.1.5. Missile Shield

5.3

5.1.6 Seismic Platform

5.3

5.1.7 Cable Tray

5.3

5.1.8 Stud Handling System

5.3

5.2 Improved Reactor Vessel Head Closure System.

5.4

5.3 Improved Manipulator Crane (Refueling Machine)

5.4

5.3.1. Single Integrated Gripper Mast Assembly (SIGMA)

5.4

5.4. Improved Lighting System

5.11

5.5. Portable Underwater TV System

5.11

5.6 Improved Refueling Machine Control System

5.12

5.7 Reactor Cavity Filtration System

5.12

5.8 Refueling Cavity Cleaning Equipment

5.14

5.9 Reactor Vessel O-Ring Groove Cleaning Equipment

5.15

5.10 Portable RCC Change Tool

5.15

5.11 Reactor Vessel Stud Cleaning

5.17

5.12 Improved Burnable Poison Rod Assembly Handling Tool

5.17

5.13 Containment. Access Handling Equipment.

5.17

5.14 Cavity Access Equipment

5.18

5.15 CRDM Electrical Test Equipment 


\section{TABLE OF CONTENTS (cont)}

Section

6

7

Appendix
Title

Page

ANALYSIS OF POTENTIAL BENEFITS

6.1

6.1 Utilization of Time

6.1

6.2 Time Utilization Factor During Zion Refueling

6.3

6.3 Estimated Refueling Critical Path Time With

. Recommended Equipment Modifications

6.4 Projected Zion Refueling Critical Path Time Without Proposed Equipment Modifications

6.15

6.5 Estimated Improvement in Labor Expenditures

6.15

6.6 Estimated Reduction in Radiation Exposure

6.17

Modifications

7.1

7.1

7.1 Conclusions

7.3

7.2 Recommendations

A. 1 


\section{LIST OF ILLUSTRATIONS}

Figure

1.1

1.2

3.1

3.2

3.3

3.4

3.5

3.6

3.7

3.8

3.9

3.10

3.11

3.12

3.13

3.14

3.15

3.16

3.17

3.18

3.19

3.20

3.21

3.22

3.23

3.24

3.25
Title

Page

Commonwealth Edison Company Service Territory

1.2

Zion Nuclear Generating Station

1.4

Outage Coordination Center

3.10

Cable Tray in Vertical Stored Position

3.11

Nozzle Cover Sealing

3.12

Stud Tensioners

3.13

Stud Removal Tools

3.14

3.15

3.16

3.17

3.18

R.V. Head Lifting Rig Installed

Details of Upper Head Assembly - Showing Lift Rig, Seismic Support Platform and Stud Hoists

3.19

3.20

3.21

Lower End of Drive Rod Unlatching Tool

3.22

Upper End of.Drive Rod Unlatching Tool

3.23

Internals Lifting Rig

3.24

Internals Lifting Rig Installed

3.25

3.26

Manipulator Crane Front View

3.27

Manipulator Crane Side View

3.28

Manipulator Crane Control Panel

3.29

Manipulator Crane Walkway

3.30

Remote Video Inspection Equipment

3.31

3.32

3.33

Spent Fuel Pool and Bridge

3.34 


\section{LIST OF ILLUSTRATIONS (cont)}

Figure

Tịtle

Page

3.26

Cavity Cleaning Equipment and Head Assembly Protection

3.35

3.27

Cavity Cleaning Cage and High Pressure Equipment

3.36

3.28

3.29

Head Protective Covering for Cavity Cleaning

3.37

Personnel Access Hatch Inside Containment

3.38

3.30

3.31

Reactor Coolant Pump Motor Maintenance

3.39

Reactor Coolant Pump Rotor Maintenance

3.40

4.1

Zion Unit 1 Ref. 1976 Task Performance Vs Outage Time

$4.7 / 4.8$

5.1

Integrated Vessel Head Package

5.2

5.2

5.3

Quick-Disconnect Stud Tensioner

5.5

Head Stud Adapter (For Quick-Disconnect Tensioner)

5.6

Fast Stud Spin-Out Tool

5.7

Quick-Disconnect Tensioner Gripping Operation

5.8

Sigma Mast Manipulator Crane

5.10

Westinghouse Reactor. Cavity Filtration System

5.13

Portable RCC Change Tool

5.16

Work Path for Typical Refueling with Equipment

Modification

$6.9 / 6.10$ 


\section{LIST OF TABLES}

Table

Title

Page

1.1

Commonwealth Edison Company Nuclear Generating Stations

1.3

1.2

Cycle I-II Refueling/Maintenance Outage Scope of Work

1.6

1.4

Zion Unit 1 - First Refueling 1976 Tabulation of Observed Performance of Refueling Activities

$4.3 / 4.4$

4.2

Refueling Work Items Ranked According to Time Required During 1976 Refueling of Zion Unit 1

Major Refueling Work Categories Ranked According to Time Required During 1976 Refueling of Zion Unir 1

4.12

Reactor Disassembly/Assembly Work Times

4.14

Time of Work Items on the Refueling Critical Path

4.16

Zion Refueling Study-Observed and Estimated Improved Values for Typical Refueling

$6.5 / 6.6$

Refueling Time Benefits With Proposed Equipment Changes

6.14

Estimate of Labor Savings with Proposed Equipment Modifications

6.16

Estimate of Reduction of Radiation Exposure

6.18

Allocation of Refueling Benefits to Equipment Improvements

6.19

6.5

Summary of Benefits of Refueling Equipment Improvements

7.2 


\section{SECTION 1 INTRODUCTION}

The U.S. Department of Energy (formerly ERDA) has established a refueling outage technology improvement program to identify and demonstrate improved refueling, maintenance, and inspection procedures and equipment. This program is part of DOE's Light Water Reactor Technology Program established in 1976 to minimize consumption of oil and gas for electric power generation and to reduce dependence on foreign energy resources by making better use of existing nuclear capacity.

This project, as part of DOE's refueling outage program, is being conducted by Commonwealth Research Corporation in conjunction with Westinghouse Electric Corporation. Commonwealth Edison Company's Zion Nuclear Generating Station is being used for the observation and evaluation of refueling outages. Section 2 of this report provides an outline of the project.

Commonwealth Research Corporation is an implementing agency for research projects which use the resources and facilities of Commonwealth Edison Company.

Commonwealth Edison is an investor owned utility serving 2.8 million customers in northern Illinois within its approximately 11,525 square mile service territory which includes Chicago (Figure 1.1). Its generating plant consists of 5,453 MW nuclear, 8,962 MW fossil, and 1,857 MW fast start gas turbine peaking units. The system record peak load of 13,932 MW was recorded on July 15, 1977.

The Company has been using nuclear power for electric generation since 1960. Its seven nuclear units currently in operation (Table 1.1) together produced $40 \%$ of Edison's output in 1976. This nuclear generation replaced alternate fuels equivalent to either 14 million tons of low-sulfur coal or 44 million barrels of residual oil and saved Edison's customers \$184 million in reduced fuel adjustment charges (compared to what such charges would have been if low-sulfur coal had been used instead of nuclear). Construction work is in progress on six more nuclear units at three sites which will boost the Company's nuclear capacity to about $11,700 \mathrm{MW}$ by the mid-nineteen-eighties.

Zion Nuclear Generating Station (Figure 1.2) houses the 6th and 7th nuclear units on the Edison system - two pressurized water reactor units with a total net capability of $2080 \mathrm{MW}$. The Station is located on the shore of Lake Michigan in the city of Zion in the north-east corner of Illinois about midway between Chicago and Milwaukee. 


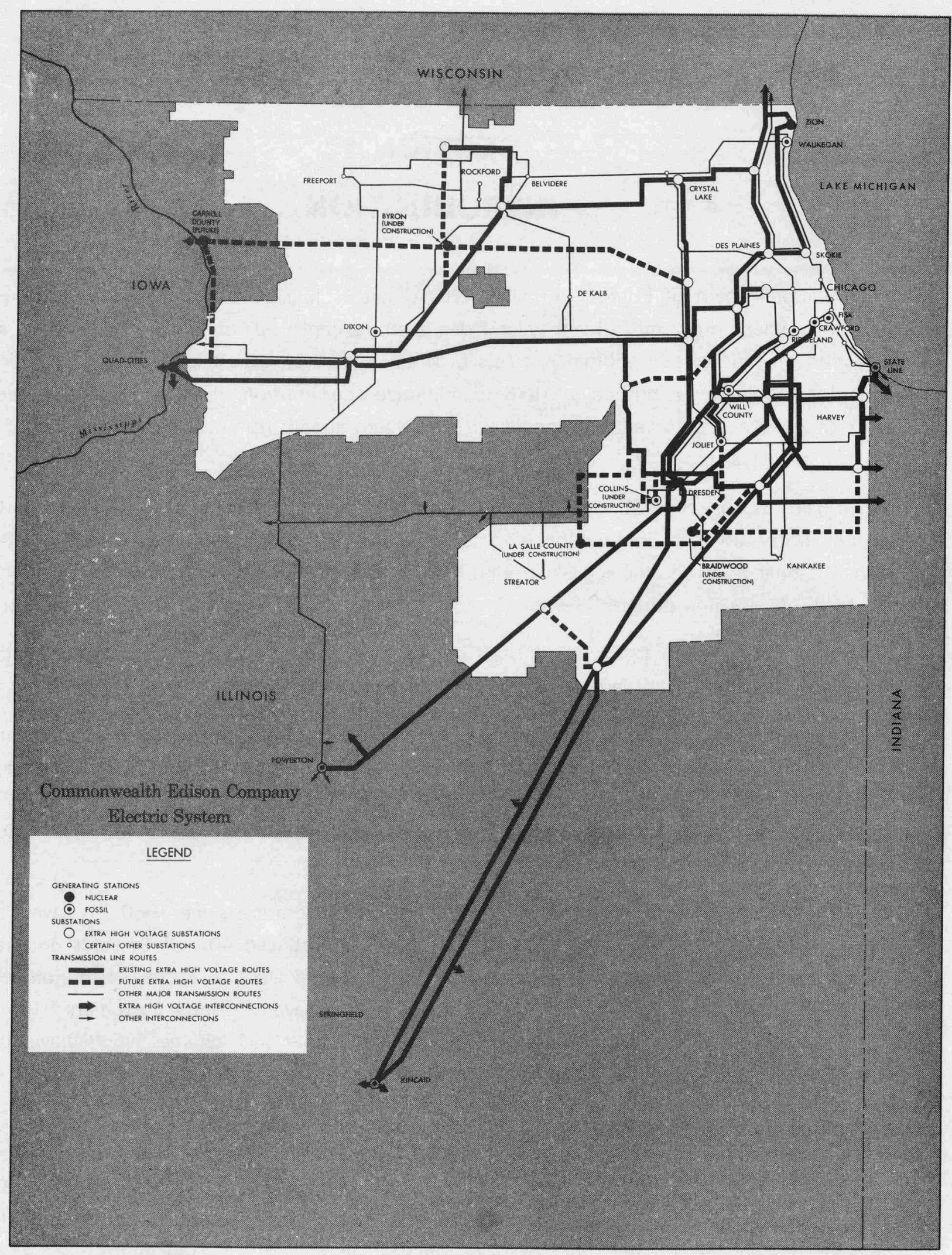

Figure 1.1 Commonwealth Edison Company Service Territory 
TABLE 1.1

COMMONWEALTH EDISON COMPANY NUCLEAR GENERATING STATIONS

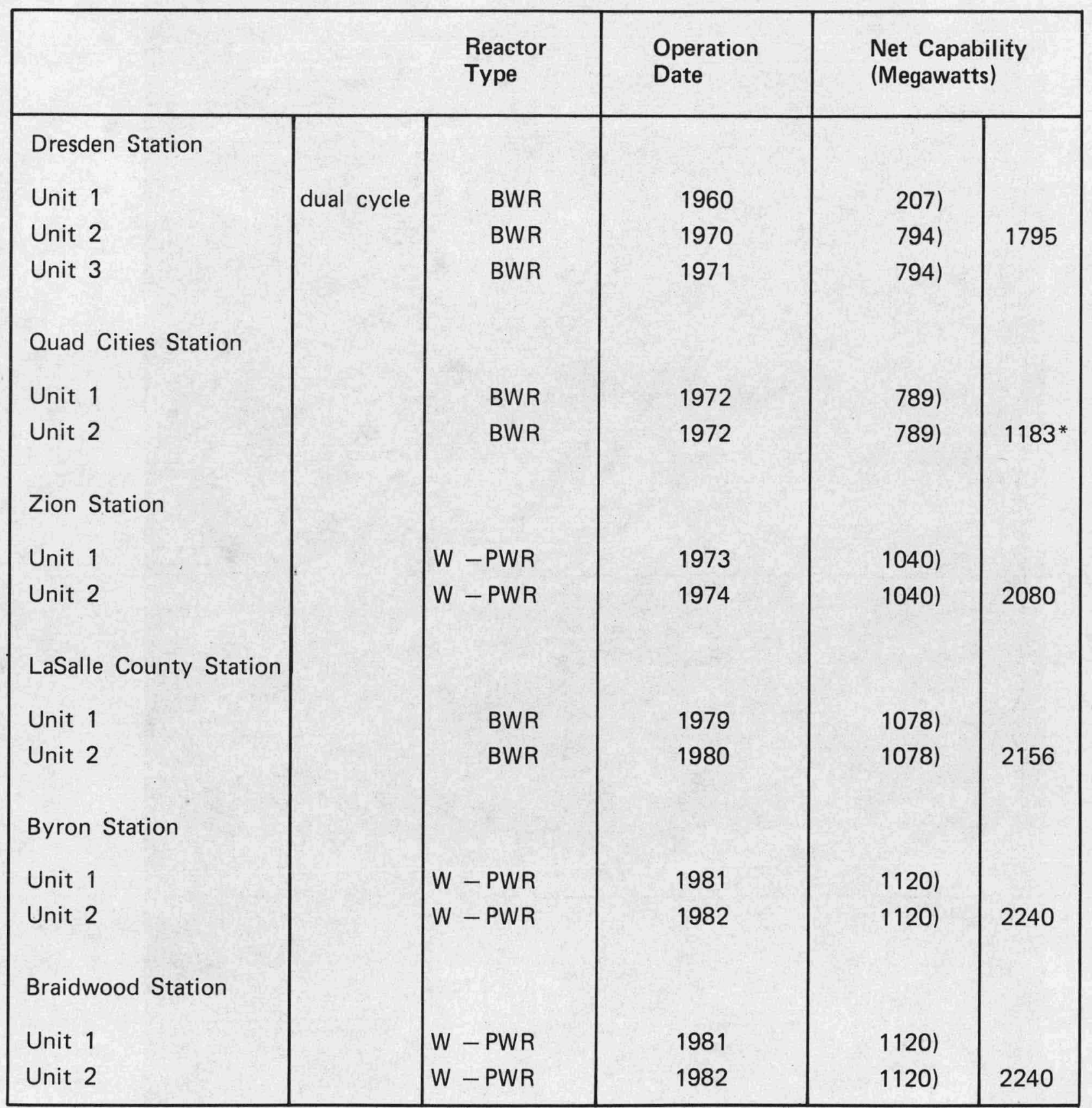

* $75 \%$ of Quad Cities Station is owned by Commonwealth Edison Company, $25 \%$ by lowa-lllinois Gas and Electric Company. 


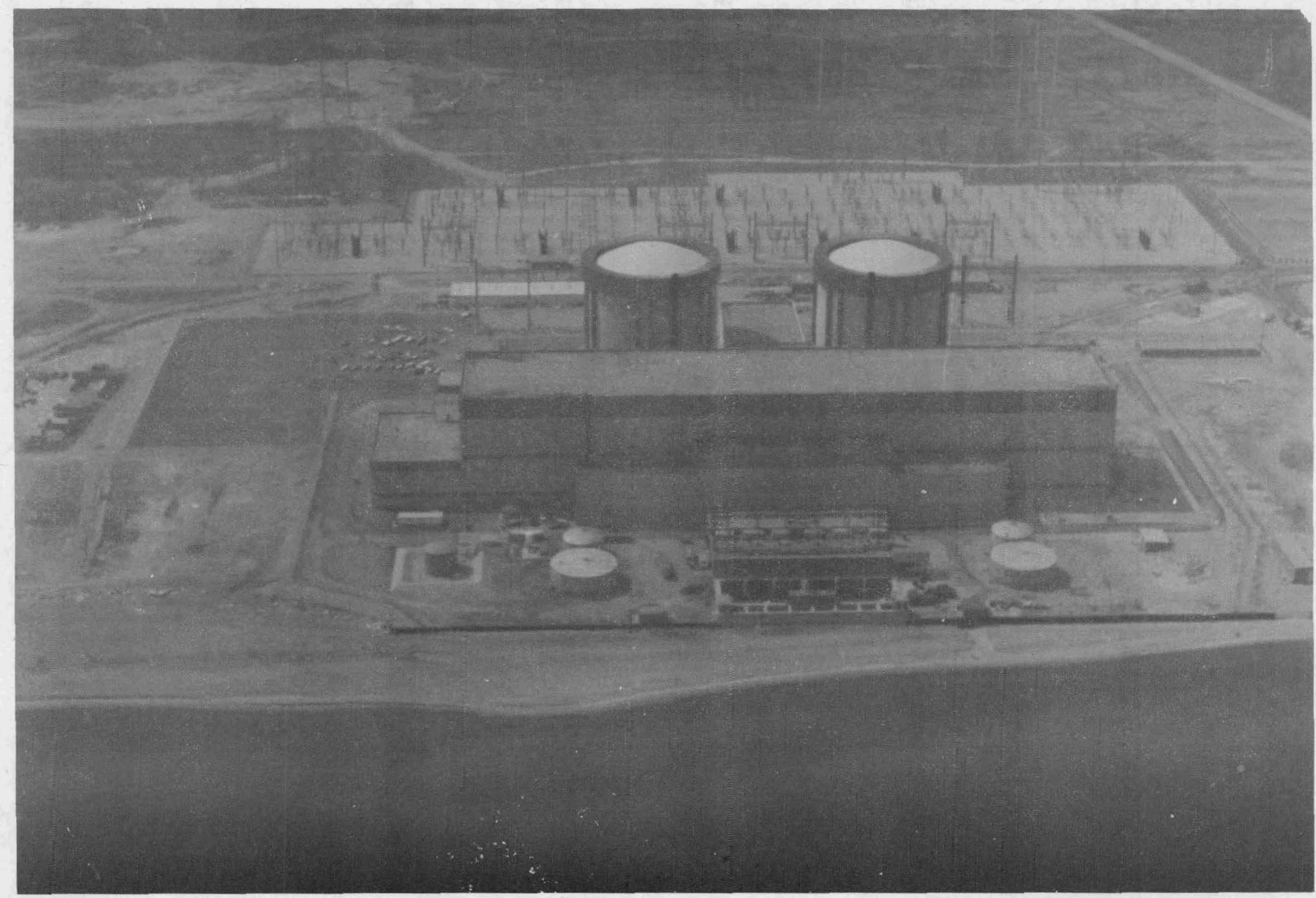

Figure 1.2 Zion Nuclear Generating Station 
Zion's two nuclear steam supply systems as well as the turbine-generator units were supplied by Westinghouse Electric Corporation on a non-turnkey basis. Sargent and Lundy is the station architect-engineer and Commonwealth Edison provided its own construction management.

The Zion reactor plants are four loop PWRs with a licensed rating of $3250 \mathrm{MWt}$, each located in spray-type containments. The turbine-generators are $1800 \mathrm{rpm}$ four cylinder, tandem compound, sextuple flow, condensing units with a nameplate rating of $1085 \mathrm{MW}$. Condenser cooling is provided by a once-through cooling system to Lake Michigan.

The PSAR for the station was submitted in July of 1967, the FSAR in November, 1970, and the environmental report in May, 1971. Unit 1 fuel loading was begun on April 7, 1973, the reactor taken critical for the first time on June 19, and the generator initially synchronized to the Edison grid on June 28. Initial criticality for Unit 2 was achieved on Christmas Eve, 1973 , with initial generation. two days later.

Being among the first of the large, high power density reactor plants placed in operation, the Zion units were subjected to an extensive (and extended) startup testing and power escalation program. In addition, the units were limited by the NRC (then AEC) to $85 \%$ of full power throughout the first core cycles until operating experience with 1000 MWe reactor plants was gained and until the fuel could be examined visually at the first refueling. Unit 1 was taken off-system for its first refueling/maintenance outage on March 5, 1976, almost 3 years from core load.

The observation phase of this project for the Department of Energy was begun with this initial refueling outage. Table 1.2 outlines the scope of the work performed at this initial refueling.

A number of changes in outage "software" - planning, organization, and procedures - were. developed from the experience gained during this outage and applied during the initial refueling/maintenance outage of Zion Unit 2 which was conducted in early 1977. These areas will be discussed in the final report for this project.

Similarly, several modifications to hardware were developed by the station for inclusion in Unit 2's outage, and design concepts for additional hardware changes to shorten refueling activities were generated. These items are discussed in this report.

Shortening refueling/maintenance outages, the goal of this program, is especially important for a large generating unit like those at Zion. A reduction in outage duration by one day can save Edison's customers approximately a quarter of a million dollars in replacement fossil fuel costs, and replaces alternate fuels equivalent to 14 thousand tons of low-sulfur coal or 44 thousand barrels of residual oil. 
TABLE 1.2

\section{CYCLE I-II REFUELING/MAINTENANCE OUTAGE} SCOPE OF WORK

Refueling: 60 spent fuel assemblies removed and replaced with new assemblies.

84 burnable poison rod assemblies removed.

Turbine Overhaul:

1C Low Pressure Turbine inspected and overhauled

Unit 1 Generator inspected and overhauled

Governor valves, stop valves, and intercept valves inspected and overhauled

1C Steam Generator Feedwater Pump Turbine inspected.

3 Reactor Coolant Pump motors disassembled and inspected.

Eddy Current Inspection performed on 1A Steam Generator.

Sludge Lancing performed on all four Steam Generators.

Inservice Inspection of piping, welds, and supports.

69 technical specification required refueling surveillances completed.

37 modifications made to existing systems.

643 work request (repair) jobs completed.

Major modifications included:

Installation of air-operated main steam isolation valve bypass valves.

Reroute of piping and components in the Volume Control Tank valve aisle to more accessable locations.

Reactor Coolant Pump motor oil lift system and thrust runner changes.

Reroute and changes to Condensate Storage System piping to permit split (unit) as well as shared system operation. 


\section{SECTION 2 \\ PROGRAM DESCRIPTION}

\subsection{PHASE I}

Phase I of the program is subdivided into the following tasks:

\subsubsection{Task A - Development of an Improved Master Plan for the Refueling/Maintenance Outage}

This task was begun with observations of the first refueling outage of Zion Unit 1 during March, April and May of 1976. A detailed plan had been prepared by Commonwealth Edison for the scheduling and management of the outage. Comparison of this plan with the actual performance of the outage identified those items that caused unexpected delays.

A number of changes to procedures and a few equipment modifications have been made to minimize these delays and to reduce the time required for other work items.

\subsubsection{Task B - Verification of the Improved Master Plan}

The effects of the changes implemented in Task $A$ were evaluated during the first refueling outage of Zion Unit 2 begun in January, 1977. The effects of these modifications and recommendations for further improvements will be included in the final report prepared under Task $E$.

\section{2:1.3 Task C - Development of Improved Refueling Procedures}

The 1976 refueling of Zion Unit 1, including preparatory operations such as degassing and draining of the reactor coolant system and removal of the reactor vessel head, was observed in detail and evaluated to develop procedural improvements that could be made to reduce the overall time required for the refueling portion of the outage.

The fuel movement operations were performed without serious delays, but a number of recommendations were developed for improving the preparatory procedures.

Section 4 of this interim report provides an analysis of the Unit 1 refueling, and Section 5 describes conceptual equipment design changes that have been identified to improve the refueling systems. The potential benefits of these changes are evaluated'in Section 6 . Development and demonstration of these changes are recommended in an extension of the program. 


\subsubsection{Task D - Verification of Improved Refueling Procedures}

The results of the outage improvement efforts will be published in a final report. The improved master plan developed for scheduling and managing the outage will be included to assist other plants in improving their availability:

\subsubsection{Task E - Phase I Final Report}

The results of Phase I will be documented in a final report. 


\section{SECTION 3 \\ DESCRIPTION OF REFUELING EQUIPMENT AND PROCEDURES}

\subsection{DESCRIPTION OF REACTOR COMPONENTS ASSOCIATED WITH REFUELING}

The following brief description is given of the Zion nuclear reactor components involved in the refueling operation. Figures 3.1 through 3.31 illustrate some of the equipment and activities associated with the refueling.

Each of the units at the Zion station is a Westinghouse 4-Loop pressurized water reactor of standard design. The reactor core contains 193 mechanically identical fuel assemblies. Each fuel assembly is a $15 \times 15$ array of fuel rods and is approximately $8.5 \mathrm{in}$. square and $13 \mathrm{ft}$, $4 \mathrm{in.} \mathrm{long.} \mathrm{The} \mathrm{core} \mathrm{also} \mathrm{contains} \mathrm{rod} \mathrm{cluster} \mathrm{control} \mathrm{assemblies,} \mathrm{burnable} \mathrm{poison} \mathrm{assemblies,}$ neutron source assemblies, and plugging devices, all of which are inserted and removed from the core with the individual fuel assemblies in which they are positioned. The core assembly is supported inside the reactor pressure vessel by a removable internals structure.

The Westinghouse core uses the multi-region concept that usually requires only one third of the core (64 assemblies) be replaced at each refueling. Additional fuel assemblies must be removed, however, in order to transfer core insert components and to be compatible with the requirements of the subsequent fuel cycle. Other fuel assemblies which do not require insert changes are shuffled to new core locations.

The reactor vessel is positioned in the containment so that only the vessel flange and head assembly protrude above the floor of the refueling cavity. The refueling cavity is a stainless steel lined reservoir which is kept flooded with borated water during refueling to a depth of about 24 feet to provide radiation shielding as fuel assemblies are moved to and from the reactor vessel. The cavity is large enough to provide space for the underwater storage of the reactor upper internals, control rod drive shafts, reactor head guide studs and various component handing tools. Space is also provided for the storage of the lower reactor internals, which are removed every 10 years as part of the reactor in-service inspection program.

A number of components associated with the reactor vessel head are identified here since they. must be moved as part of the refueling operations. Large concrete missile shield blocks are supported on beams placed directly above the reactor vessel head assembly. The electrical cables 
of the control rod drive mechanisms (CRDM's), rod position instrumentation leads and core thermocouple leads are supported in a pivoted cable tray placed between the beams. The CRDM cooling fans and plenums are mounted on top of the missile shield. Ducting connects the fan plenums to a cooling shroud surrounding the CRDMs mounted on the reactor vessel head. A seismic support platform mounted on the head provides restraint for the top ends of the CRDMs. Heavy adjustable lateral seismic support bars tie the platform to lugs in the cavity walls.

\subsubsection{Description of Refueling Operations}

The refueling operations can be grouped in the following discrete tasks:

- Preparation of the reactor coolant system

- Preparations for containment entry

- Draining of the reactor coolant system

- Disassembly and removal of reactor components and equipment to achieve access to the reactor core for refueling

- Fuel movement including removal of spent fuel, insertion of new fuel, and repositioning of partially spent fuel and other core components to obtain the core configuration required for the next fuel cycle

- Re-assembly of the reactor components

The work required to accomplish these tasks is described in detail in the remainder of this section. The data and observations of the performance of these tasks obtained under this program during two refueling outages are tabulated and evaluated in Sections 4 and 6.

\subsubsection{Preparation of the Reactor Coolant System}

Before the reactor coolant system can be opened, the radio-chemical levels must be reduced to insure that personnel exposure will be within allowable limits. The primary objective is the removal of cobalt and cesium nuclides, and xenon gas from the coolant.

The hydrogen level must be reduced to prevent an explosion hazard and the boron concentration must be increased to the level required to provide adequate shutdown margin throughout the refueling operation.

The adjustments to the coolant chemistry are made using the chemical and volume control system (CVCS). Degassing of the coolant can be started prior to the reactor shutdown and is continued throughout the cooldown and depressurization procedures. 
Removal of cobalt is continued throughout the entire refueling, but is most effective with the RCS full so that removal from the components at higher system elevations can be achieved.

After the reactor is shut down, cooldown and depressurization is accomplished by continuing circulation with the reactor coolant pumps and rejecting heat through the steam generators. As the water volume shrinks due to cooling, additional makeup water is supplied to keep the system full. The system pressure is maintained above the saturation pressures by continued operation of the pressurizer. As cooldown continues all but one of the reactor coolant pumps are shutdown to reduce the addition of pump energy to the reactor coolant. The rate of cooldown is controlled to specification limits to prevent damage to reactor components. When cold shutdown conditions are achieved the residual heat removal system is put into service and operated throughout the refueling.

\subsubsection{Preparations for Containment Entry}

The containment atmosphere is sampled and purged using the containment ventilation system to achieve safe conditions for the entry of maintenance personnel. A radiation field survey is performed on the work areas within containment. Entry of workmen into the containment is then controlled throughout the outage by Radiation Protection personnel.

\subsubsection{Draining and Venting of the Reactor Coolant System}

After cooldown and depressurization the reactor coolant is partially drained to the reactor coolant drain tank. Nitrogen cover gas is introduced into the system through the pressurizer relief tank and as the coolant level is lowered the nitrogen fills the pressurizer and the reactor vessel head. The level of the reactor coolant is monitored at Zion with a level indicator with a readout in the control room. The coolant level is lowered to the mid-plane level of the reactor vessel nozzles.

The gases under the reactor vessel head are sampled and analyzed. When they are safe for release they are vented to the containment purge system to reduce the reactor coolant system to atmospheric pressure. The reactor coolant system is then ready for opening.

\subsubsection{Reactor Disassembly}

The bottom mounted, in-core instruments are removed from the core and drawn into storage locations in the seal table room. The in-core thimbles are also retracted out of the fuel assemblies. Low pressure seals are then installed between the thimbles and the seal table to prevent leakage of water when the reactor cavity is flooded for refueling.

Disassembly of the reactor upper structure is begun with disconnecting the thermocouple leads at the five instrument penetrations on the reactor vessel head. The electrical connections 
to the control rod drive mechanism (CRDM) ventilation system is then removed along with the ducting connecting the fan plenum to the cooling shroud on the vessel head. The fans and plenum are removed from the top of the missile shield blocks using the polar crane.

The massive missile shield blocks are unbolted from their support beams and are transported by the polar crane to storage locations on the concrete walls of the steam generator compartments.

The CRDM cable tray is unbolted from between the missile shield support beams and pivoted into a vertical position and locked on a support frame erected for this purpose. The missile shield beams are then unbolted from their supports and lifted to storage positions along the steam generator compartment walls. The eight part length mechanisms are then unlatched.

As final preparation for removal of the reactor vessel head, the five instrument ports are opened, their conoseals are removed and, protective guide sleeves are installed to protect the thermocouples when the head is lifted over them. The removable insulation sections are removed from the head and vessel flange to expose the studs for detensioning and removal. To achieve a uniform release of the flange clamping force an initial partial detensioning pass of the fifty-four studs is made. Three studs are detensioned at a time using Biach hydraulic tensioners. The three units are mounted on power hoists provided on a circular track on the reactor vessel head assembly. After the studs are detensioned they are rotated free from the vessel flange. Conventionally the studs are rotated manually using wrenches. The Zion maintenance staff however has made. much use of a patented pneumatic device (with trade name of "Smoothie") that maintains a constant upward force to reduce thread friction as the stud is rotated. Air driven spinner tools are used to rotate the studs out of engagement. This equipment used at the Zion station has increased the speed and reduced the manual effort of removing the vessel studs. When they have been removed, the studs and nuts are loaded into handling boxes and removed from the cavity for inspection, cleaning and lubrication. The head hoists and the polar crane are used in conjunction for the stud removal operations.

Three guide studs are installed in selected locations in the vessel flange to maintain proper alignment as the head and subsequently the upper internals are lifted. Special adaptors are used to mount the guide studs and seal the stud holes in which they are positioned. Plugs are placed in the rest of the threaded holes in the reactor vessel flange to protect them from corrosion when the cavity is flooded. An improved plug design has been incorporated at the Zion Station. An expandable rubber seal is used which includes provision for filling the stud hole with nitrogen gas to provide a protective atmosphere and to permit leak testing of the seal prior to flooding of the cavity.

In preparation for flooding, all openings in the cavity floor are sealed. The Zion Station has incorporated an improved custom molded inflatable rubber seal ring in place of the 
conventional metal seal ring to seal the annular space between the reactor vessel flange and the surrounding cavity. Bolted gasket seals are used under the cover plates for the vessel nozzle inspection ports and the excore nuclear instrumentation ports.

The head lifting rig, a tripod fixture, is attached to lugs on the head assembly and rigged to the polar crane. A load cell is rigged in line with the lift to measure the force applied in lifting the head so that binding can be immediately detected. All unnecessary tools and equipment are removed and the cavity is cleaned prior to flooding. Final checks and adjustments are made of the refueling equipment that will be submerged when the cavity is flooded.

The reactor vessel is now flooded with water from the refueling water storage tank (RWST) to a level just below the flange. Head lifting is then started. An intermediate stop is made after about $6 \mathrm{ft}$ of lift to perform a quick inspection to verify that there is no binding of the full length drive rods in the thermal sleeve penetrations of the head assembly. Flooding of the cavity is initiated when head lifting resumes. The head is moved to the storage pedestal at the end of the reactor cavity opposite the refueling canal. Replacement O-ring seals to be used in reassembly have been previously placed in the storage trough at the bottom of the pedestal.

After the head has been removed, the full length drive rods are unlatched from the fiftythree control rods. This operation is done from the manipulator crane using the drive rod unlatching tool. Several drive rods are selected for inspection and are moved to storage racks mounted on the wall of the reactor cavity.

The guide tube covers must be removed to permit removal of the drive rods. This is also done from the manipulator crane using another special tool. The remainder of the drive rods are left in place and are removed with the upper internals.

The internals lift rig, also a tripod fixture, is attached to the upper internals by engaging three lift studs into mating holes on the internals flange. The lifting rig includes features that permit handling and placing a cover plate over the exposed vessel flange seal surface. The upper internals are lifted from the vessel using the polar crane again with a load cell installed. The upper internals are stored beside the reactor in the refueling cavity. The core is now exposed for beginning the fuel movement operations.

\subsubsection{Fuel Movement}

The fuel management program for a reactor specifies the core locations for each fuel assembly for the next fuel cycle and the type of core insert for each location. The individual moves required to remove the spent fuel, insert new fuel, and reposition those assemblies remaining the core and transfer the core inserts are carefully planned to eliminate errors and minimize the number of moves required. 
Fuel assemblies are handled with their inserts in place using the gripper mast of the manipulator crane (refueling machine). Spent fuel assemblies are transferred from the containment to the spent fuel building and new fuel assemblies are brought into the containment using the fuel transfer system. Transfer of RCC rods, secondary neutron sources, and thimble plugs from one fuel assembly to another is done in the RCC change fixture in the refueling canal within the containment. Changing of burnable poison assemblies is done in the spent fuel building using a special tool for this purpose. Similarly, thimble plugs are changed either in the fuel building or the containment using a special tool.

A typical sequence of operations in the fuel movement operation consists of the following steps (in this example the fuel assembly selected contains a RCC control rod):

- The manipulator crane is indexed to the required core location

- The telescoping mast is lowered and latched to the fuel assembly to be removed

- The fuel assembly and its insert are raised completely into the cylindrical stationary mast before lateral motion is permitted

- The fuel assembly is transported to the RCC change fixture and inserted into a vacant basket

- The manipulator crane is positioned over the basket of the fuel transfer car. The basket contains a new fuel assembly which has been transported into the containment from the fuel storage building

- The manipulator crane is used to transfer the new fuel assembly into another vacant location in the RCC change fixture

- The carriage is moved so the spent fuel assembly is positioned under the RCC change fixture. The control rod is latched and raised into the fixture

- The carriage is moved to position the new fuel assembly under the change fixture and the RCC is lowered and released into the assembly

- The manipulator crane is used to transport the spent fuel assembly to the basket on the fuel transfer car. The basket is rotated to the horizontal position and transferred through the fuel transfer tube to the spent fuel building for storage. A new fuel assembly is taken into containment on the return trip of the transfer car

- The manipulator crane is used to pick up the new fuel assembly with its control rod in place, transport it to the reactor, and lower the assembly into its assigned location

Sequence variations occur depending on the type of insert in the spent fuel assembly and that which is required for the new fuel assembly. Partially spent fuel assemblies which do not require insert changes are moved directly to their new locations in the core. During those outages when an In-Service-Inspection of the reactor vessel is required, the entire core is transferred to the fuel storage building. In this case the lower internals are also removed to provide access for the vessel inspection. 
During each refueling, a number of fuel assemblies are inspected using a TV camera at the RCC change fixture. A tape is recorded of the inspection in order to provide a permanent record. If a more comprehensive examination is required, the fuel assembly is transferred to the fuel storage building where a specially prepared video inspection station would be located.

After the core has been loaded, a TV camera mounted on the manipulator crane is used to verify that the correct core configuration has been assembled. The condition of the reactor internals and selected drive rods is examined also using miniaturized video equipment. This is normally performed at approximately 3 year intervals. Also periodically a capsule containing a specimen of reactor vessel material is removed for testing via an access plug on the lower internals. The reactor is now ready for reassembly.

\subsubsection{Component Maintenance Performed Parallel to Core Loading}

During fuel movement operations, a number of component maintenance and inspection activities are performed. Reactor vessel studs are cleaned, inspected, and lubricated to assure ease of installation. The used O-ring seals are removed from the reactor vessel head and disposed of. Sealing surfaces on the head flange must be carefully cleaned before the new seals are installed. The inside clad surface of the head is inspected and a partial inspection of the structural head welds may be performed in accordance with the Section XI of the ASME Code. Maintenance and lubrication is performed on the CRDM cooling fans but electrical and instrumentation checks are usually delayed until handling of the head is completed.

\subsubsection{Reactor Reassembly}

The upper internals are moved from their storage position with the lifting rig and polar crane and brought into position over the reactor. They are slowly lowered over the guide studs and into the reactor vessel. Guidance features on the upper internals and vessel provide correct final positioning and engagement with the fuel assemblies. in the core. The load cell attached to the lift rig is monitored to detect any binding and to determine when the internals are seated. The lift rig is disengaged by unthreading the lift screws and the vessel flange protective ring is engaged to the lift rig using the other set of lift screws provided for this purpose. The lift rig and protective ring are then raised and transported to storage.

Any drive rods removed for inspection are now re-installed in the internals using the manipulator crane and the drive rod handling tool. The guide tube covers at these locations are replaced using the manipulator crane and the guide tube cover tool. Full length drive rods are latched to their control rods using the latching tool. Each control rod is tested to verify latching and that the friction drag force is within procedural limits. This assures that proper alignment achieved between the internals and the core has been achieved. 
The reactor vessel head is now lifted from the storage pedestal using the head lifting rig and positioned over the vessel. Tether ropes are used to maneuver the massive head into position over the guide studs in the vessel flange. Zion Station maintenance personnel have incorporated a guide bar bolted to the main crane hook for attaching the ropes. This prevents the application of bending loads to the lift rig when turning the load. As the head is slowly lowered over the studs, the load cell in the line of lift is monitored for indications of binding. The water level in the cavity is lowered while the head is being lowered to prevent any contact with the clean head flange seal. When the head approaches the elevation of initial engagement of the drive rods into the thermal sleeves of the head a short pause is made. The cavity water-level is lowered to just below the vessel seal surface. An inspection is then made to verify that the control rods are properly aligned for entry into the thermal sleeves. The head is then lowered to approximately one foot above the vessel flange. After the sealing surface of the vessel flange has been cleaned, set down of the head is completed. The lifting rig is detached and moved to its storage position on the head storage pedestal.

Work in the area is now temporarily halted for cavity decontamination. (The inflatable seal between the reactor flange and the cavity is removed to prevent further accumulation of contaminants during the cavity cleaning operation.) After the cavity has been cleaned, the guide studs are removed and stored in racks provided on the cavity wall and the stud hole plugs are removed, packaged and taken out of the containment for decontamination. The threaded stud holes in the vessel flange are cleaned in preparation for stud installation. The studs are installed using the same equipment as in their removal. They are tightened with Biach tensioners in a multipass sequence to assure correct head seating and equalized stud loading.

The protective sleeves are removed from the five instrument ports and the conoseals are replaced. The eight part-length drive shafts are latched and their conoseals are replaced. These last two operations can be started as soon as at least six studs have been sufficiently tensioned to assure the head is properly seated. The replacement of the reactor vessel flange insulation is usually delayed until all attachments to the head have been completed to prevent damage by standing or walking on it.

The missile shield support beams are then replaced and bolted in position above the head assembly. The CRDM cable tray is released and pivoted into position between the beams and bolted in place. The missile shield blocks are then reinstalled and bolted to the support beams. The CRDM cooling fans and plenum are installed on top of the missile shield and the ducting is then reassembled to the cooling shroud on the reactor vessel head. The reassembly of the upper structure is completed by installation of the seismic support bars which brace the head structure to the cavity wall. Electrical connection of the CRDM's and their cooling fans is done after testing to procedural requirements is completed. 
Removal of the low pressure seals from the seal table and reinsertion of the in-core instruments into the core can be done at anytime after the cavity is drained and the R.V. head replaced. High pressure seals are then installed between the thimbles and the seal table after which the in-core instruments are inserted. Replacement and sealing of the blind flange on the fuel transfer tube and closing of the cavity drain valves completes the refueling portion of the outage. 


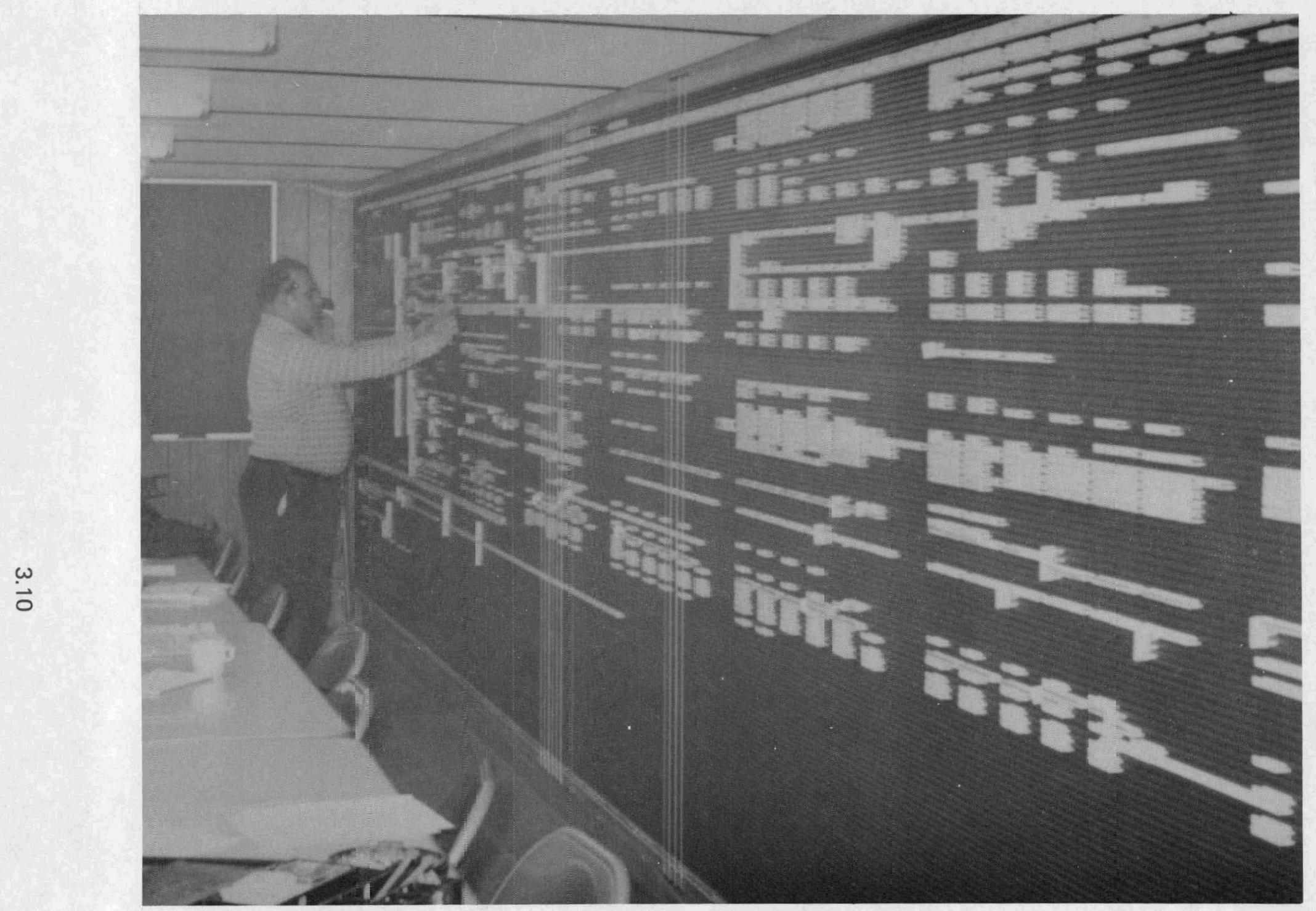

Figure 3.1 Outage Coordination Center 


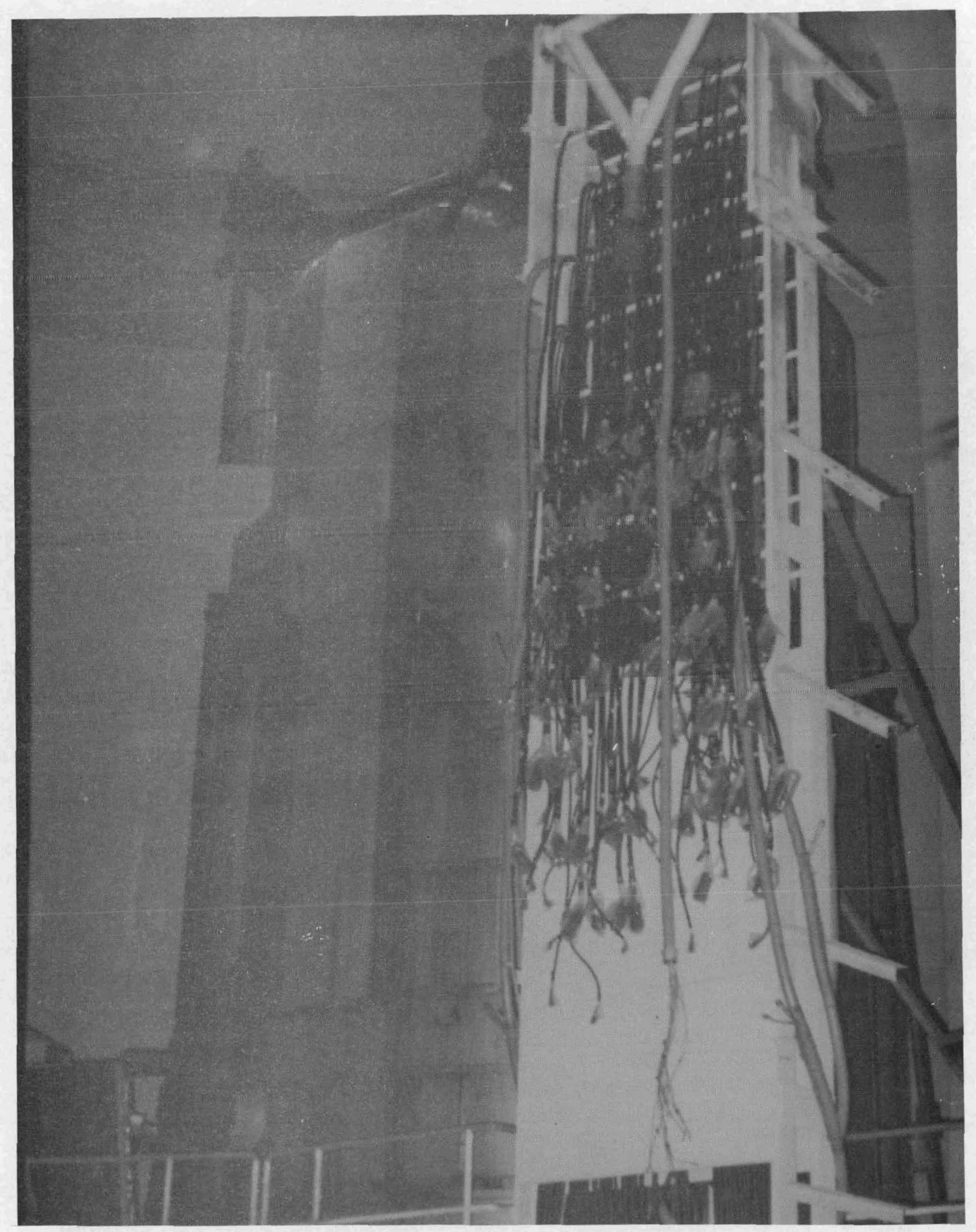

Figure 3.2 Cable Tray in Vertical Stored Position 


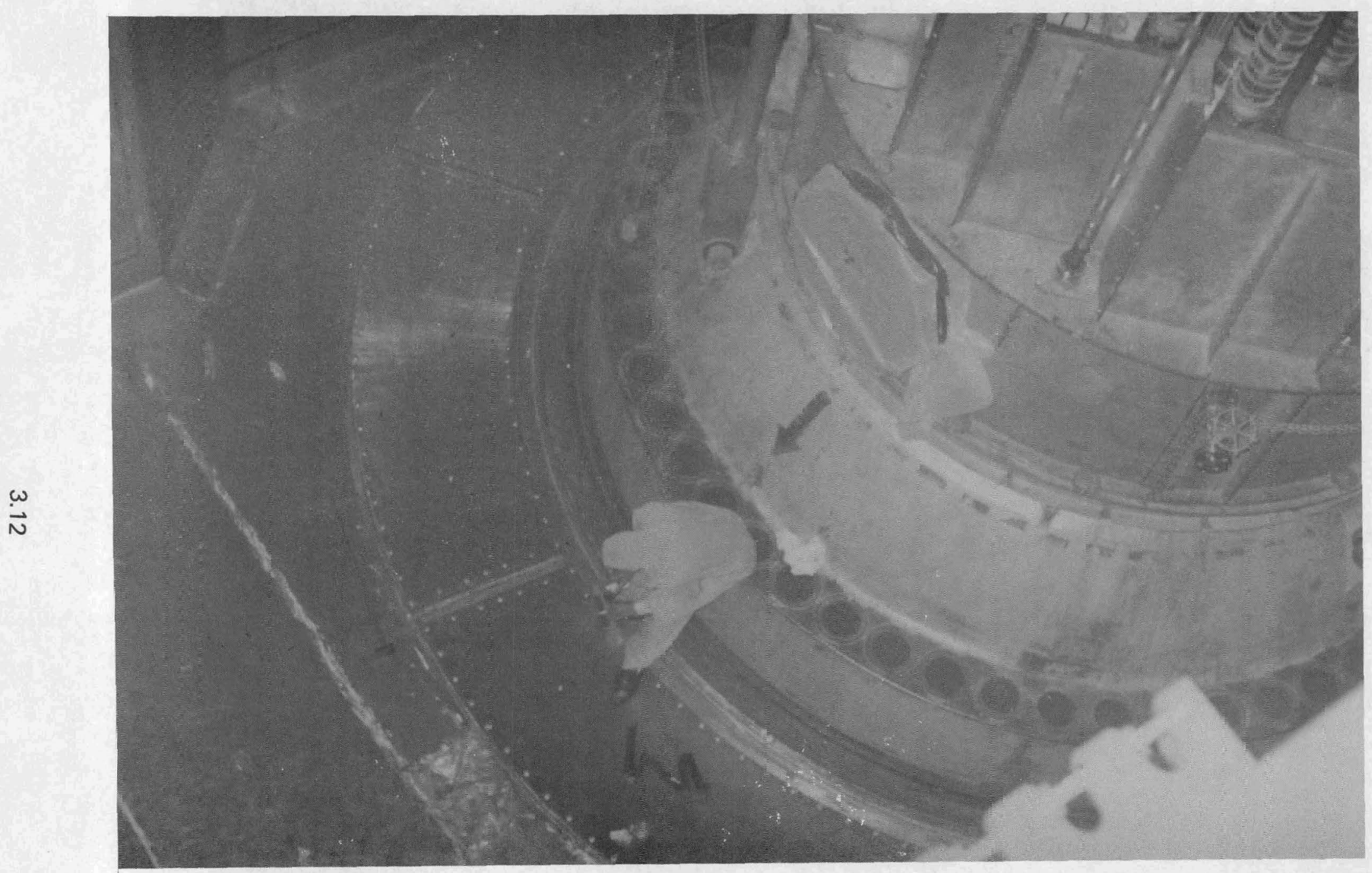

Figure 3.3 Nozzle Cover Sealing 


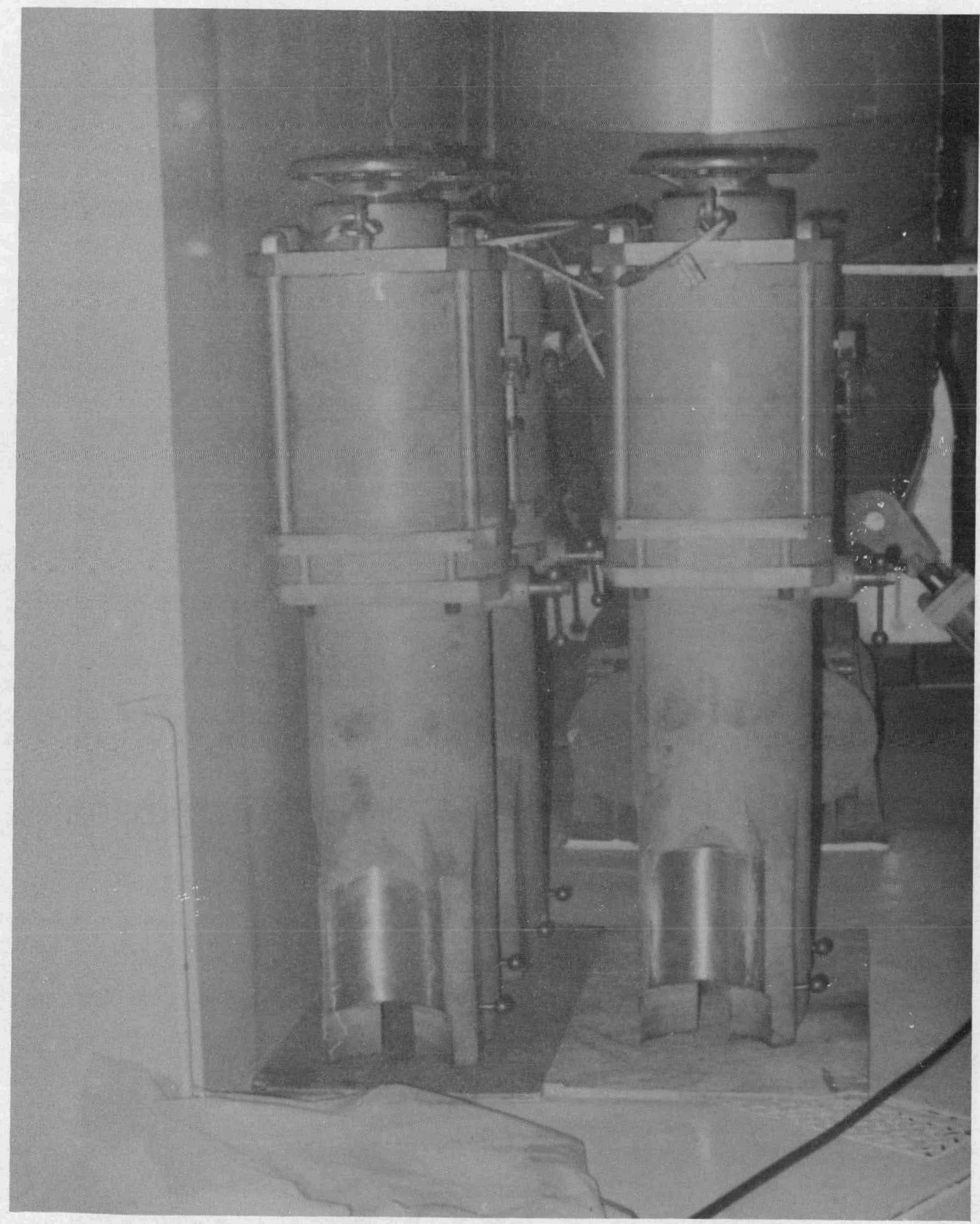

Figure 3.4 Stud Tensioners 


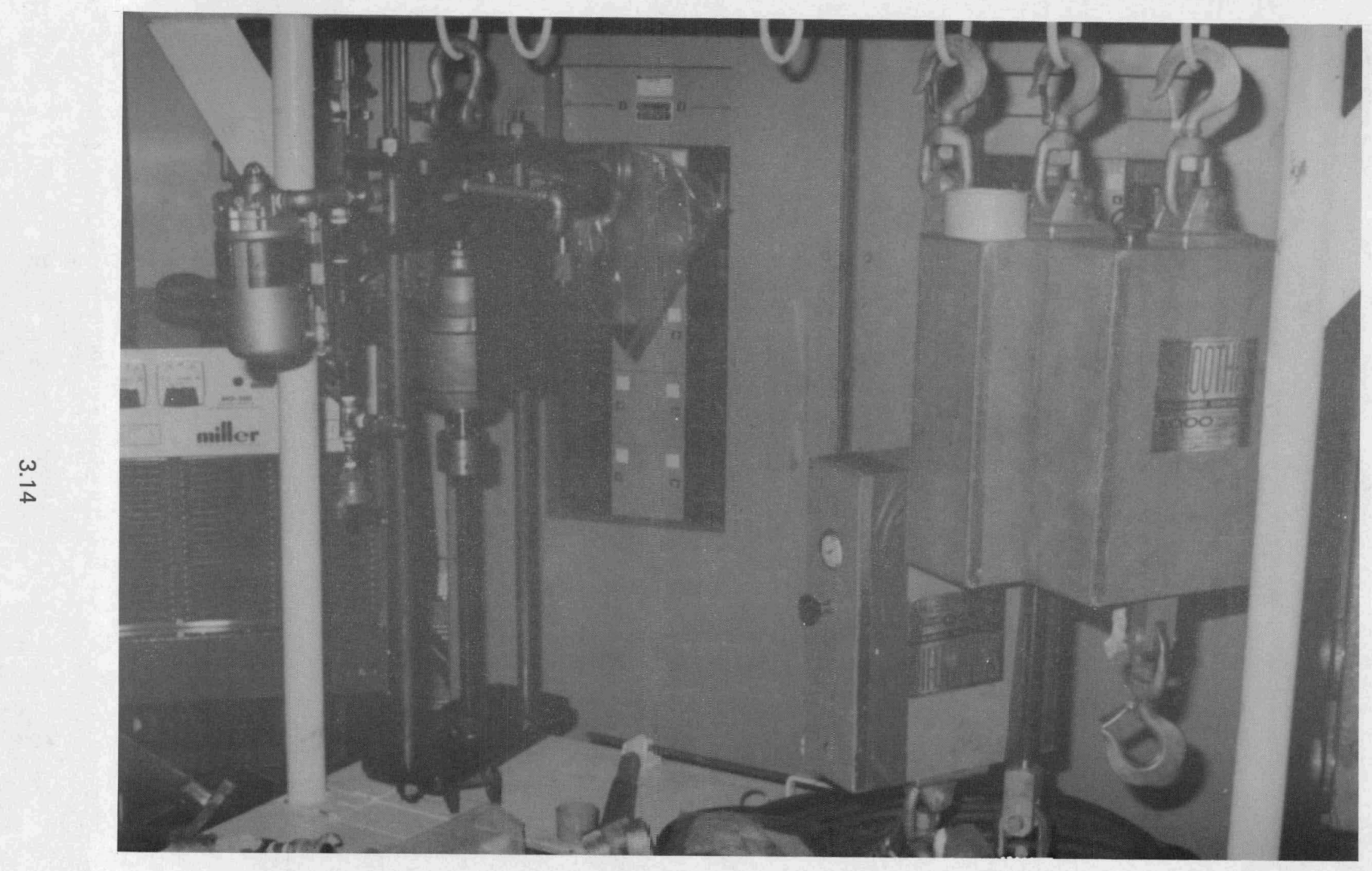

Figure 3.5 Stud Removal Tools 


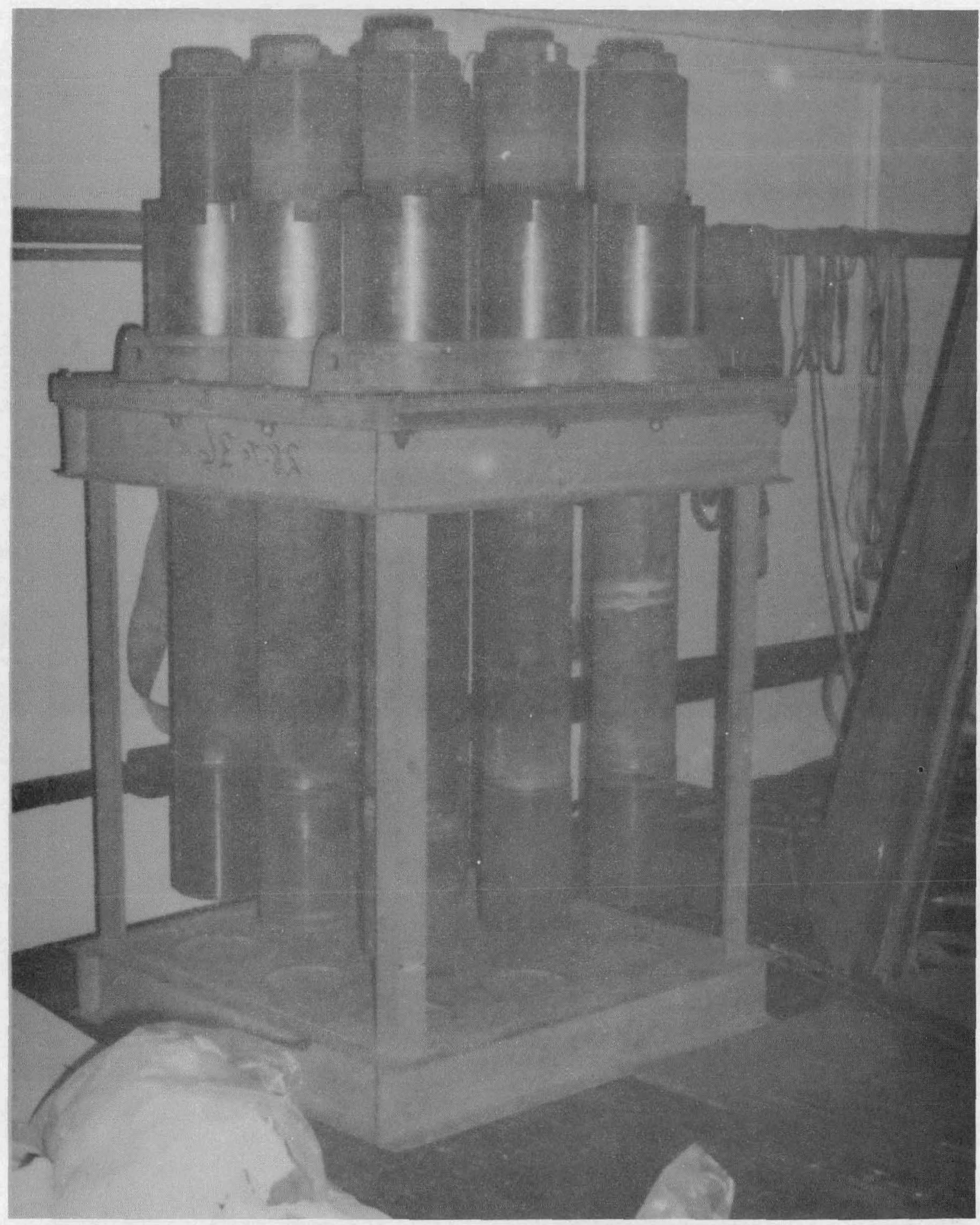

Figure 3.6 Studs in Carrying Box 


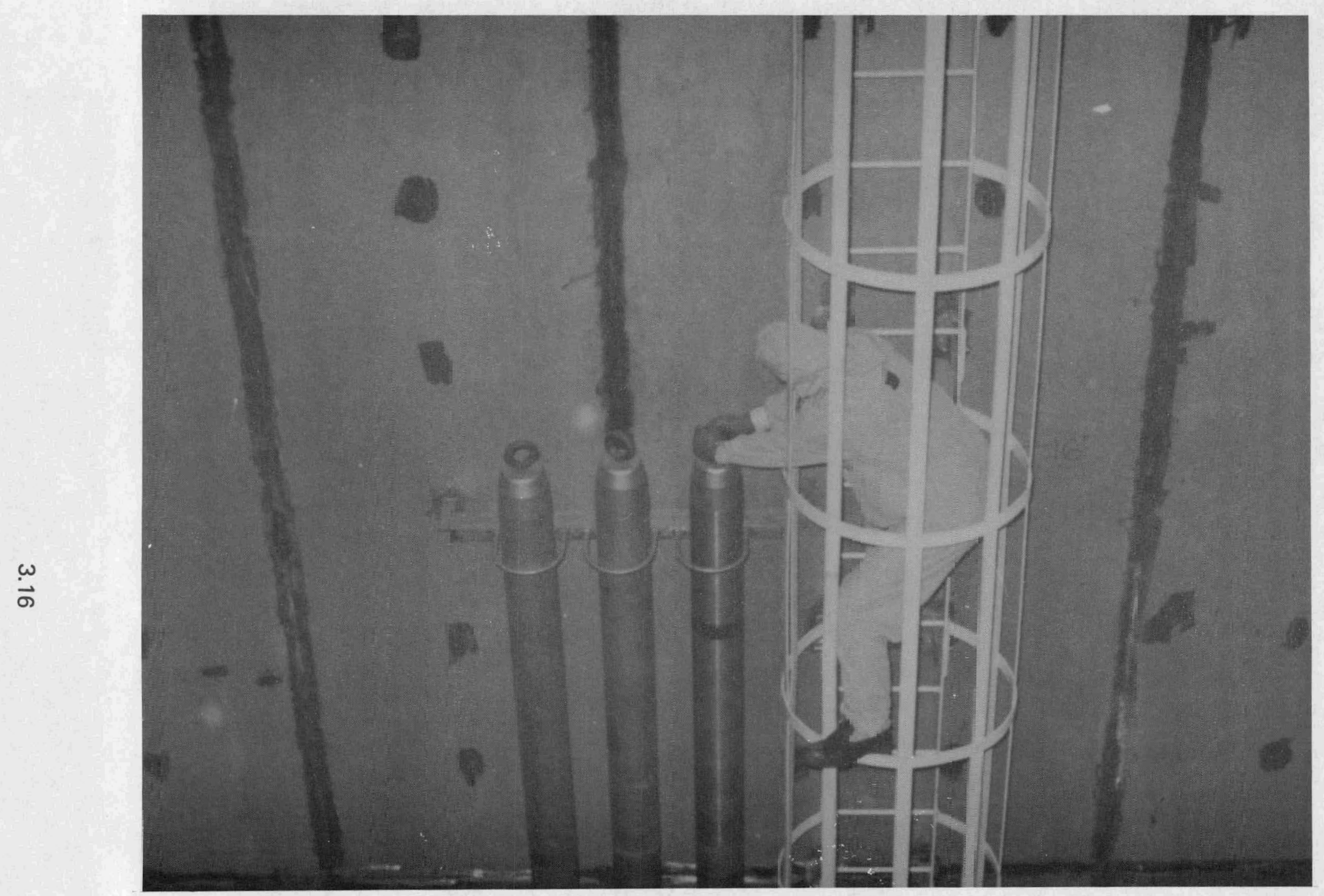

Figure 3.7 Reactor Vessel Head Guidə Studs 


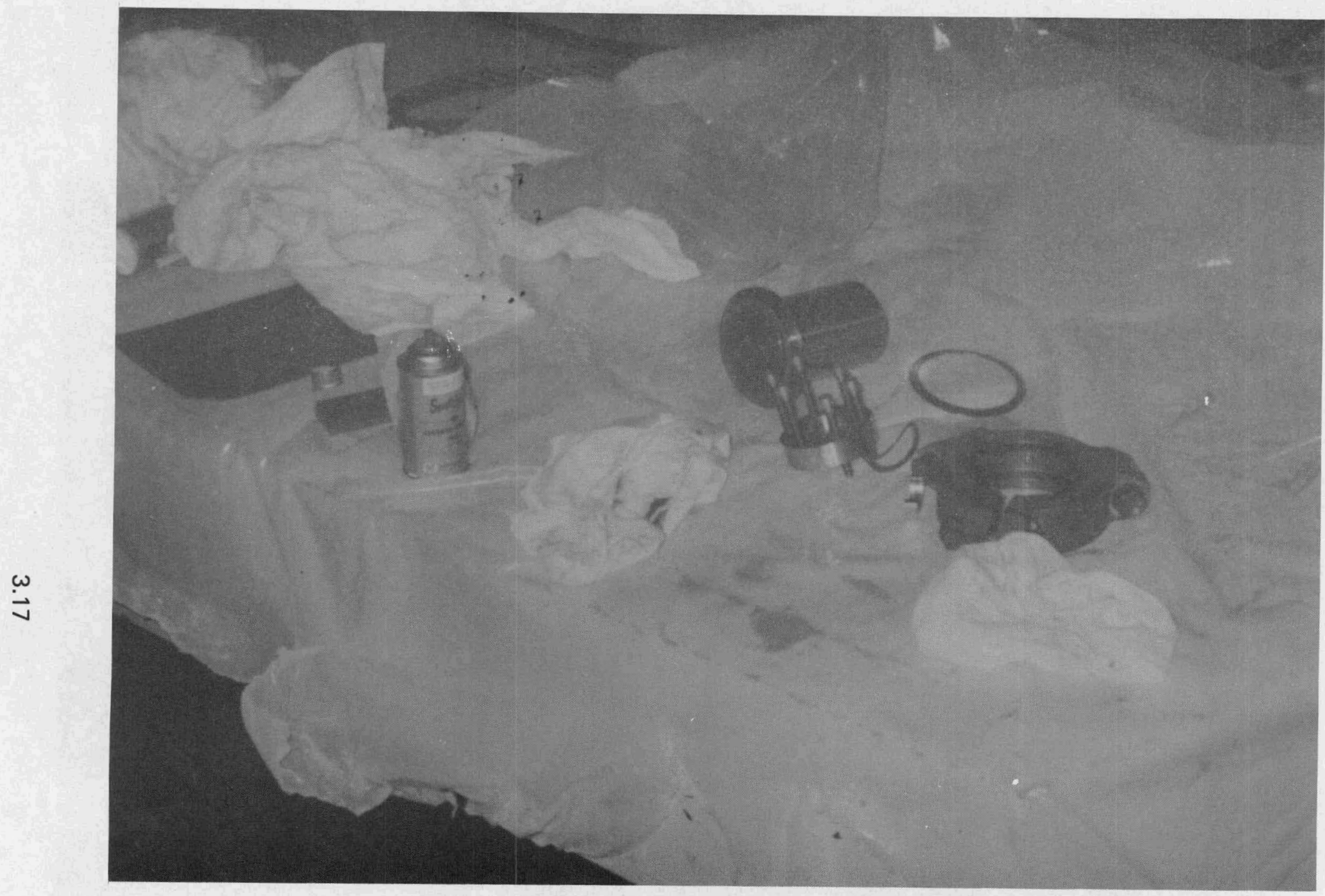

Figure 3.8 Instrument Port Conoseals (Disassembled for Cleaning) 


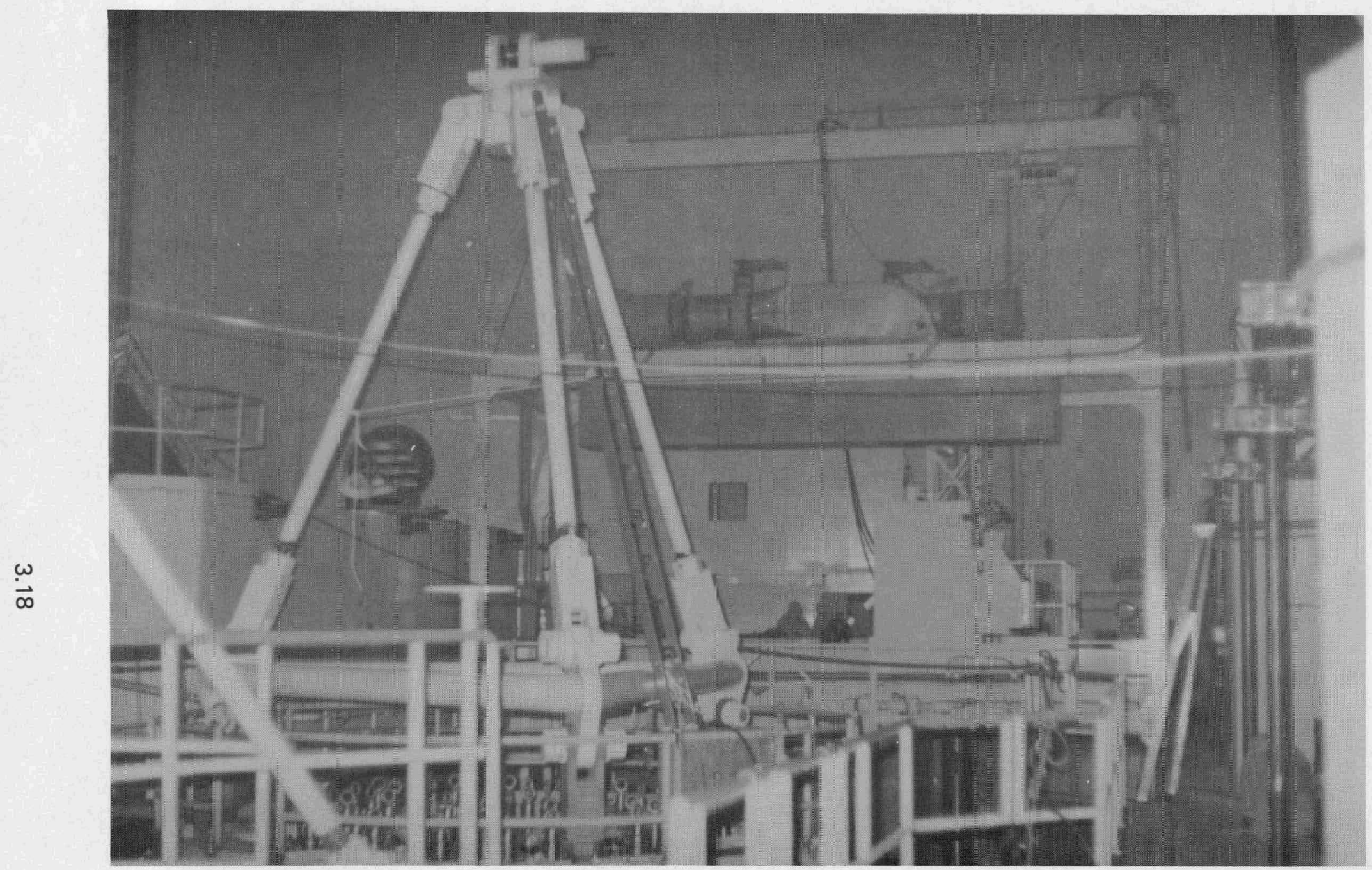

Figure 3.9 R.V. Head Lifting Rig Installed 


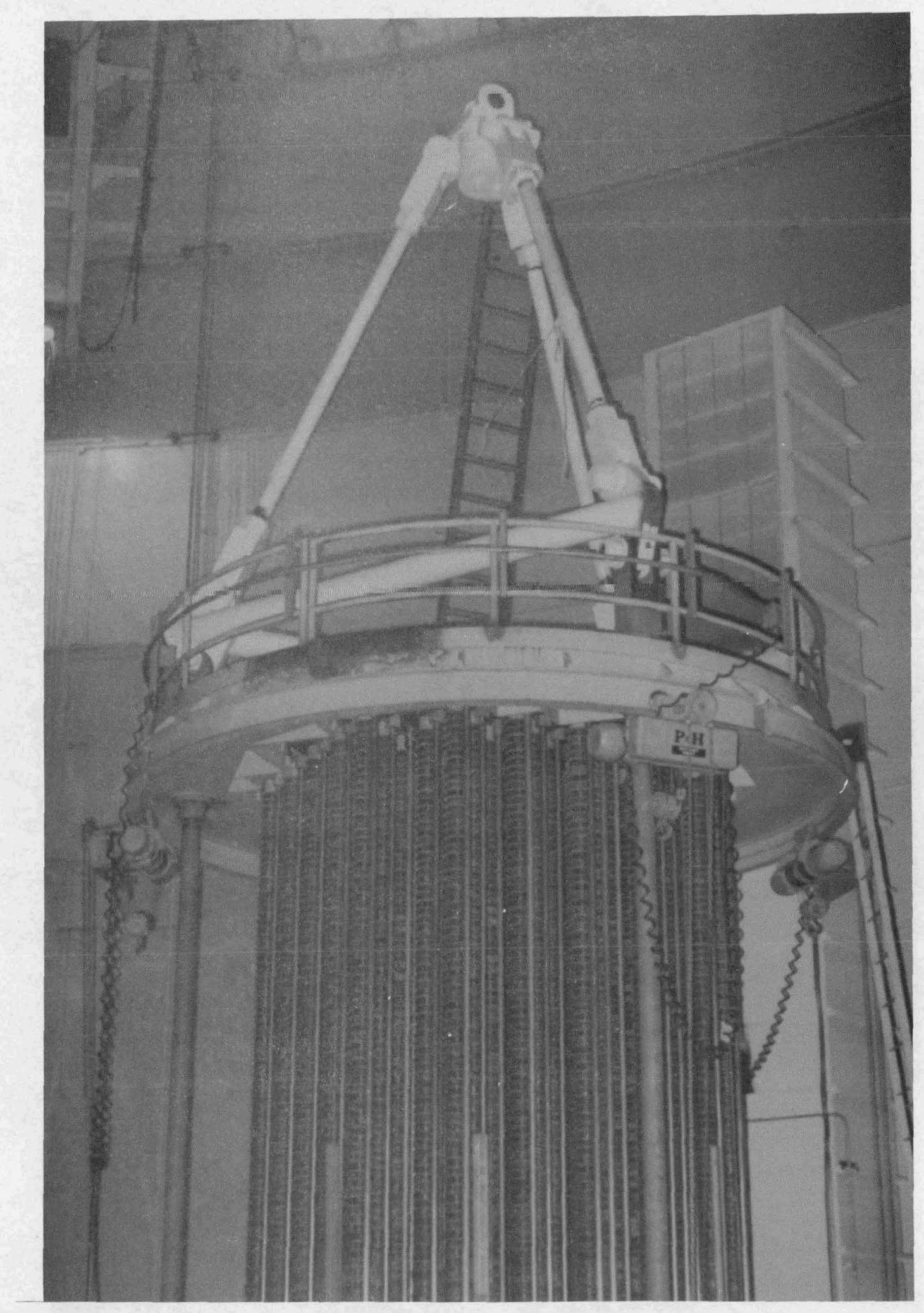

Figure 3.10 Details of Upper Head Assembly - Showing Lift Rig, Seismic Support Platform and Stud Hoists 


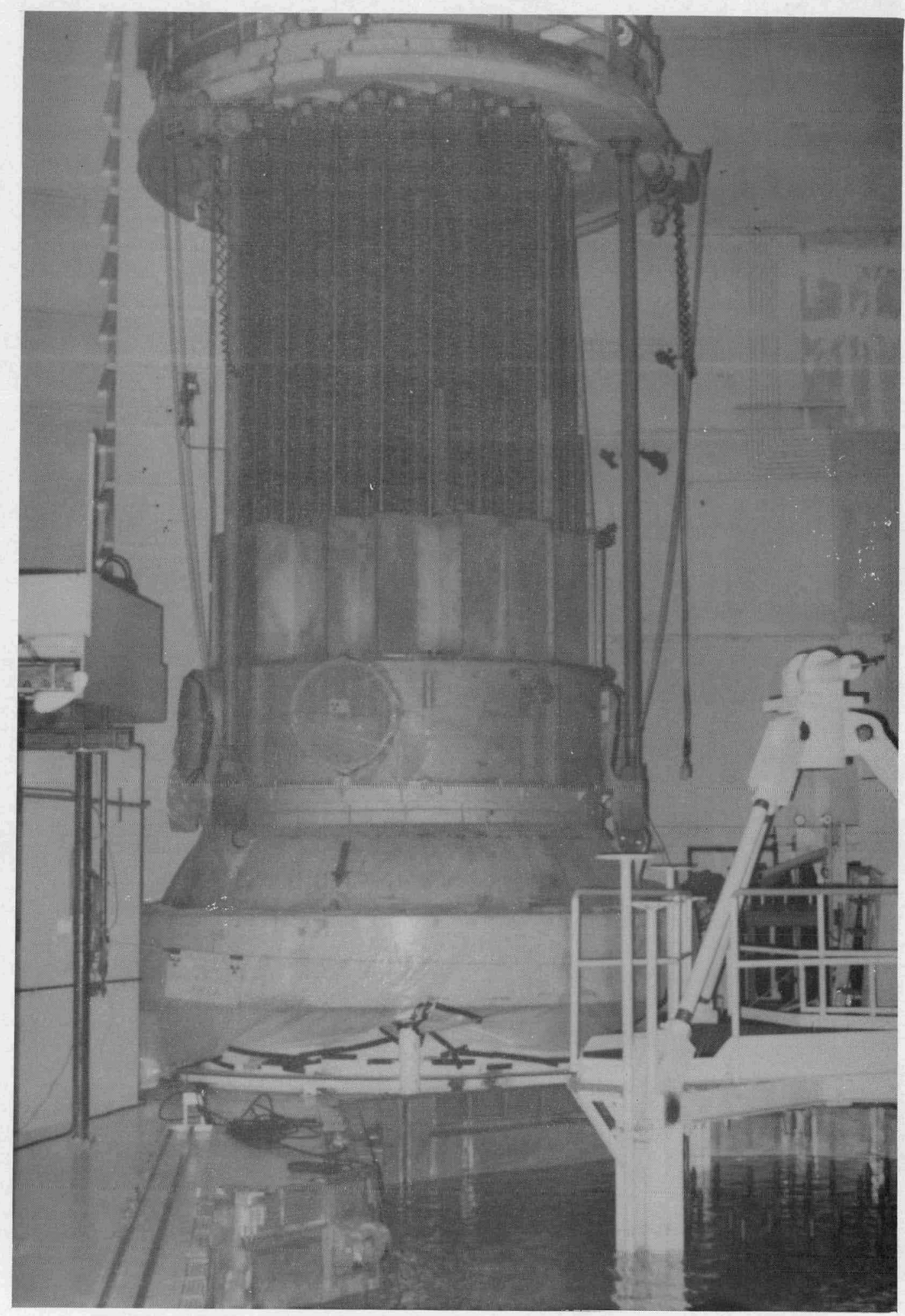

Figure 3.11 R.V. Head in Stored Position 


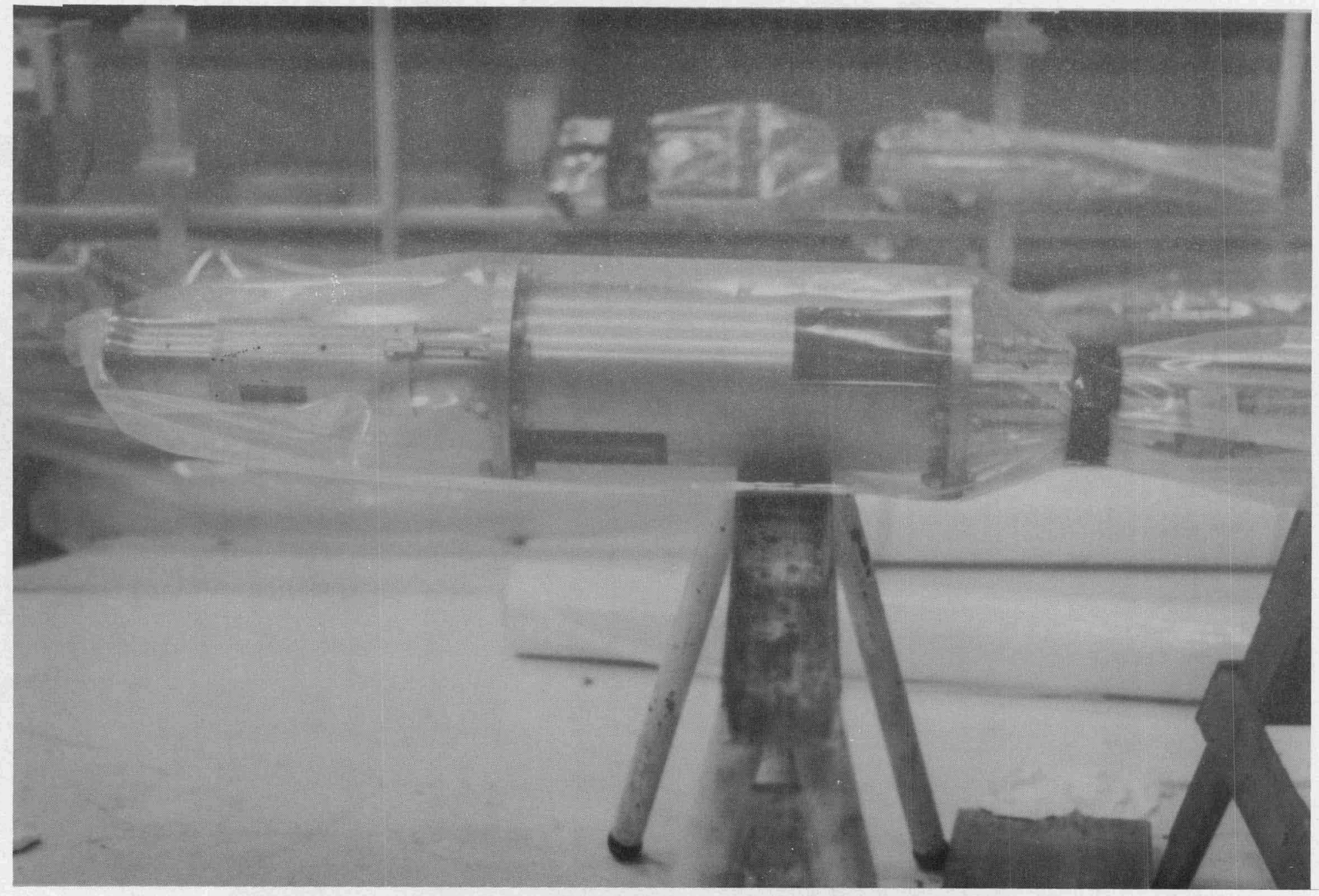

Figure 3.12 Lower End of Drive Rod Unlatching Tool 


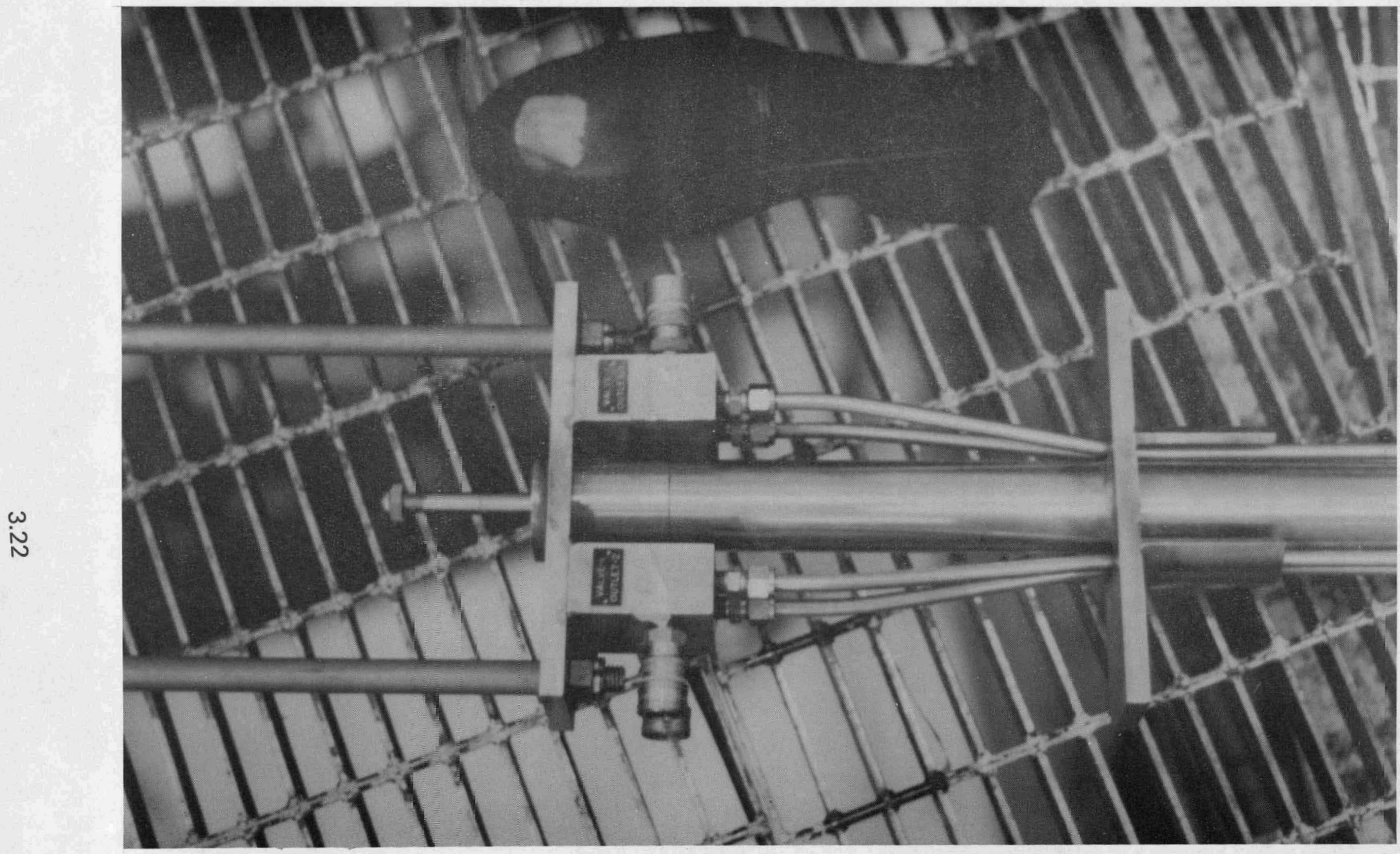

Figure 3.13 Upper End of Drive Rod Unlatching Tool 


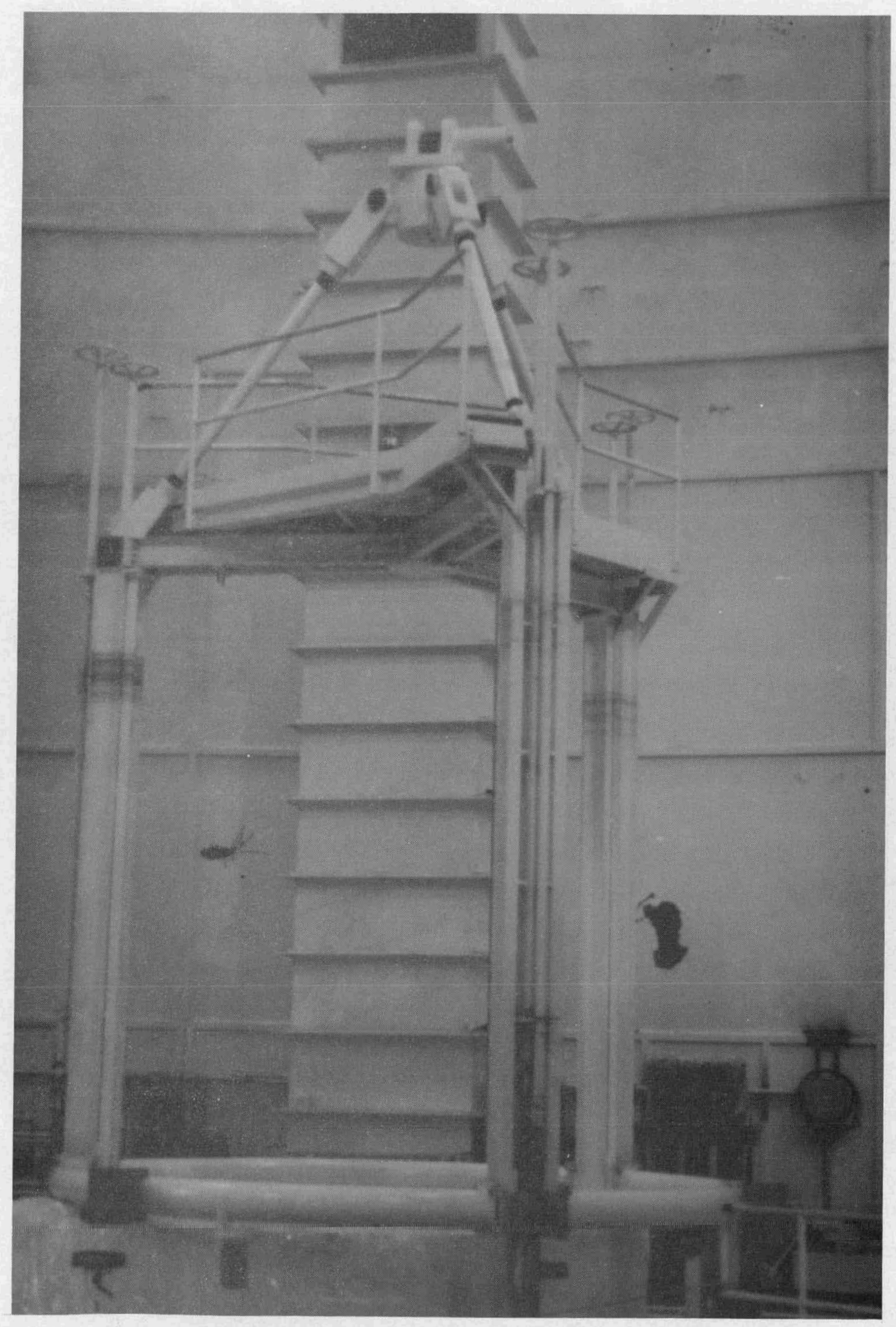

Figure 3.14 Internals Lifting Rig 


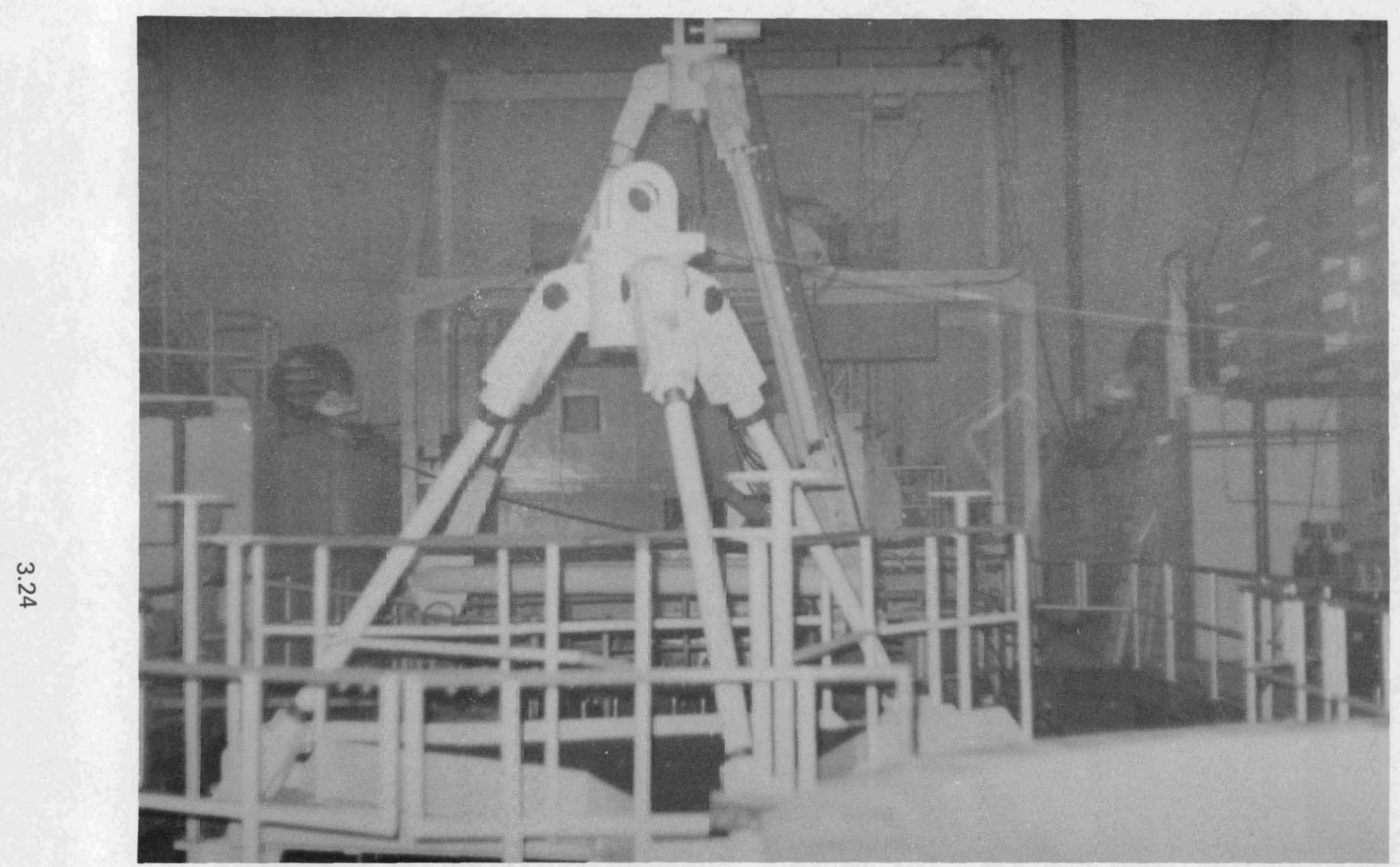

=igure 3.15 Internals Lifting Rig Instal ed 


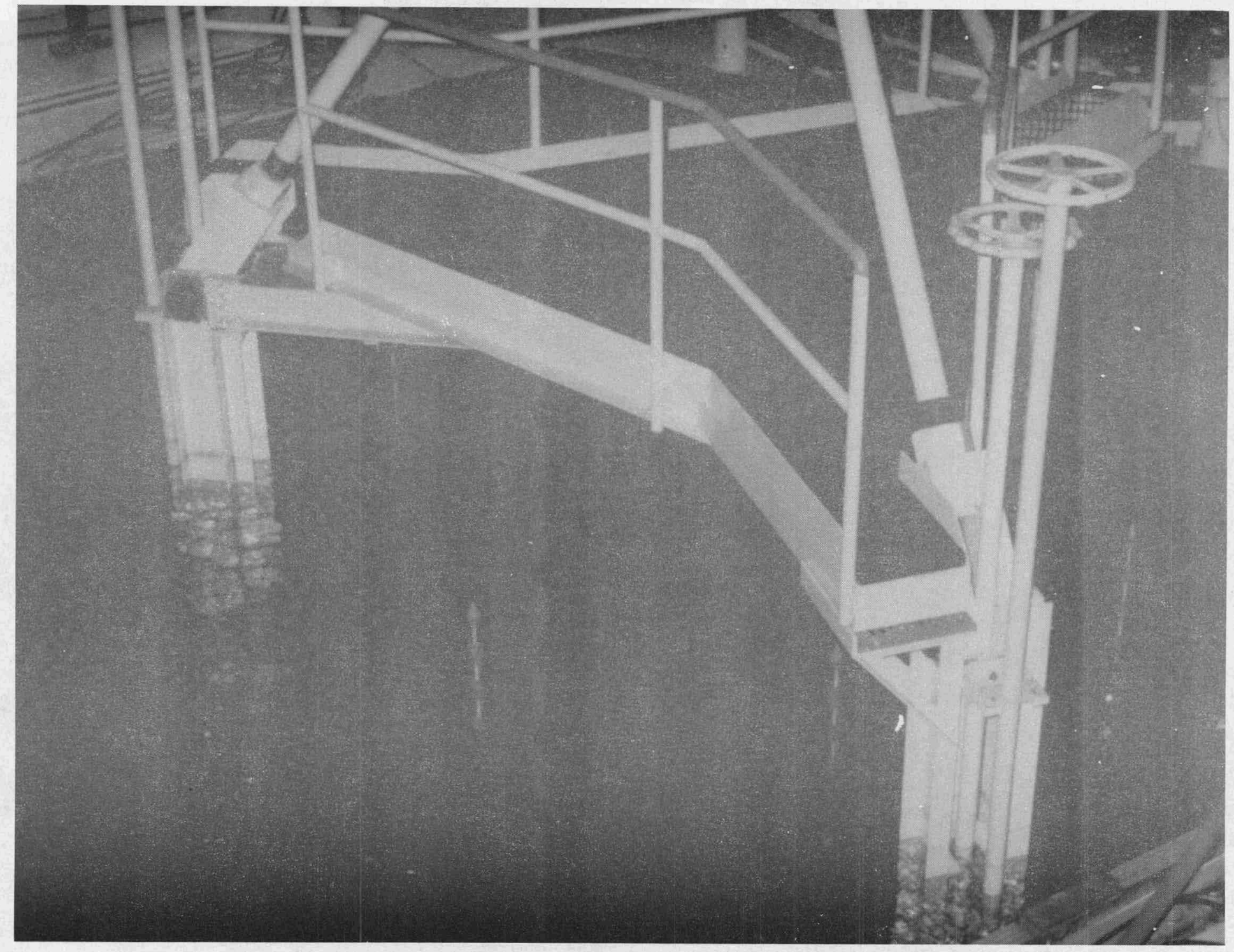

Figure 3.16 Upper Internals in Storage Location 


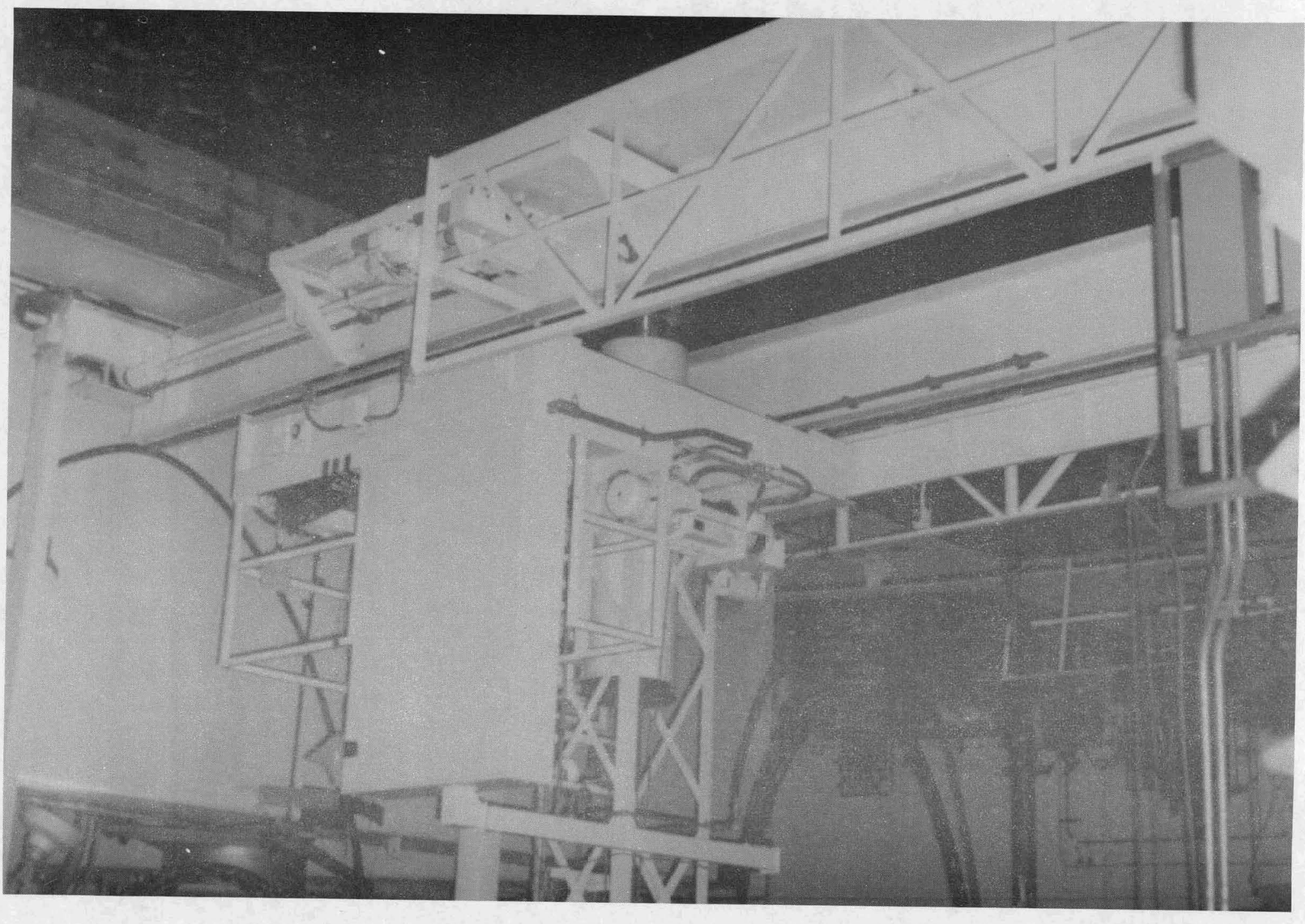




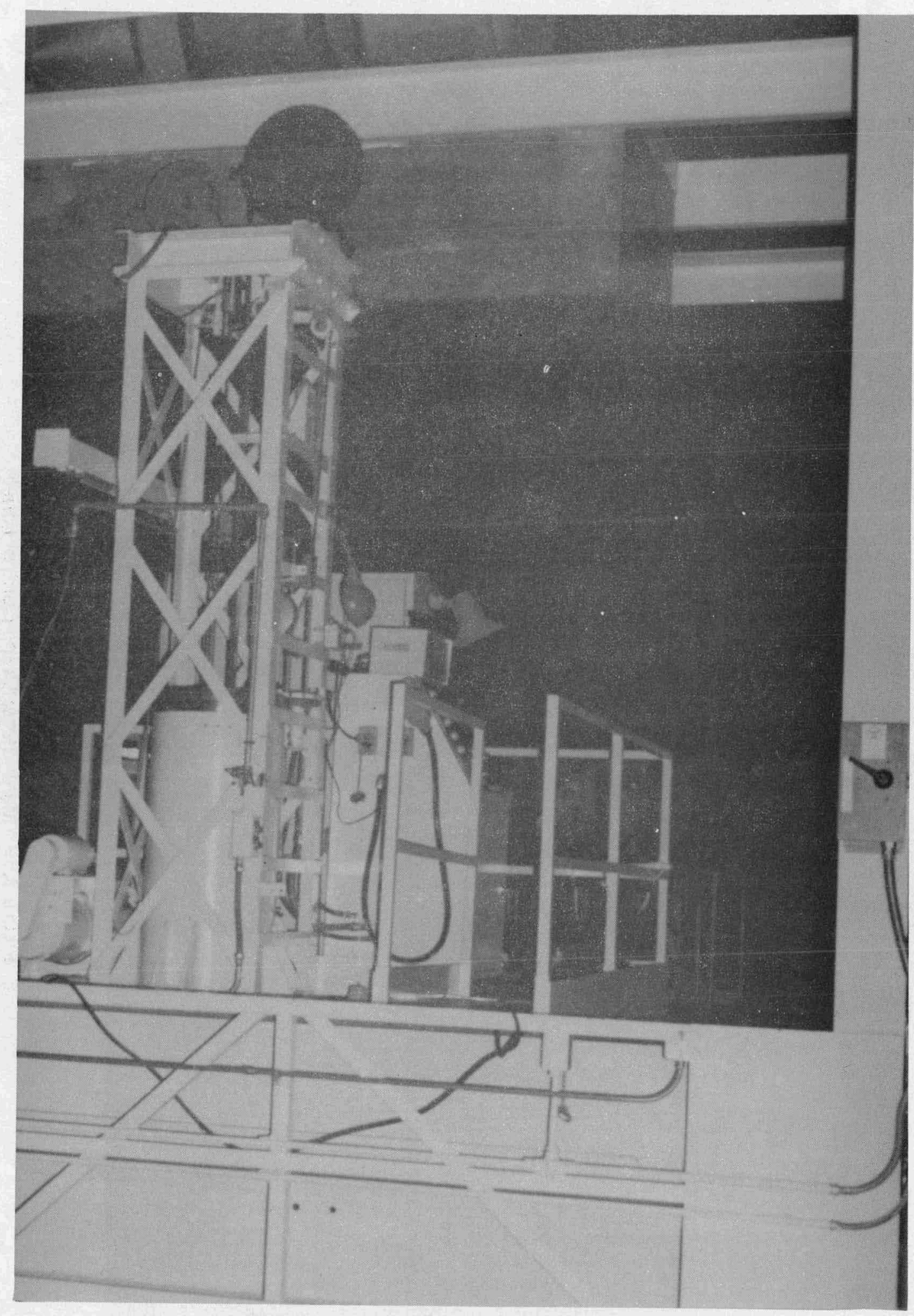

Figure 3.18 Manipulator Crane Side View 
Figure 3.19 Manipulator Crane Control Panel 


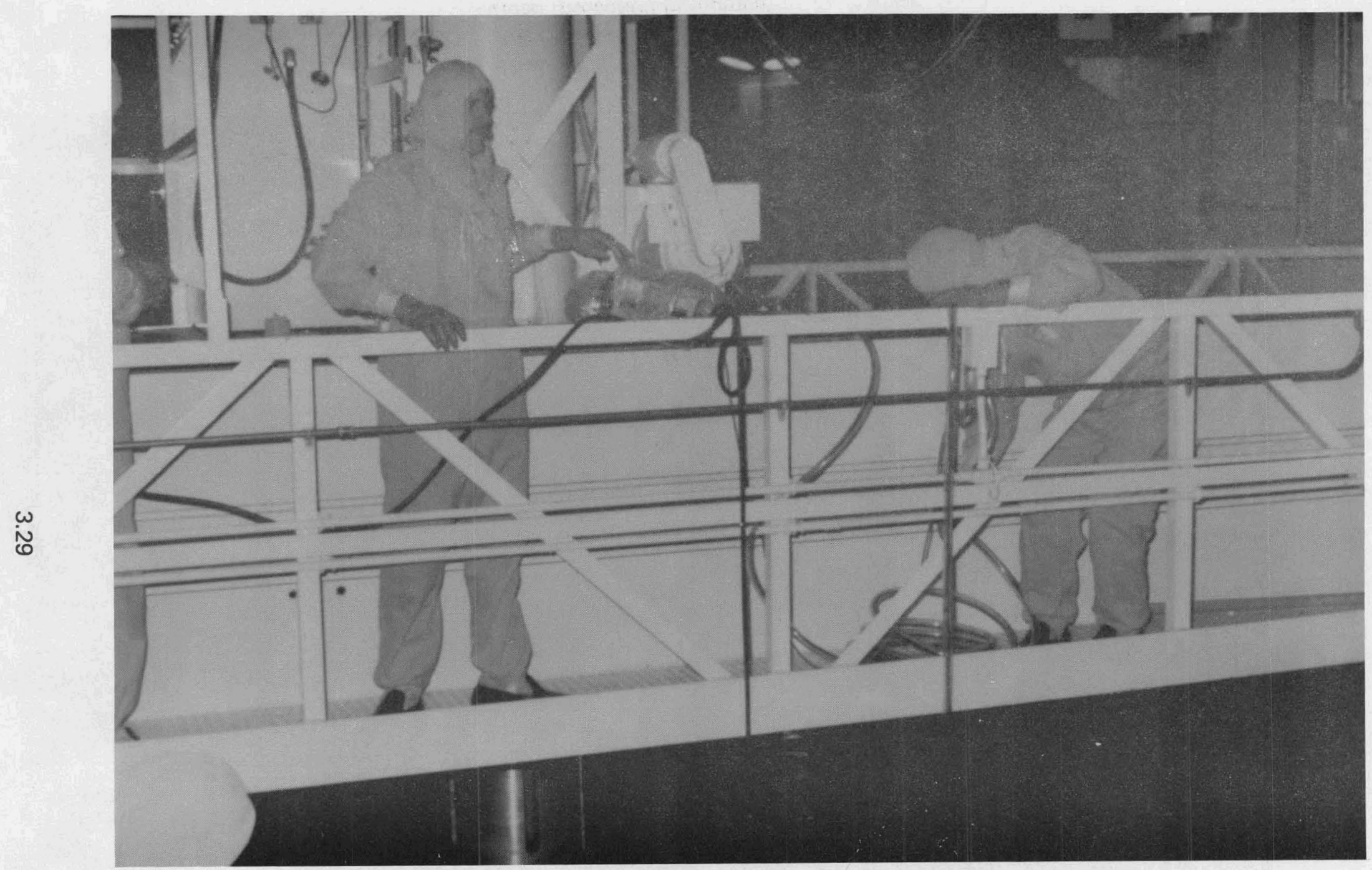

Figure 3.20 Manipulator Crane Walkway 


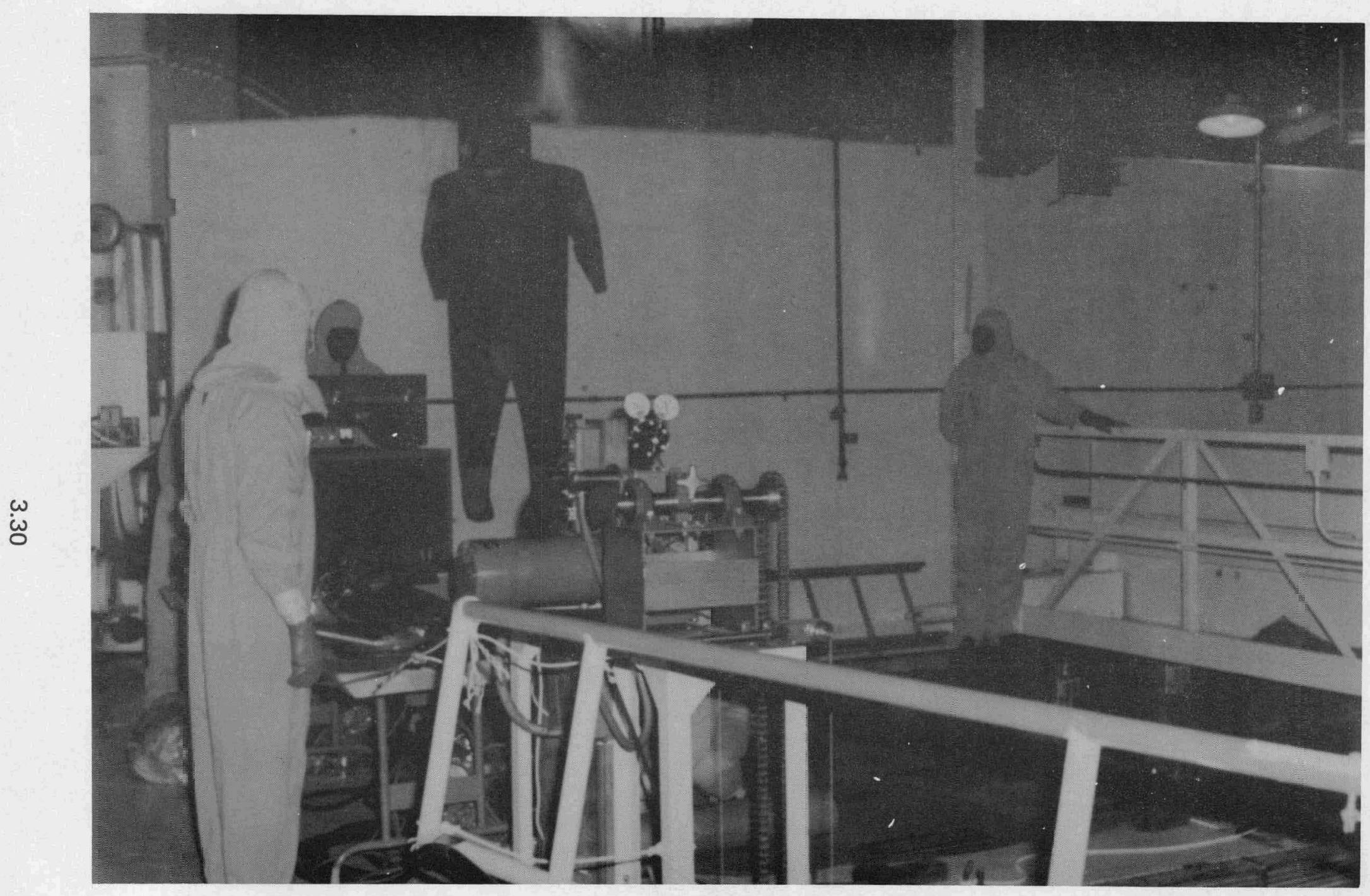

Figure 3.21 RCC Change Fixture Carriage, Lift Drive, and Remote Video Inspection Equipment 


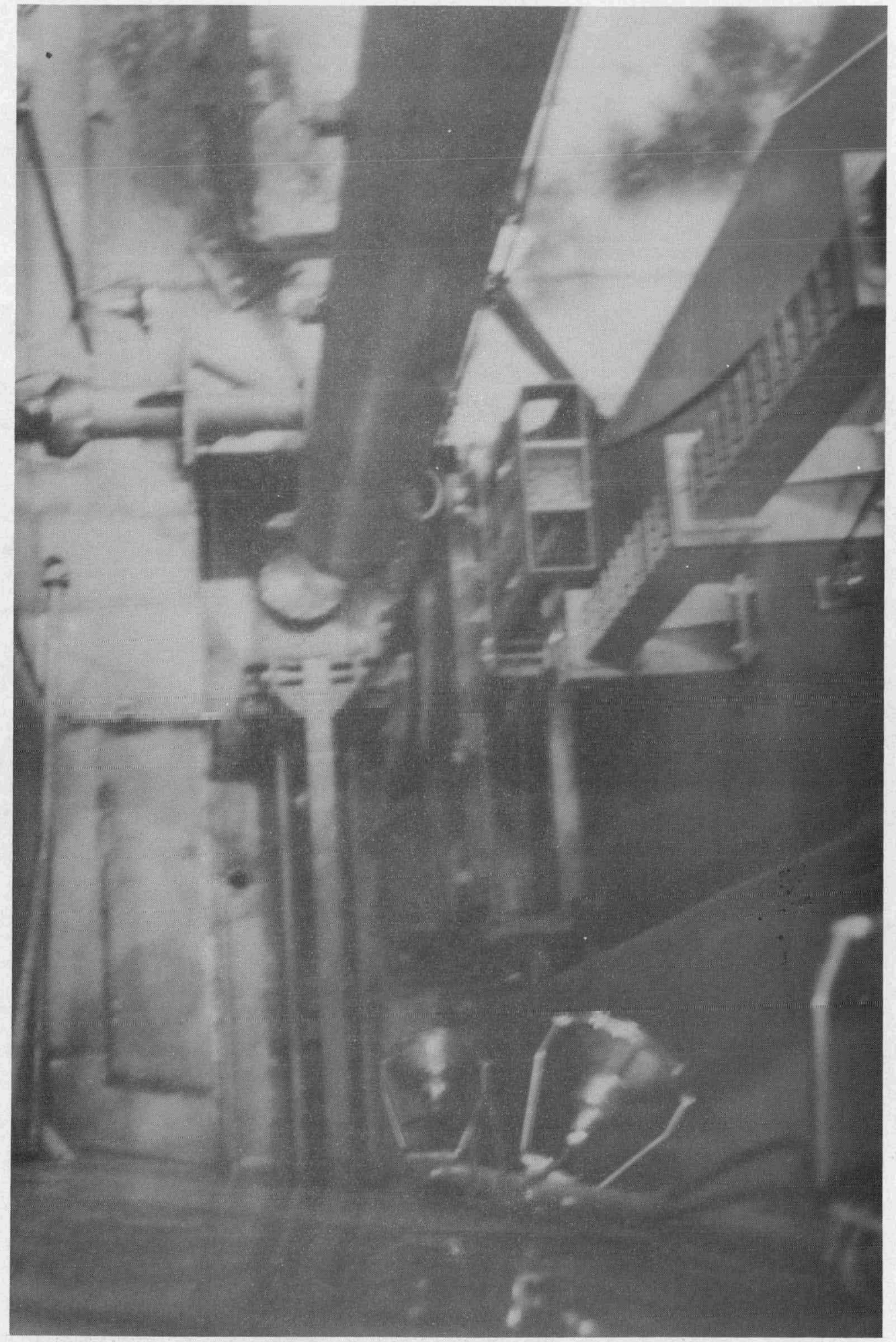

Figure 3.22 Refueling Canal Equipment Details - Upender, Manipulator Mast, RCC Change Fixture and Carriage 


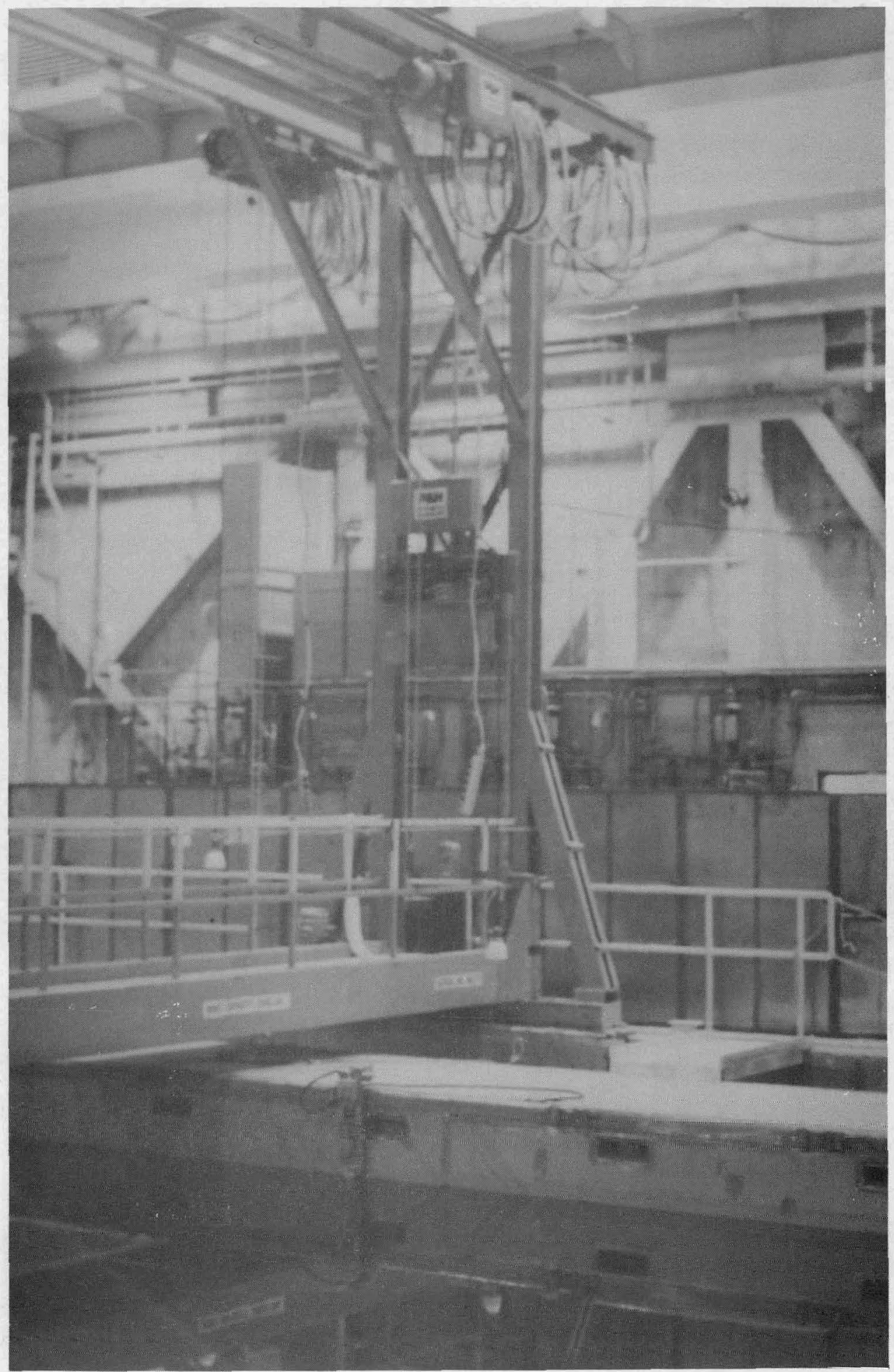

Figure 3.23 Spent Fuel Pool Bridge and Hoists 


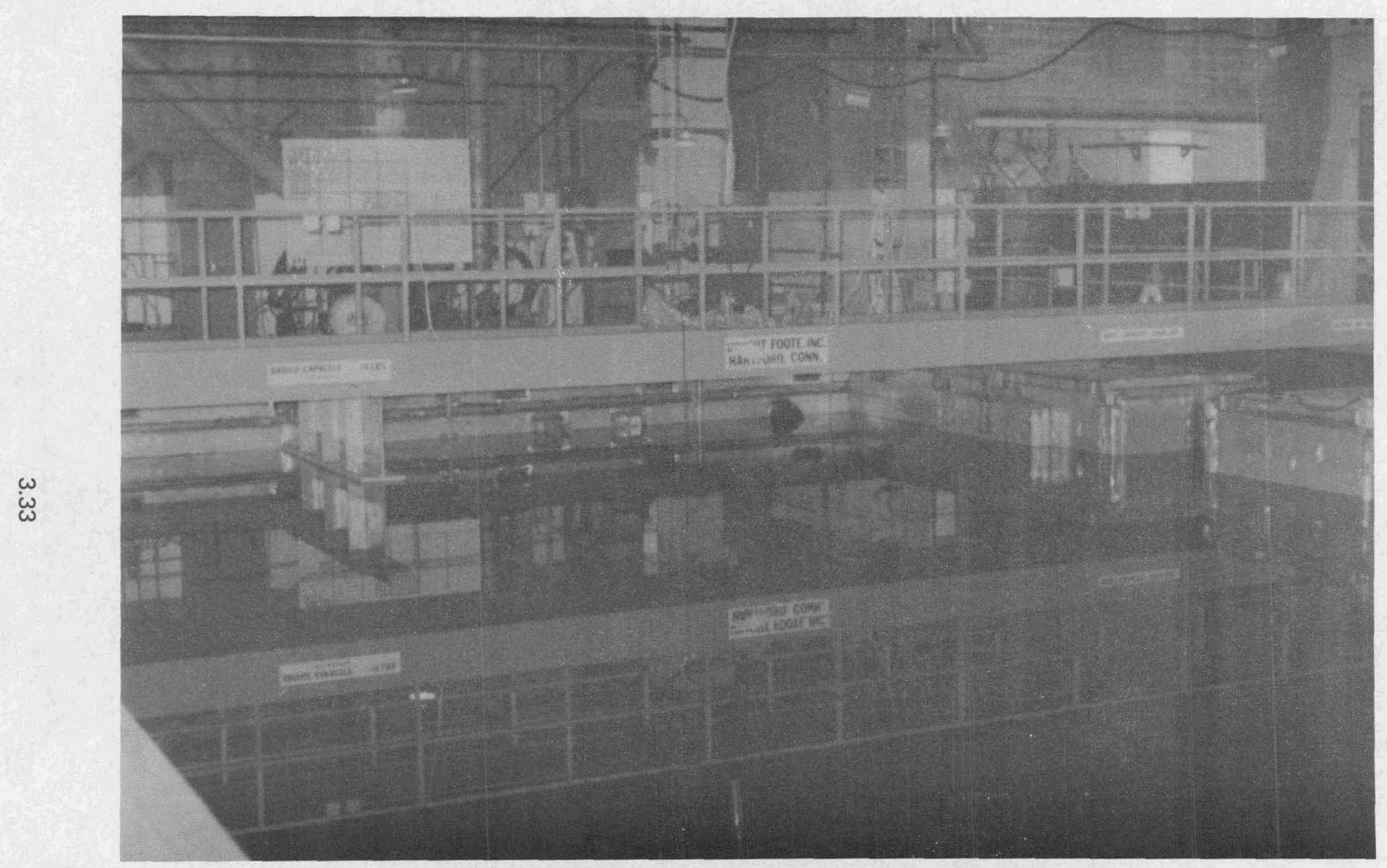

Figure 3.24 Spent Fuel Pool and Bridge 


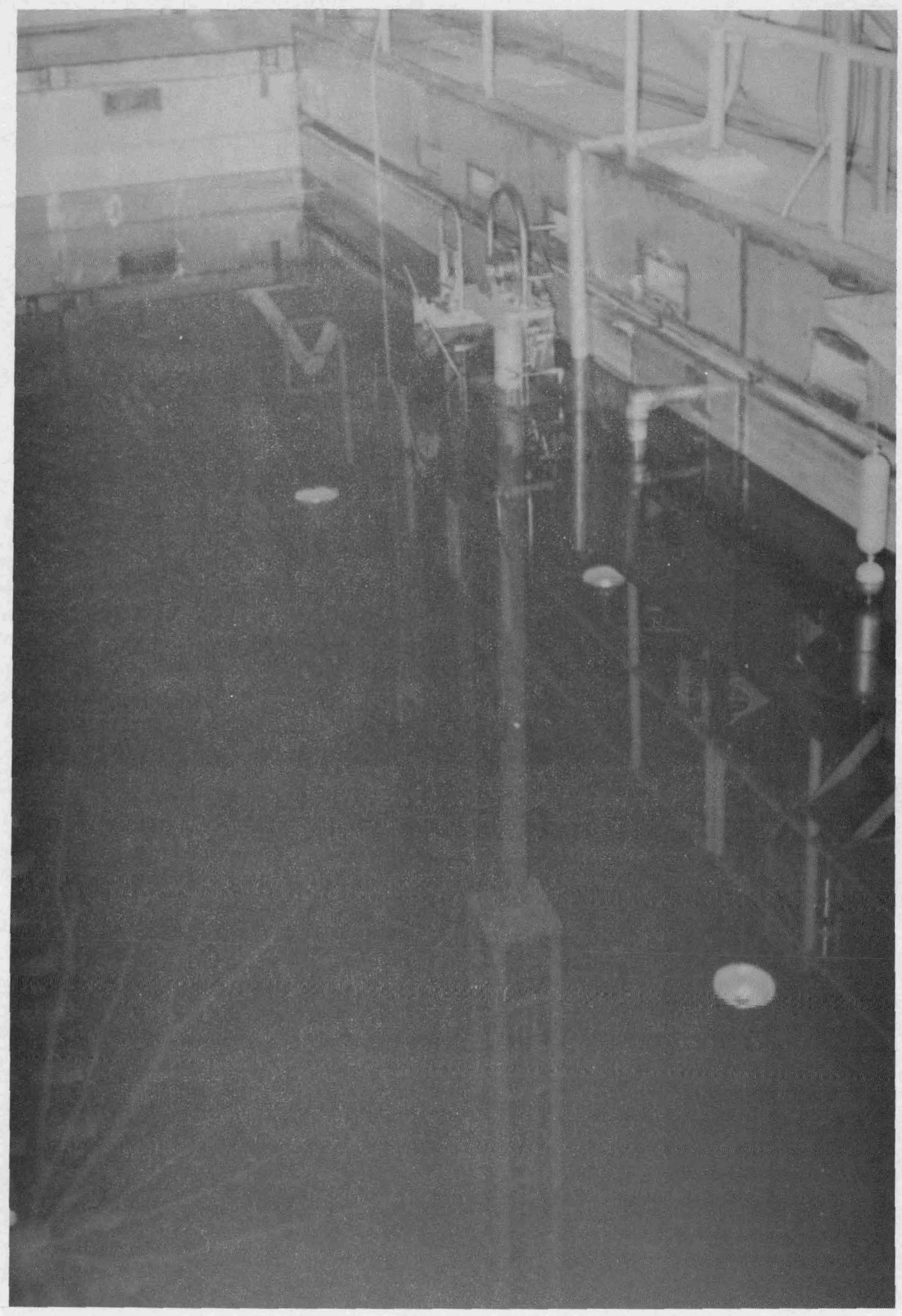

Figure 3.25 Burnable Poison Handling Tool 


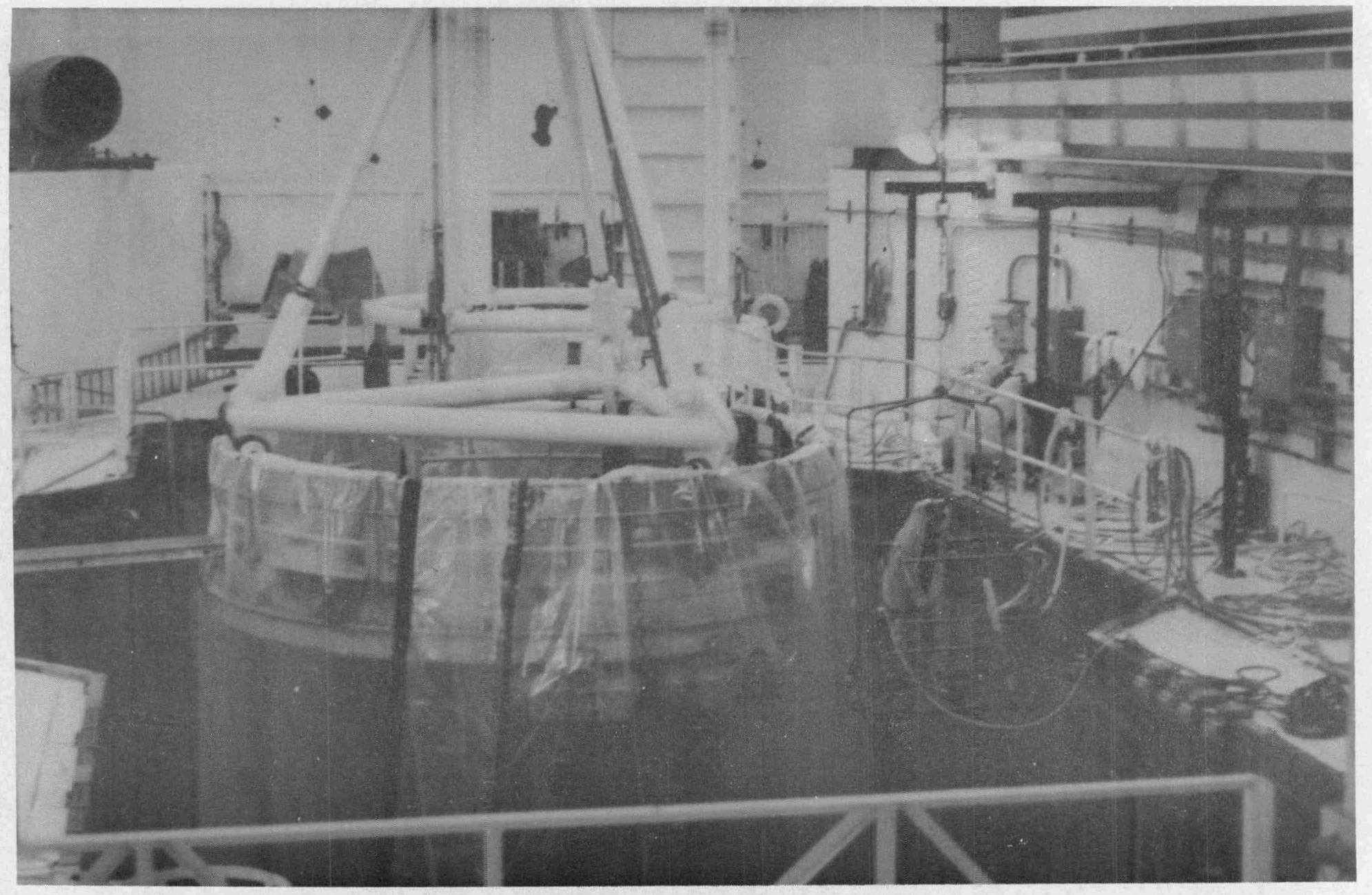

Figure 3.26 Cavity Cleaning Equipment and Head Assembly Frotection 


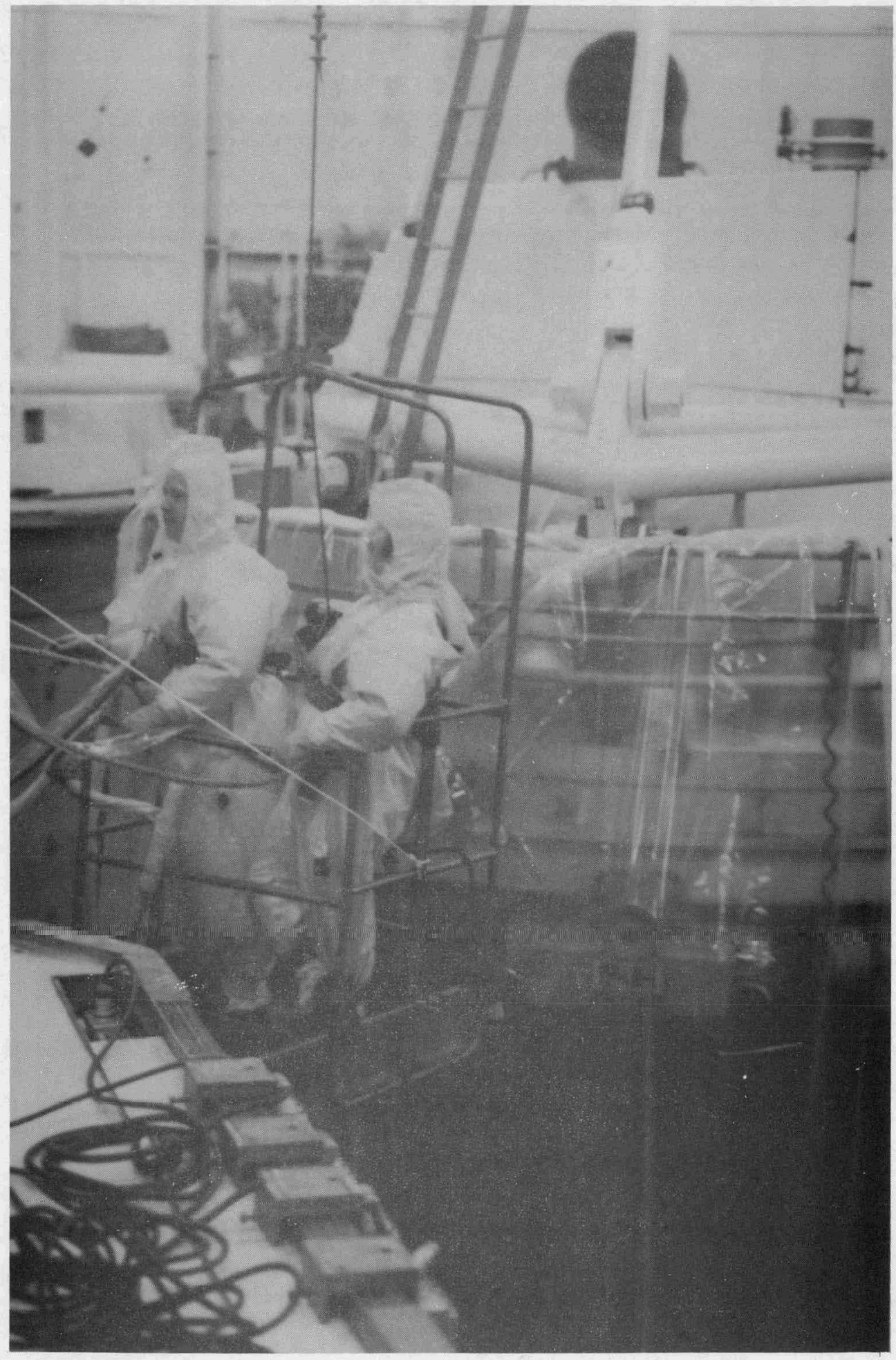

Figure 3.27 Cavity Cleaning Cage and High Pressure Equipment 


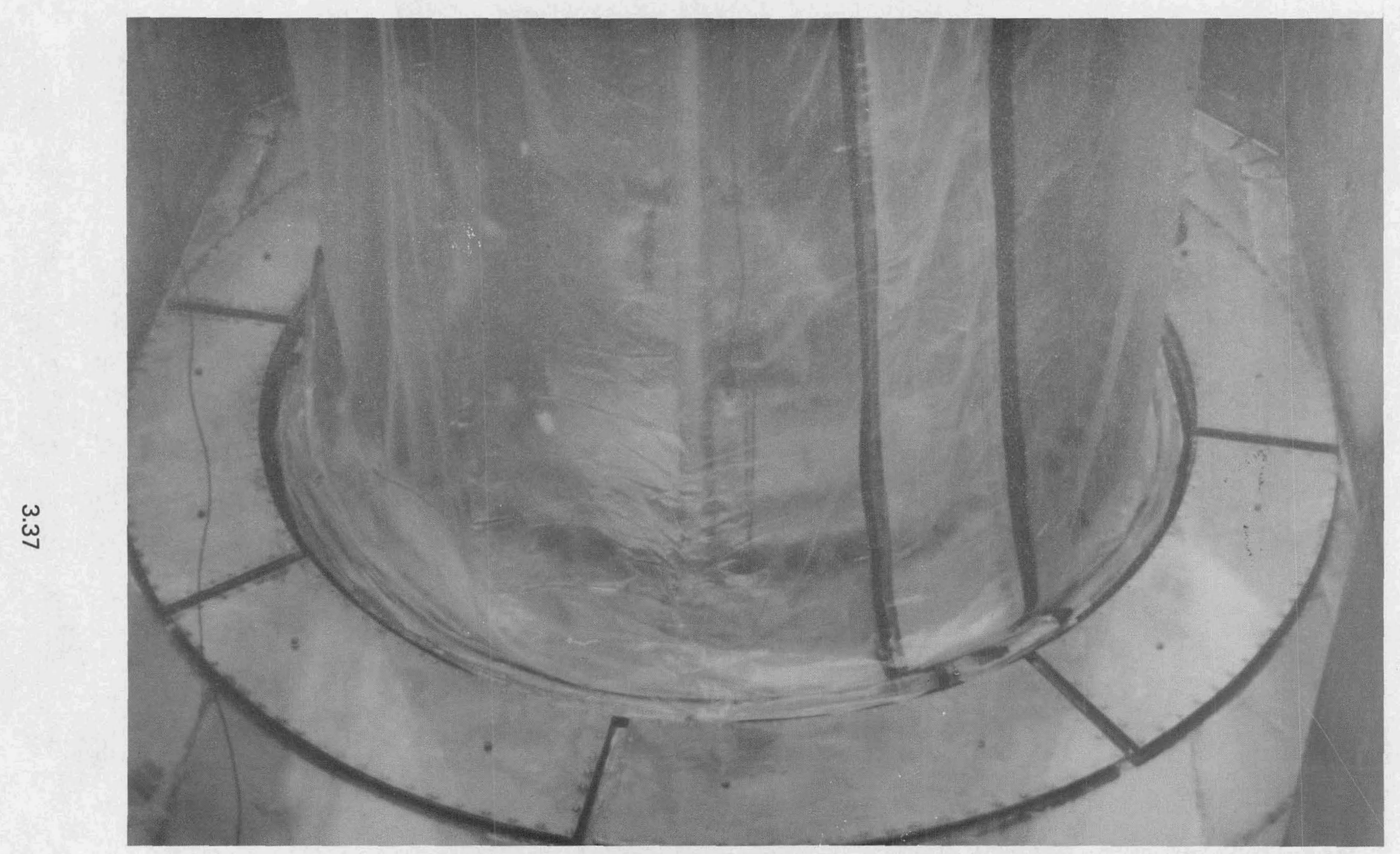

Figure 3.28 Head Protective Covering for Cavity Cleaning 


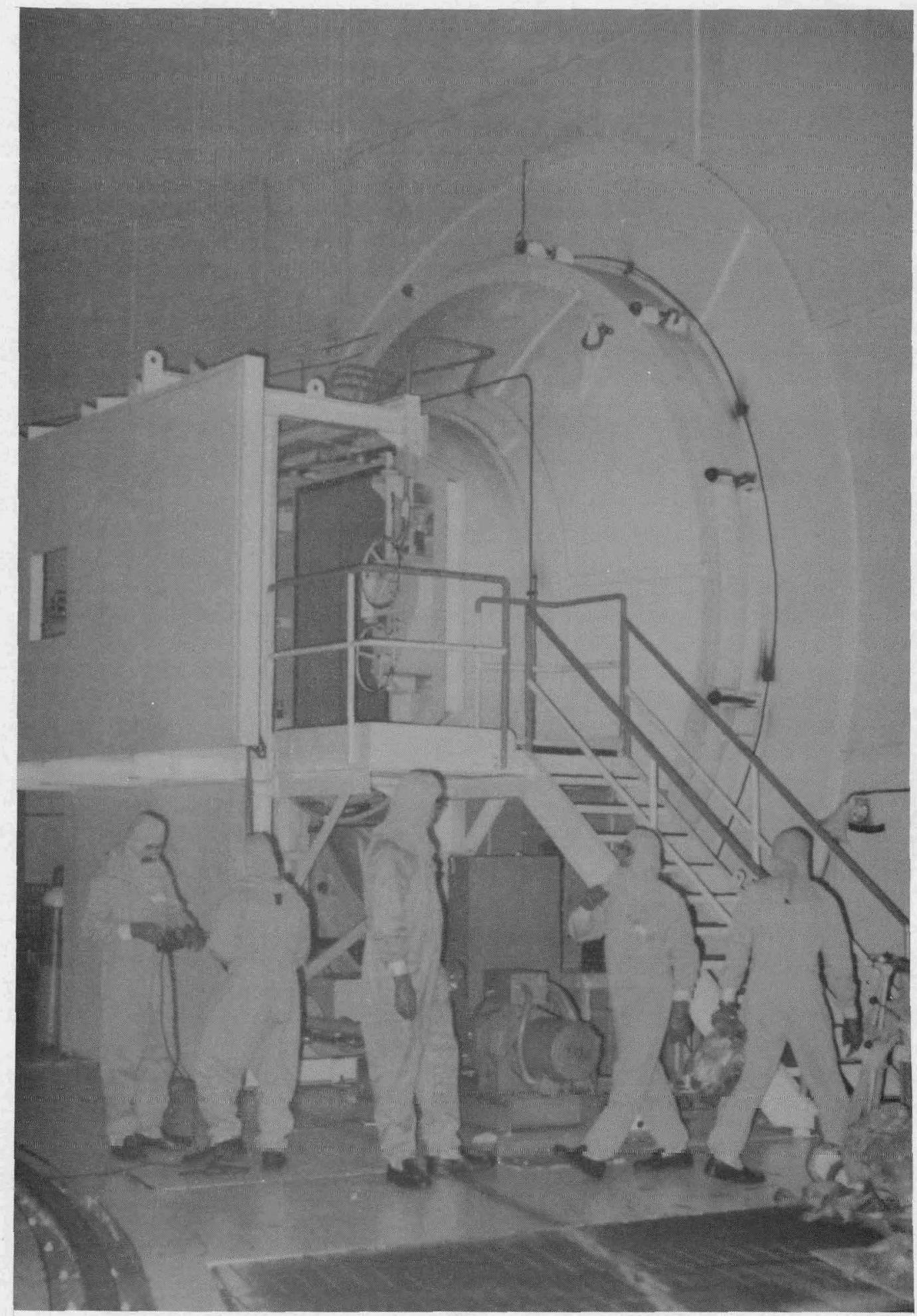

Figure 3.29 Personnel Access Hatch Inside Containment 


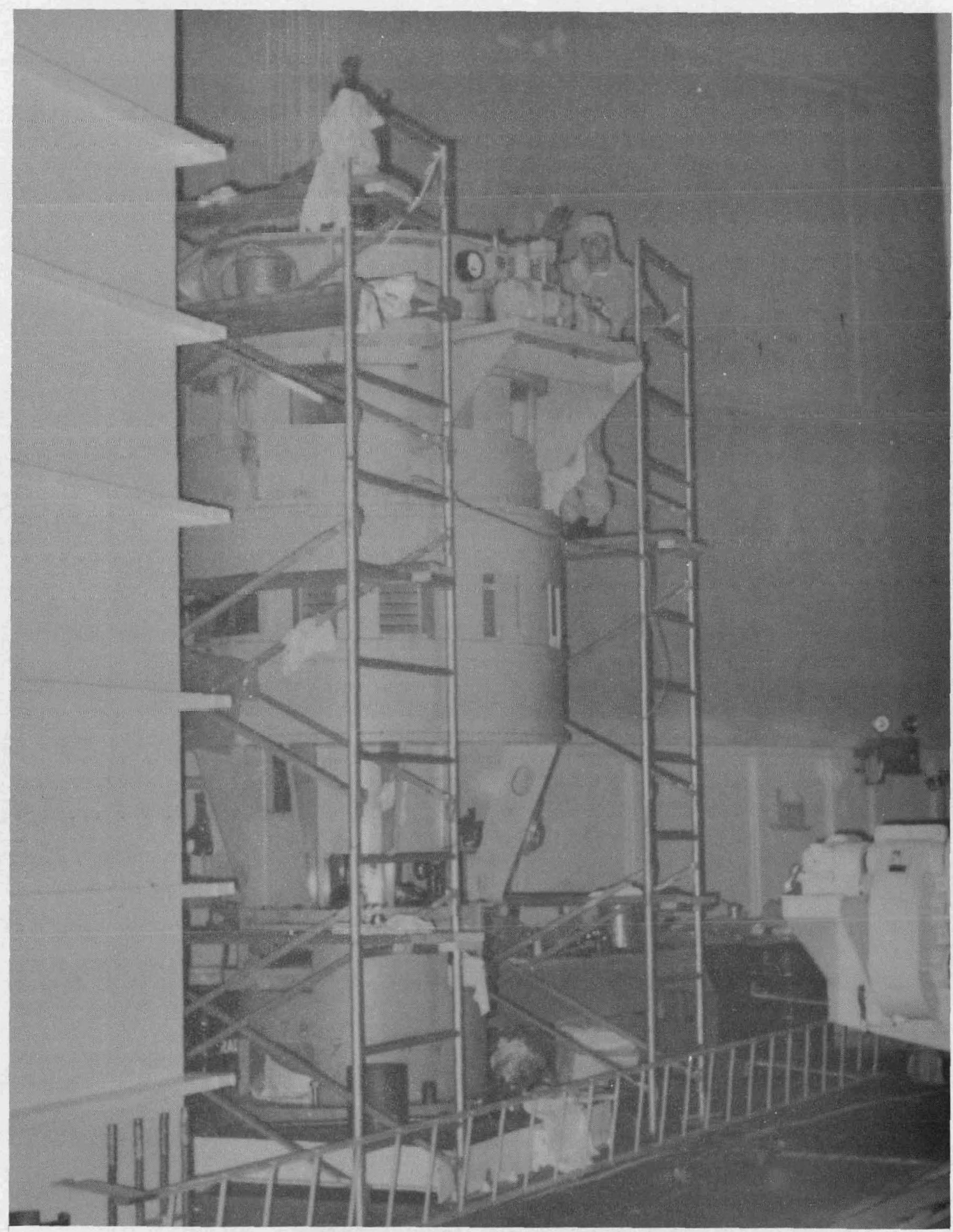

Figure 3.30 Reactor Coolant Pump Motor Maintenance 


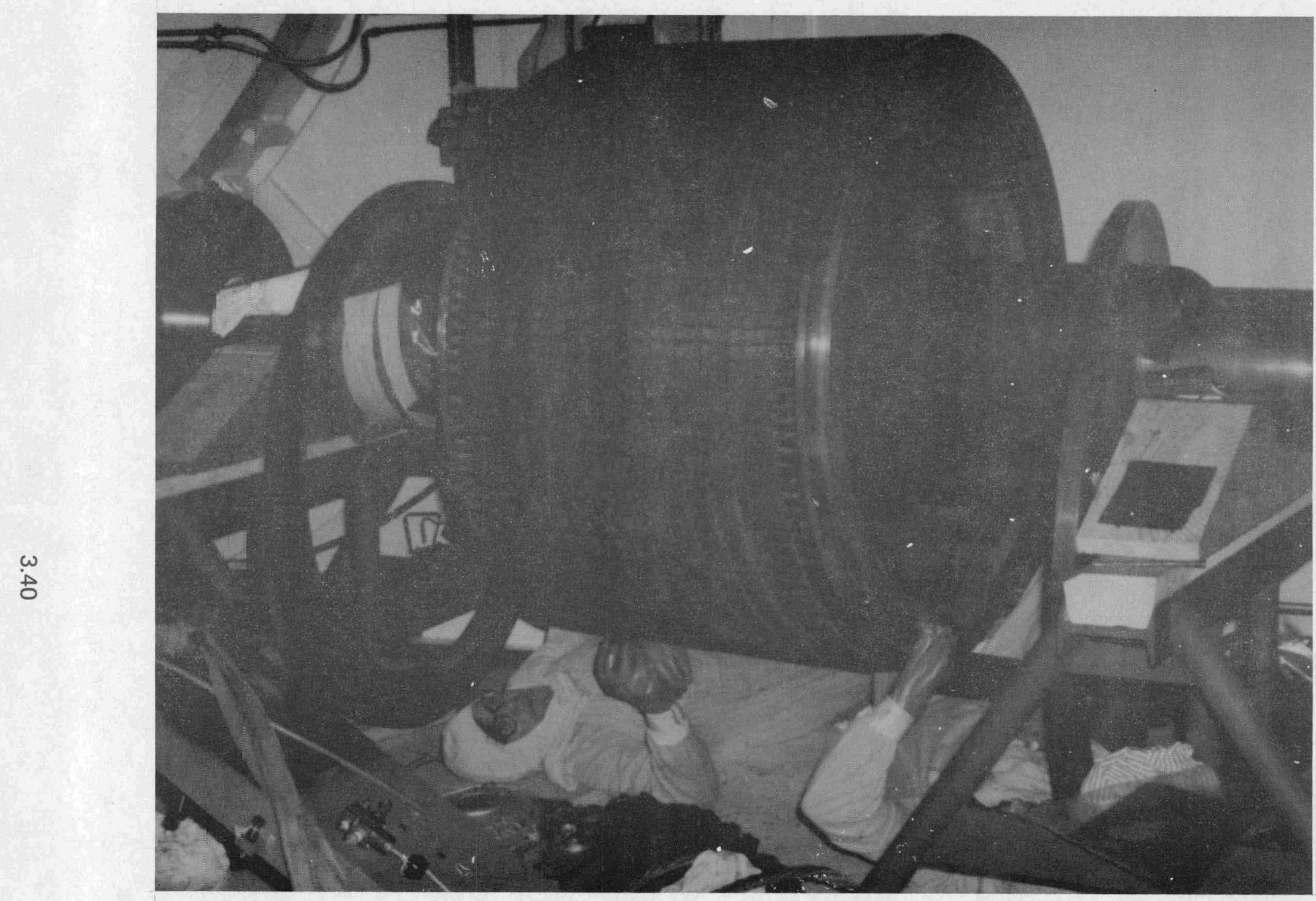

Figure 3.31 Reactor Coolant Pump Rotor Maintenance 


\section{SECTION 4 \\ EVALUATION OF 1976 REFUELING OF ZION UNIT 1}

\subsection{INTRODUCTION}

In order to achieve the primary objective, improvement of availability in a typical PWR by reduction of the required time for refueling outages, it was necessary to determine the details of the work tasks to be performed, that is, how they are accomplished and how much time is required.

During the initial refueling outage of Zion Unit 1 in 1976, direct intensive observations were made of the refueling activities performed within the containment. Periodic evaluations of activities in the fuel handling building were also made. One Westinghouse technician was assigned to provide complete coverage for each of the two, 10 hour daily work shifts. The Westinghouse engineer in charge of the program activity provided overall coverage, in addition to conducting his own observations of key activities. The engineer attended the daily outage status meetings and held frequent discussions with the Zion Station, contract maintenance, and operating personnel. Shift logs were reviewed to gather additional information not obtained by direct observation. A similar but reduced monitoring effort was made of the key operations during the 1977 refueling outage of Zion Unit 2 in order to confirm the evaluations made of Unit 1. Particular attention was given to the problem areas identified during the Unit 1 refueling and to an evaluation of the effectiveness of the changes that had been made to alleviate those problems.

The data obtained by the monitoring effort was compiled and reviewed to provide:

- Total elapsed time from start to completion of each task

- Actual work time to perform the task

- Manpower required to perform the task

- Equipment required

- Radiation field in the area where work was performed

- Causes and duration of interruptions.

The information obtained is included in this section and has been used to identify areas where potential improvements could be made to shorten the time required for refueling. Observation and evaluations were also made, in less detail, of other work activities performed throughout the plant in addition to refueling. Turbine generator maintenance outage experience is discussed in the appendix. The results of this parallel effort will be included in the final report of this program. 


\subsection{TABULATION OF REFUELING DATA}

The observations and other data obtained concerning the refueling activities are displayed in the following pages.in several ways. Table 4.1 tabulates data for the refueling related tasks in the sequence in which they were performed during the 1976 refueling of Zion Unit 1. Included with each task are the date and times when the work was started and completed. The total elapsed time from start to completion is. shown as well as the actual work time, which is the man-machine time spent in productive effort toward completing the task. This data along with the number of men engaged in the work is a measure of work content of the task and indicates the potential benefit of efforts made to increase task efficiency. The table also includes the radiation field dose rate in the areas where each task was performed. $A$ conservatively high estimate of the personnel radiation exposure for each task is made by combining the dose rate, number of men working and work time. The actual exposures were considerably less than this since the workmen did not spend the full work time directly in the radiation field.

Table 4.2 displays the same work tasks ranked according to the work time required to complete each task. Ranking by elapsed time is not included since it could be misleading. Many tasks have an inordinately long elapsed time compared to the work time. In some cases this is indicative of a problem as in item 65 - "Install Upper Internals" where additional effort was required to retrieve a foreign object from the vessel flange before the internals could be installed. Other such difficulties are identified elsewhere in this report. In other tasks, however, such as item 39 "Clean R.V. Studs", the excessive elapsed time resulted from work postponement (since this task was not on the outage critical path) to free maintenance personnel for critical path assignments.

The same data for the Unit 11976 refueling is shown in bar chart form in Figure 4.1. The elapsed time for each item is shown as a bar extending from the time of start to the time of completion. The actual work time numbers are shown above each bar. The bars are shaded for the time periods when tasks were on the critical path for completion of the refueling operation. Other tasks done in parallel with the refueling critical path are left as unshaded bars. Several primary system maintenance and modification tasks that are not part of the normal refueling operation are also included. With the exception of item 66 "Drive Rod Modifications," which, was on the critical path for three days, these tasks did not interfere with refueling operations.

\subsection{ANALYSES OF WORK TIME DATA}

Table 4.2, which ranks the various tasks in order of the work time required, can be used to identify those tasks which offer the greatest potential for reductions in overall refueling time. Table 4.3, which combines these tasks into groups of related items, is somewhat easier to evaluate. 


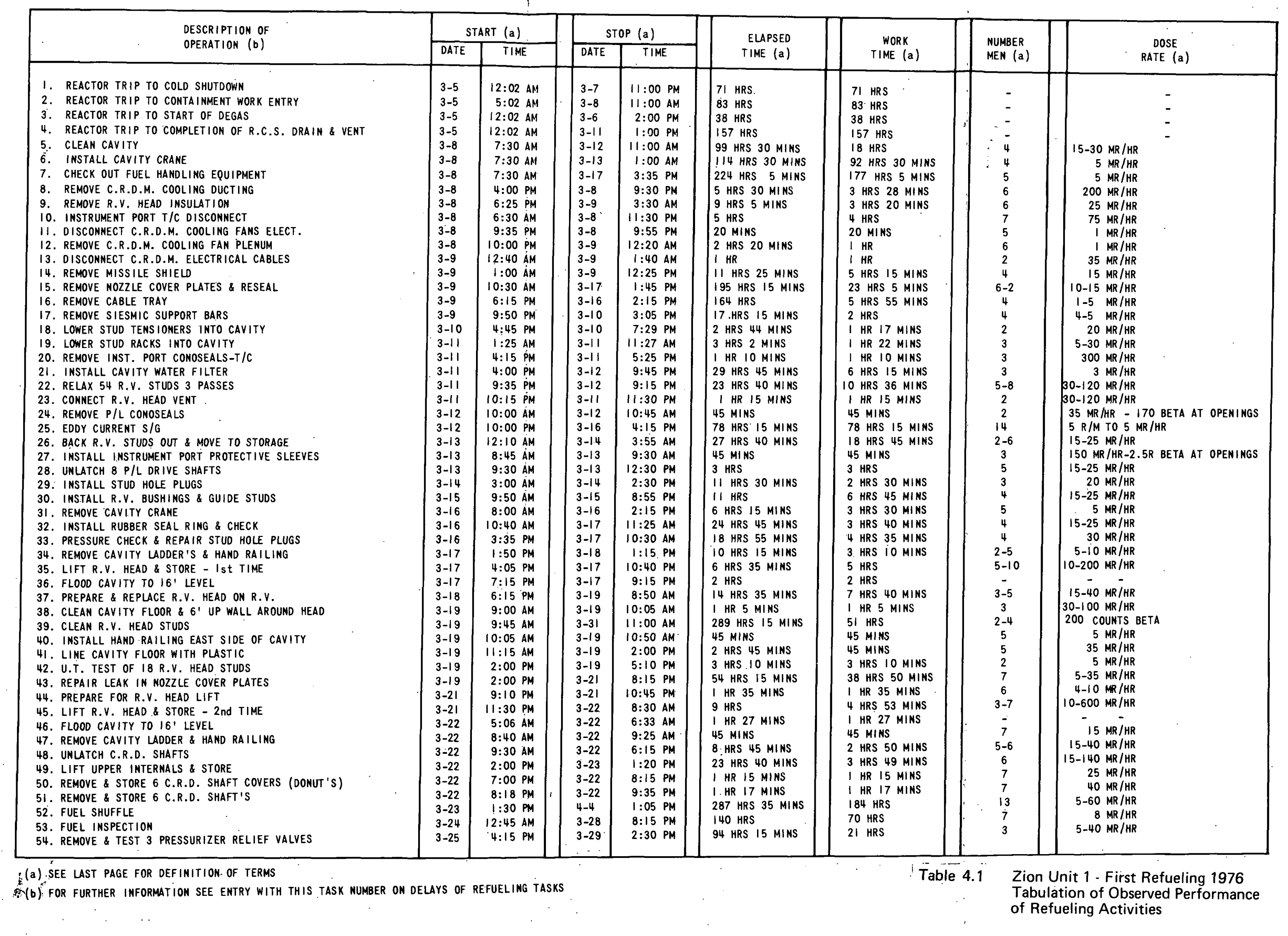




\begin{tabular}{|c|c|c|c|c|c|c|c|c|}
\hline DESCRIPT ION OF OPERATION & \multicolumn{2}{|c|}{ START (a) } & \multicolumn{2}{|c|}{ STOP (b) } & $\begin{array}{l}\text { ELAPSED } \\
\text { TIME (c) }\end{array}$ & $\begin{array}{l}\text { WORK } \\
\operatorname{TINE}(\mathrm{d}) \text {. }\end{array}$ & $\begin{array}{c}\text { MUMBER } \\
\text { MEN }(e)\end{array}$ & $\begin{array}{l}\text { DOSE } \\
\operatorname{RATE}(f)\end{array}$ \\
\hline 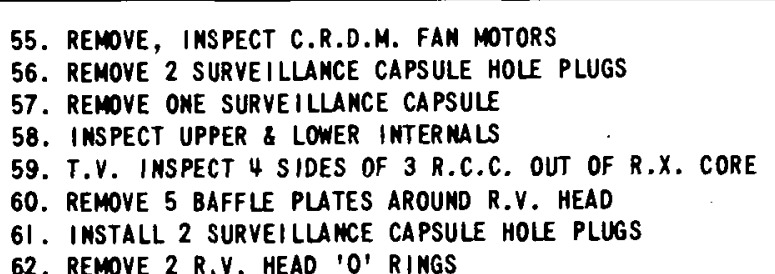 & $\begin{array}{l}3-26 \\
3-27 \\
3-27 \\
-3-27 \\
3-29 \\
4-1 \\
4-4 \\
4-4\end{array}$ & $\begin{array}{ll}8: 00 & \text { AM } \\
10: 10 & \text { AM } \\
2: 32 & \text { PM } \\
3: 30 & \text { PM } \\
8: 45 & \text { AM } \\
9: 45 & \text { AM } \\
8: 10 & \text { AM } \\
9: 0 & \text { AM }\end{array}$ & $\begin{array}{l}4-13 \\
3-27 \\
3-27 \\
3-28 \\
3-29 \\
4-1 \\
4-4 \\
4-4\end{array}$ & $\begin{array}{l}1: 30 \text { AM } \\
2: 32 \text { PM } \\
3: 28 \text { PM } \\
8: 15 \text { PM } \\
12: 30 \text { PM } \\
2: 00 \text { PM } \\
9: 15 \text { AM } \\
4: 05 \text { PM }\end{array}$ & $\begin{array}{l}432 \text { HRS } \\
4 \text { HRS } 22 \text { MINS } \\
56 \text { HINS } \\
28 \text { HRS } \\
3 \text { HRS } 45 \text { MINS } \\
4 \text { HRS } 15 \text { MMLS } \\
1 \text { HR5 } 5 \text { MINS } \\
7 \text { HRS } 5 \text { MINS }\end{array}$ & $\begin{array}{l}\text { EST. } 80 \text { HRS } \\
2 \text { HRS } 57 \text { MINS } \\
56 \text { MINS } \\
15 \text { HRS } 35 \text { MINS } \\
33 \text { HRS } 5 \text { MINS } \\
3 \text { HRS } 15 \text { MINS } \\
11 \text { HR } 5 \text { MINS } \\
5 \text { HRS } 45 \text { MI INS }\end{array}$ & $\begin{array}{c}2-3 \\
5 \\
5 \\
5-3 \\
5 \\
5 \\
5 \\
5-5 \\
4-5\end{array}$ & 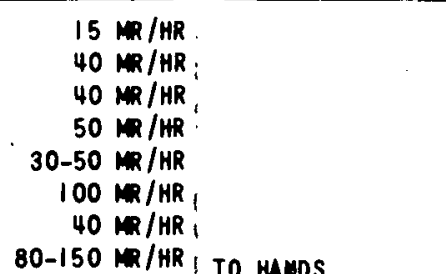 \\
\hline $\begin{array}{l}\text { 63. MAP REACTOR CORE } \\
\text { 64. CLEAM SEAT \& INSTALL } 2 \text { R.V. HEAD 'O' R IMGS }\end{array}$ & $\begin{array}{l}4-4 \\
4-4\end{array}$ & $\begin{array}{l}2: 25 \mathrm{PM} \\
4: 10 \mathrm{PM}\end{array}$ & $\begin{array}{l}4-4 \\
4-8\end{array}$ & $\begin{array}{l}9: 00 \mathrm{PM} \\
2: 30 \mathrm{AM}\end{array}$ & $\begin{array}{l}6 \text { HRS } 35 \text { MIMS } \\
82 \text { HRS } 20 \text { MI IMS }\end{array}$ & $\begin{array}{l}5 \text { HRS } 20 \text { MIMS } \\
40 \text { HRS } 30 \text { MIMS }\end{array}$ & $\begin{array}{l}4 \\
7\end{array}$ & 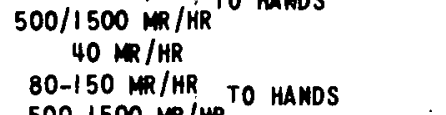 \\
\hline 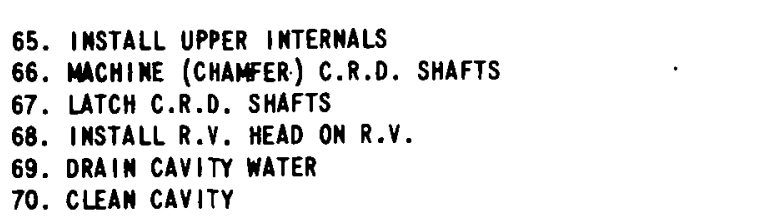 & $\begin{array}{l}4-5 \\
4-5 \\
4-8 \\
4-9 \\
4-9 \\
4-9\end{array}$ & $\begin{array}{l}8: 00 \text { AM } \\
8: 00 \text { AM } \\
6: 50 \text { PM } \\
8: 15 \text { AM } \\
9: 15 \text { AM } \\
3: 50 \text { PM }\end{array}$ & $\begin{array}{l}4-6 \\
4-6 \\
4-9 \\
4-9 \\
4-9 \\
4-23\end{array}$ & $\begin{array}{l}9: 20 \text { AM } \\
6: 46 \text { PM } \\
1: 00 \mathrm{PPM} \\
3: 30 \mathrm{PM} \\
3: 30 \mathrm{PM} \\
3: 30 \mathrm{PM}\end{array}$ & $\begin{array}{l}25 \text { HRS } 20 \text { MINS } \\
82 \text { RRS } 20 \text { MINS } \\
6 \text { HRS } 10 \text { MINS } \\
7 \text { HRS } 15 \text { MINS } \\
6 \text { HRS } 15 \text { MINS } \\
14 \text { DAYS EST }\end{array}$ & $\begin{array}{l}5 \text { HRS } \\
333 \text { HRS } \\
4 \text { HRS } 40 \text { MINS } \\
4 \text { HRS } 40 \text { MINS } \\
6 \text { HRS } 15 \text { MMTS } \\
\text { 170 HRS EST. }\end{array}$ & $\begin{array}{l}4-7 \\
6-9 \\
4 \\
3-7 \\
12\end{array}$ & 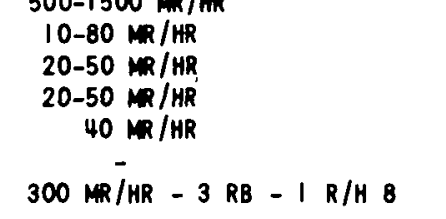 \\
\hline $\begin{array}{l}\text { 71. LATCH P/L C.R.D. SHAFTS } \\
\text { 72. INSTALL P/L C.R.D. SHAFTS CONOSEALS } \\
\text { 73. REPOVE R.V. HEAD GUDE STUDS } \\
\text { 74. REAOVE TTC PORT COVERS \& INSTALL CONOSEALS }\end{array}$ & $\begin{array}{l}4-12 \\
4-12 \\
4-13 \\
4-13\end{array}$ & $\begin{array}{l}3: 20 \text { PM } \\
8: 45 \text { PM } \\
12: 3 \mathrm{PM} \\
3: 30 \mathrm{PMH}\end{array}$ & $\begin{array}{l}4-12 \\
4-13 \\
4-13 \\
4-16\end{array}$ & $\begin{array}{l}9: 15 \mathrm{PM} \\
2: 0 \mathrm{AM} \\
3: 0 \mathrm{PPM} \\
5: 00 \mathrm{PM}\end{array}$ & $\begin{array}{l}5 \text { HRS } 55 \text { MINS } \\
5 \text { HRS } 15 \text { MINS } \\
2 \text { HRS } 35 \text { MMNS } \\
73 \text { HRS } 30 \text { MINS }\end{array}$ & $\begin{array}{l}5 \text { HRS } 45 \text { MINS } \\
4 \text { HRS } 10 \text { MINS } \\
1 \text { HR } 35 \text { MINS } \\
9 \text { HRS } 30 \text { MINS }\end{array}$ & $\begin{array}{c}7 \\
6 \\
8 \\
2-5\end{array}$ & 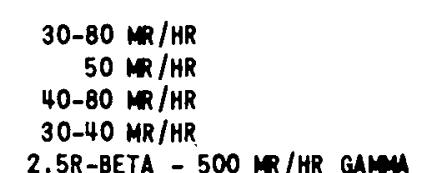 \\
\hline $\begin{array}{l}\text { 75. IMSTALL 6 R.V. HEAD STUDS-TO SEAT HEAD } \\
\text { 76. RETOVE CAVITYY SEAL RINGG (RUBBER BOOT) }\end{array}$ & $\begin{array}{l}4-13 \\
4-14\end{array}$ & $\begin{array}{l}\text { 7:00 PM } \\
10: 50 \mathrm{AMM}\end{array}$ & $\begin{array}{l}4-14 \\
4-14\end{array}$ & $\begin{array}{l}10: 45 \text { AM } \\
2: 35 \text { PM }\end{array}$ & $\begin{array}{l}15 \text { HRS } 45 \text { MINS } \\
3 \text { HRS } 45 \text { MINS }\end{array}$ & $\begin{array}{l}7 \text { HRS } 17 \text { MINS } \\
1 \text { HR } 25 \text { MINS }\end{array}$ & $\begin{array}{c}5 \\
4-6\end{array}$ & 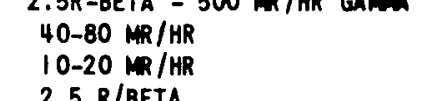 \\
\hline 77. REMOVE STUd. hOLE PLUGS & $4-14$ & $7: 10 \mathrm{PM}$ & $4-14$ & $10: 20 \mathrm{PM}$ & 3 HRS 10 MINS & 2 HRS 30 MINS & 6 & $50-100 \mathrm{NR} / \mathrm{HR}$ \\
\hline 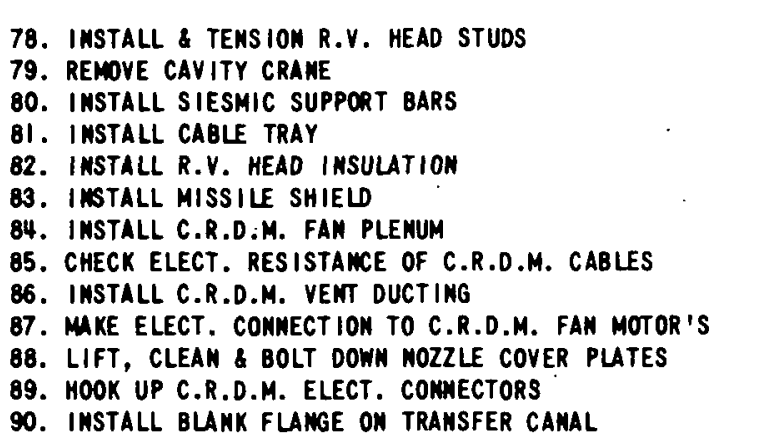 & $\begin{array}{l}4-14 \\
4-17 \\
4-17 \\
4-19 \\
4-19 \\
4-20 \\
4-20 \\
4-20 \\
4-20 \\
4-21 \\
4-21 \\
4-23 \\
4-25\end{array}$ & 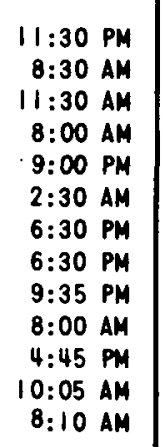 & $\begin{array}{l}4-19 \\
4-17 \\
4-17 \\
4-19 \\
4-20 \\
4-20 \\
4-20 \\
4-22 \\
4-21 \\
4-23 \\
4-25 \\
4-24 \\
4-25\end{array}$ & $\begin{array}{l}2: 20 \mathrm{PM} \\
1: 30 \mathrm{AM} \\
3: 30 \mathrm{AM} \\
2: 25 \mathrm{PM} \\
2: 25 \mathrm{PM} \\
1: 25 \mathrm{AM} \\
5: 12 \mathrm{PM} \\
9: 35 \mathrm{PH} \\
10: 25 \mathrm{PM} \\
3: 10 \mathrm{AM} \\
1: 30 \mathrm{PM} \\
2: 25 \mathrm{AM} \\
5: 30 \mathrm{PM} \\
11: 00 \mathrm{AM}\end{array}$ & 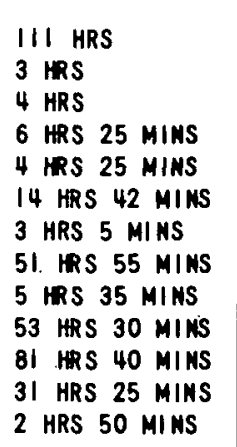 & 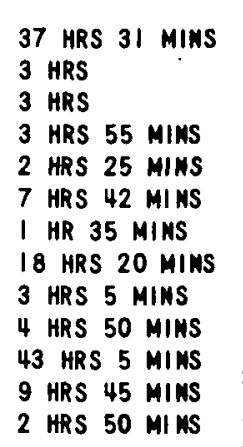 & $\begin{array}{c}6-7 \\
5 \\
5 \\
5 \\
4 \\
4-6 \\
5 \\
2 \\
5 \\
3-6 \\
2-6 \\
2- \\
3\end{array}$ & 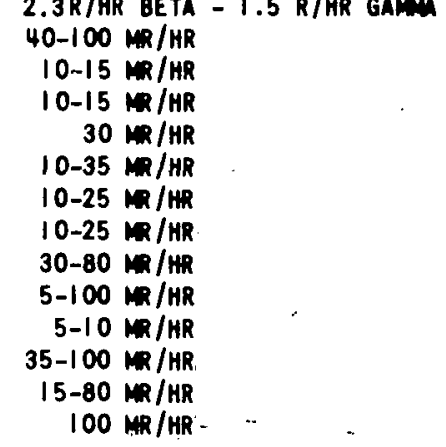 \\
\hline
\end{tabular}

\section{DEFINITION OF TERMS}

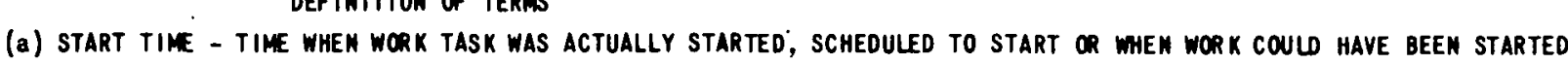

(b) STOP TIME - TIME WHEN WORK TASK WAS COMPLETED.

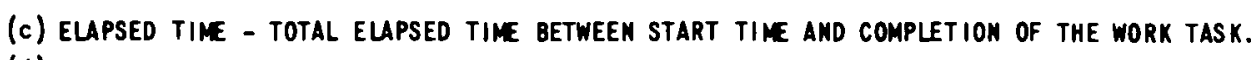

(d) WORK TIME - ACTUAL TIEE SPEHT ACTIYEYY WORKIMG TOMARD COMPLETION OF MORK TASK.

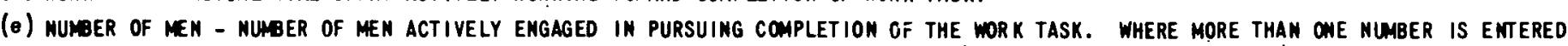

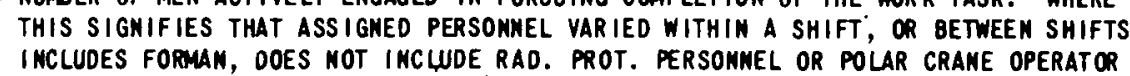

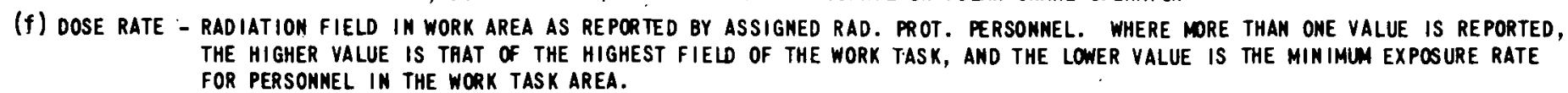

Table 4.1 (Cont) Zion Unit 1-First Refueling 1976 Tabulation of Observed Performance
Activities 


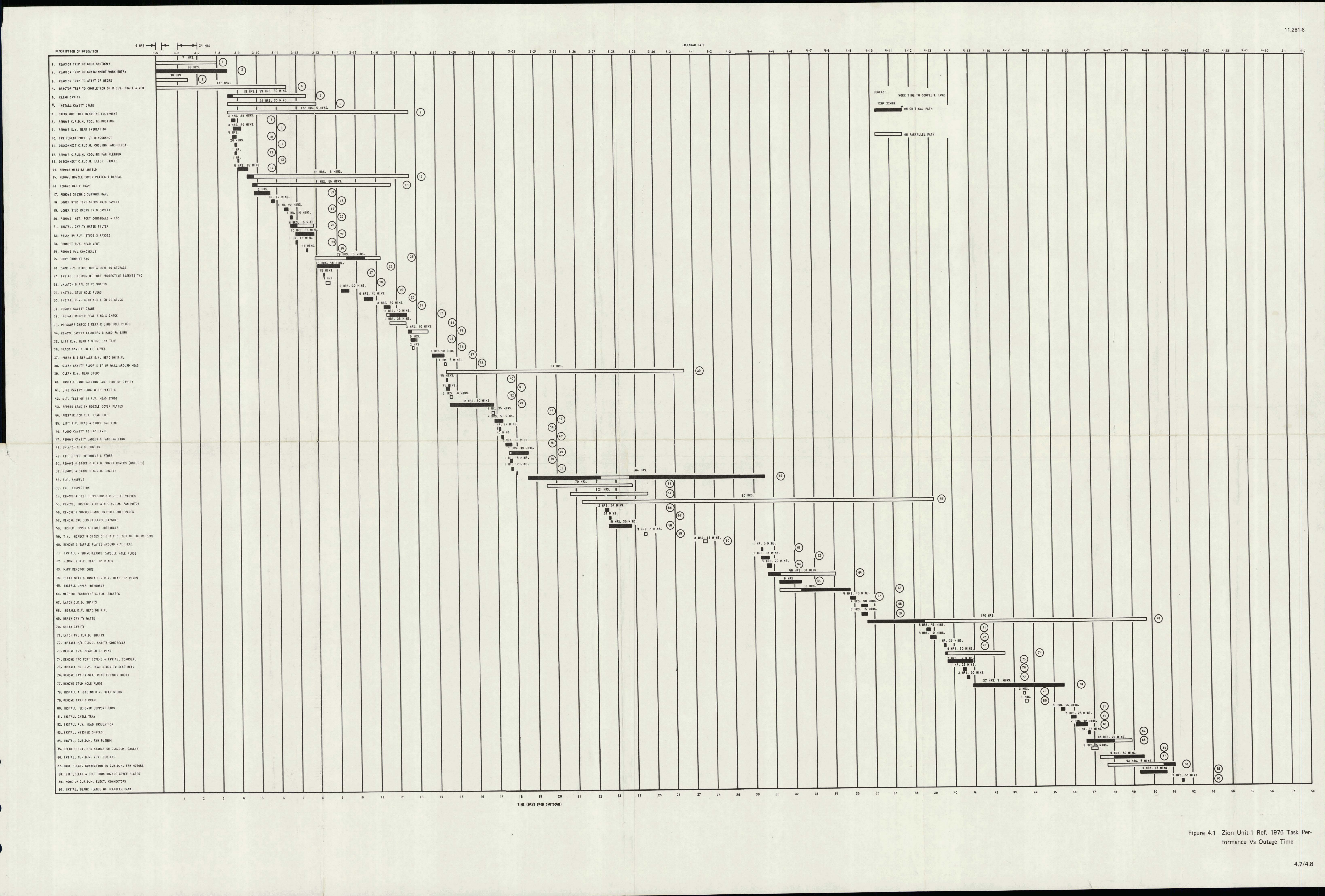


TABLE 4.2

REFUELING WORK ITEMS RANKED ACCORDING TO TIME REQUIRED

DURING 1976 REFUELING OF ZION UNIT 1

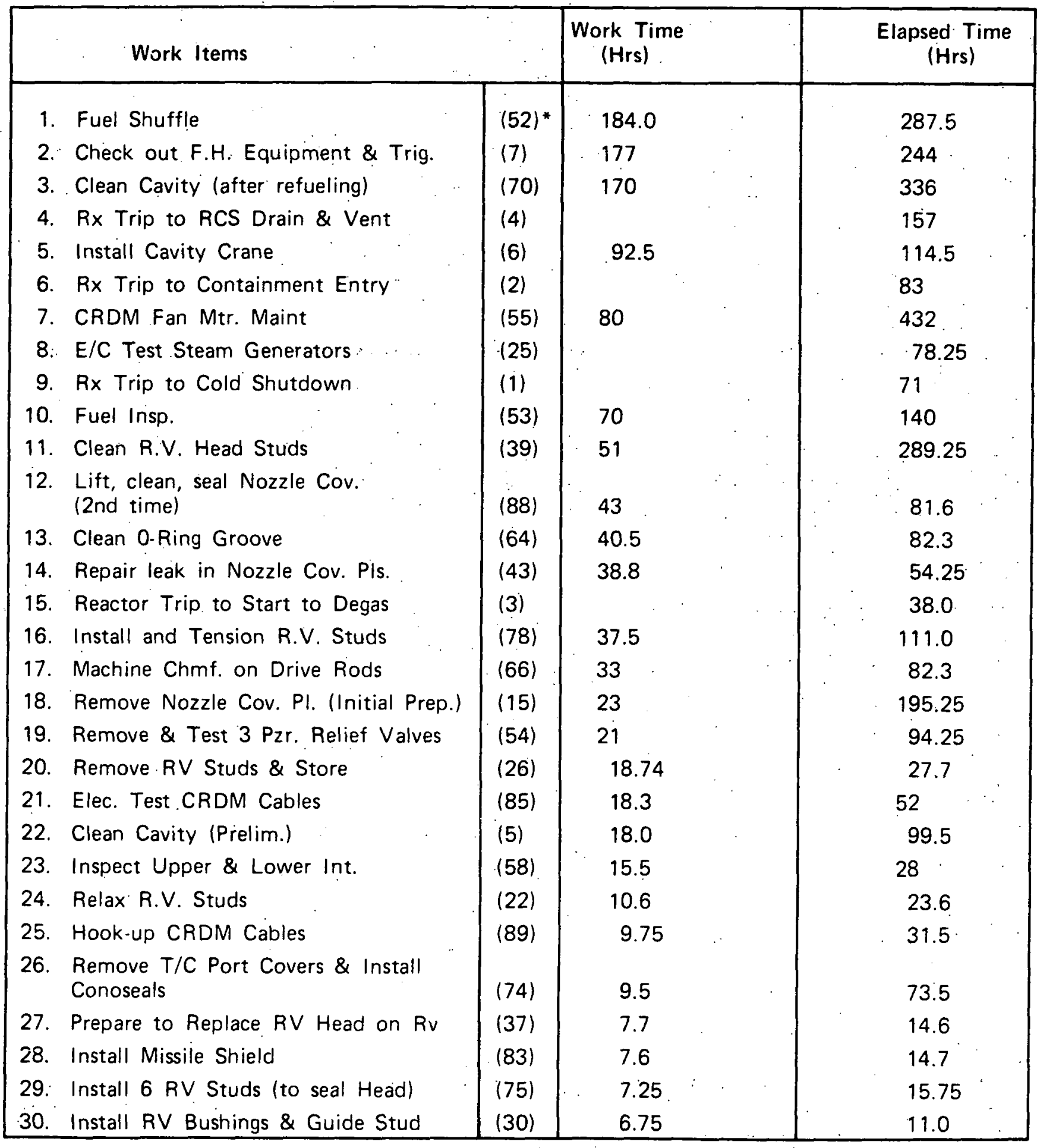

- Number in parentheses refer to Work Item Numbers in Table 4.1. 
TABLE 4.2 (cont)

REFUELING WORK ITEMS RANKED ACCORDING TO TIME REQUIRED DURING 1976 REFUELING OF ZION UNIT 1

\begin{tabular}{|c|c|c|c|}
\hline Work Items & & $\begin{array}{l}\text { Work Time } \\
\text { (Hrs) }\end{array}$ & $\begin{array}{c}\text { Elapsed Time } \\
\text { (Hrs) }\end{array}$ \\
\hline 31. Install Cavity Water Filter & $(21)$ & 6.25 & 29.7 \\
\hline 32. Drain Cavity Water & (69) & 6.25 & 6.25 \\
\hline 33. Remove Cable Tray & $(16)$ & 6.0 & 164 \\
\hline 34. Remove (2) R.V. Head 0-Rings & (62) & 5.75 & 7.0 \\
\hline 35. Latch $P / L$ Drive Rods & (71) & 5.75 & 6.0 \\
\hline 36. Map Reactor Core & (63) & 5.3 & 6.5 \\
\hline 37. Remove Missile Shield & (14) & 5.25 & 11.5 \\
\hline 38. Install Upper Internals & (65) & 5.0 & 25.3 \\
\hline 39. Lift R.V. Head \& Store (1st Time) & (35) & 5.0 & 6.5 \\
\hline 40. Lift R.V. Head \& Store (2nd Time) & (45) & 4.9 & 9.0 \\
\hline 41. Elec. Connect CRD Fan Motors & (87) & 4.8 & 53.5: \\
\hline 42; Latch $F / L$ Drive Rods & (67) & 4.6 & 6.2 \\
\hline 43. Install R.V. Head & $(68)$ & 4.6 & 7.25 \\
\hline $\begin{array}{l}\text { 44. Pressure check \& Repair Stud Hole } \\
\text { Plugs }\end{array}$ & (33) & 4.5 & 19.0 \\
\hline 45. Install $P / L$ CRD . Conoseals & (72) & 4.2 & 5.25 \\
\hline 46. Instrument Port $\mathrm{T} / \mathrm{C}$ disconnect & $(10)$ & 4.0 & 5.0 \\
\hline 47. Install Cable Tray & $(81)$ & 3.9 & 6.4 \\
\hline 48. Lift Upper Int. \& Store & (49) & 3.8 & 23.7 \\
\hline $\begin{array}{l}\text { 49. Install Vessel/Cavity Seal Ring \& } \\
\text { Check }\end{array}$ & $(32)$ & 3.7 & 24.15 \\
\hline 50. Remove Cavity Crane (1st Time) & (31) & 3.5 & 6.25 \\
\hline 51. Remove CRDM Cooling Ducts & (8) & 3.5 & 5.5 \\
\hline 52. Remove R.V. Flange Insul. & (9) & 3.3 & 9.1 \\
\hline 53. U.T. Test 17 R.V. Head Studs & $(42)$ & 3.2 & 3.2 \\
\hline 54. Remove Cavity Ladders \& Railing & (34) & 3.2 & 10.25 \\
\hline $\begin{array}{l}\text { 55. Remove } 5 \text { Baffle Plates (CRDM } \\
\text { Cooling) }\end{array}$ & $(60)$ & 3.25 & 4.25 \\
\hline 56. Install CRDM Cooling Ducts & $(86)$ & 3.1 & 5.6 \\
\hline 57. T.V. Inspect 3 RCC out of core & (59) & 3.1 & 3.75 \\
\hline 58. Remove Cavity Crane. (2nd Time) & (79) & $\cdot 3.0$ & 3.0 \\
\hline 59. Install Seismic Supports & $(80)$ & $\therefore \cdot \cdot$ & 4.0 \\
\hline Unlatch $8 \mathrm{P} / \mathrm{L}$ Drive Shafts & (28) & 3.0 & 3.0 \\
\hline
\end{tabular}


TABLE 4.2 (cont)

REFUELING WORK ITEMS RANKED ACCORDING TO TIME REQUIRED DURING 1976 REFUELING OF ZION UNIT 1

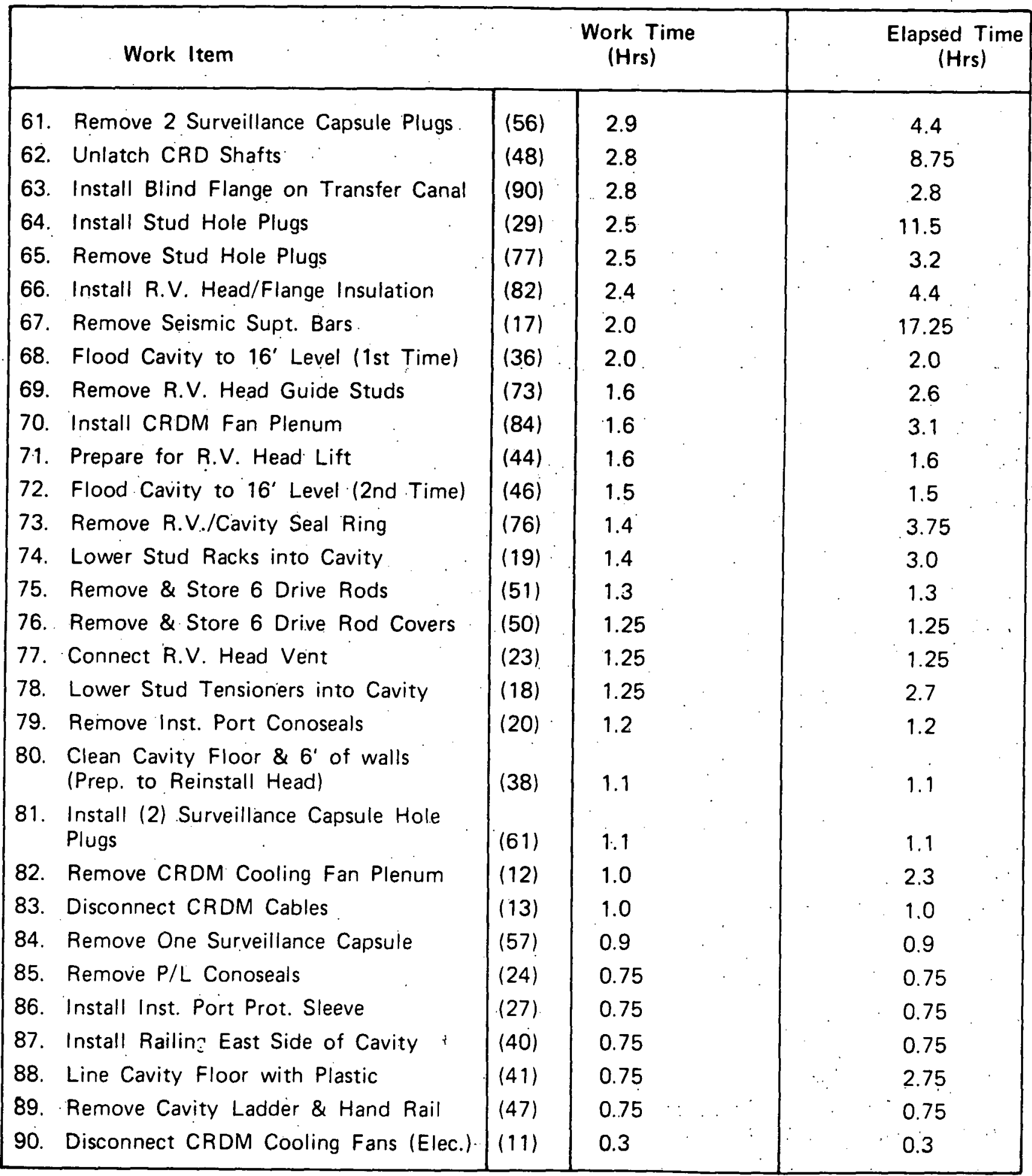


TABLE 4.3

MAJOR REFUELING WORK CATEGORIES RANKED ACCORDING TO TIME REQUIRED DURING 1976 REFUELING OF ZION UNIT 1

\begin{tabular}{|l|c|c|}
\hline \multicolumn{1}{|c|}{ Work Category } & $\begin{array}{c}\text { Work Time } \\
\text { (Hrs) }\end{array}$ & $\begin{array}{c}\text { Work Item No's. on } \\
\text { Table } 4.1\end{array}$ \\
\hline $\begin{array}{l}\text { Cavity Cleaning } \\
\text { Fuel Shuffle } \\
\text { Check out of Ref. Equipment } \\
\text { and Training }\end{array}$ & $\begin{array}{c}188 \\
184\end{array}$ & 5,70 \\
$\begin{array}{l}\text { Reactor Disassembly and } \\
\text { Reassembly } \\
\text { Lift, Clean and Sèal }\end{array}$ & 177 & 52 \\
$\begin{array}{l}\text { Nozzle Covers } \\
\text { Clean R.V. Studs } \\
\text { Clean R.V. Head } \\
\text { O-Ring Groove }\end{array}$ & 173.7 & $74,83,87,74,16,30$ \\
\hline
\end{tabular}


Cavity cleaning is found to be the task requiring the longest time. The total time is 188 hours when item 70 and item 5 are combined. This task, particularly after refueling, is also the one that causes the highest radiation exposure to the workers.

The next highest work time is 184 hours for the fuel shuffle, (item 52) including fuel handling, transfer of core components and transfer to and from the spent fuel building.

Checkout of fuel handling equipment and training of refueling personnel required 177 hours. This time was longer than will be required in the future since this was the first refueling for this unit and a large amount of time was spent familiarizing personnel with equipment operation. Since the equipment (manipulator crane, RCC change fixture, and fuel transfer system) is inaccessible during reactor operation, the checkout and training could not be performed in advance of the outage. This activity however, did not interfere with the refueling critical path work items since different work crews were involved.

The disassembly and reassembly of the reactor consists of many small tasks which individually do not require much time. However, when they are considered as a combined category, the sum of their individual work times is 173.7 hours as shown in Table 4.4 .

Installation and sealing of the reactor nozzle inspection port cover plates will be performed during each refueling outage regardless of whether nozzle inspections are required. This is done to assure the cover plates will not leak when the cavity is flooded for refueling. At the end of the outage the plates are again removed and remain off during operation as a safety precaution. The sum of the work times for these activities during the 1976 outage of Zion Unit 1 was 66 hours. In addition, a problem was encountered achieving adequate sealing, causing a delay of 4 days. The modifications made at Zion to prevent repetition of the problem in future outages will be discussed in the final report.

Another one-time activity that required significant work time that will be greatly reduced in future outages was the installation of an auxiliary cavity crane. The benefits of such a crane are significant however and should be considered in other plants.

The time from the reactor shut down through cooldown, degassing, containment entry and draining and venting of the reactor coolant system are very important since these activities are or could be on the critical path for the outage. The total time to containment entry was 83 hours during the 1976 outage. Procedural improvements made prior to the 1977 refueling of Unit 2 were effective in reducing this time and will be described in the final report.

A number of other tasks related to refueling, but not on the critical path, required long work times. Improvements to these would have an, indirect effect on shortening the length of the outage. Attention to such activities is required since improvement to overall work efficiency will affect the length of the outage by reduction of such factors as confusion within the 
TABLE 4.4

REACTOR DISASSEMBLY/ASSEMBLY WORK TIMES

\begin{tabular}{|l|c|c|c|c|}
\hline \multirow{2}{*}{ Component } & \multirow{2}{*}{ Remove } & \multicolumn{2}{|c|}{ Work Time } & \multirow{2}{*}{ Replace } \\
\cline { 3 - 4 } & 5.25 & 7.7 & 12.95 & 7.5 \\
Missile Shield & 4.8 & 9.5 & 14.30 & 8.2 \\
CRDM Cooling System & 6.9 & $32.0^{*}$ & 38.9 & 22.4 \\
Cable Tray & 32.0 & 44.8 & 76.8 & 44.2 \\
RV Studs & 4.1 & 6.75 & 10.85 & 6.2 \\
Guide Studs & 6.4 & 4.66 & 11.06 & 6.4 \\
RV Head & 3.82 & 5.05 & 8.87 & 5.1 \\
Upper Internals & & & 173.7 & 100.0 \\
& & & \\
\hline
\end{tabular}

- Includes checking of cables. 
containment, traffic through the containment access hatch, and radiation control processing. Included in this category are tasks such as cleaning the reactor vessel studs (51 hrs), cleaning the reactor vessel head O-ring grooves, and maintenance of the CRDM fan motors. This latter work task required 80 hours of work time and 432 hours of elapsed time. Similarly, eddy-current testing of steam generators exhibited a long elapsed time but did not appear to have a direct impact on refueling since this work was subcontracted.

The overall and specific effect of improvements to work times by the use of modified equipment will be discussed in Section 6.

\subsection{ANALYSES OF REFUELING CRITICAL PATH TIME DATA}

A further insight to the impact of various tasks upon the total refueling time can be obtained by assessing the data for refueling critical path items shown in the Figure 4.1 bar chart. The time required for tasks on the refueling critical path are summarized in Table 4.5 in a greatly condensed categorized format. This information indicates where improvements in work performance would have the greatest effect in reducing the total refueling outage time.

The fuel shuffle and the mechanica! disassembly and reassembly of the reactor head combined comprised $66 \%$ of the refueling critical path time and therefore deserve the greatest attention. An interesting observation that can be made is that the mechanical disassembly and assembly tasks are individually of short duration but cumulatively they were responsible for nearly $43 \%$ (22 days) of the total critical path time and require nearly twice the time of the fuel shuffie. Most of this work is eliminated by the use of an Integrated Head Package to be described later.

Delays in obtaining access to the containment at the beginning of the outage should be minimized by improving the health physics procedures and the equipment and procedures used to purge the containment. It is also essential to minimize the time required for cleanup, venting, and draining of the reactor coolant system so that disassembly of the reactor can be initiated.

Assembly and testing of electrical cables, primarily on the CRDM's were on the refueling critical path for about 3.0 days near the end of the outage. This work could also be simplified by incorporation of the Integrated Head Package and the use of the electrical test equipment described later.

Sealing of the nozzle cover plates would have been on the critical path for only a half day. but a four day delay was caused by leakage past the seal that required draining of the cavity for repairing the seal. A modified seal design was developed by the station personnel that performed very satisfactorily during the 1977 refueling of Unit 2. 
TABLE 4.5

TIME OF WORK ITEMS ON THE REFUELING CRITICAL PATH

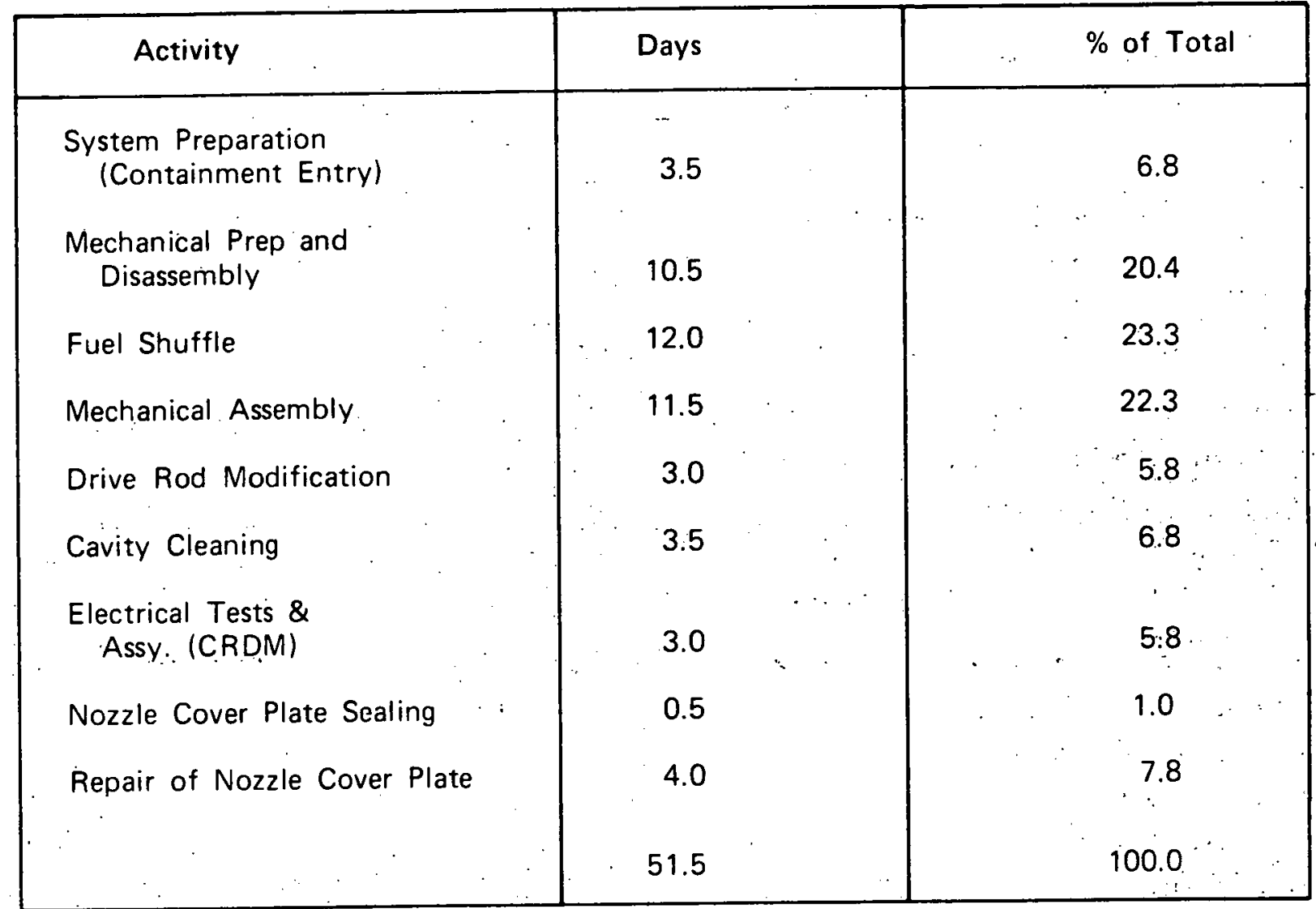


Cavity cleaning was on the critical path for only 3.5 days but required a great amount of work time and caused a high personnel radiation exposure. This work was performed manually from a powered scaffold hanging from the edge of the cavity. The scaffold was not well suited to the task and required many time consuming adjustmerits and maintenance. The task would have been on the refueling critical path for a significantly longer time and the difficulties would have been more obvious in the data, except that the task was interrupted to proceed with assembly work. An excellent method of cleaning using a high pressure water spray system was used during the Zion Unit 2 refueling outage that resulted in a marked improvement of performance. Since this task will always be on the refueling critical path ahead of reactor assembly the improved system is highly recommended.

The RCC drive rod modification noted in Table 4.5 was a one-time activity and need not be considered for future outage planning.

The data indicates that the major effort should be directed toward reducing assemblydisassembly and fuel shuffle time to achieve the largest reduction in refueling critical path time. 
$\Theta$ 


\section{SECTION 5 \\ CONCEPTUAL DESIGN OF EQUIPMENT MODIFICATIONS TO REDUCE THE TIME REQUIRED FOR REFUELING}

This section presents conceptual descriptions of equipment modifications that have been prepared for the purpose of shortening the time required for the refueling operations. Section 6 provides an analysis of the potential benefits of each modification that can be used as the basis for determining the scope of a continuation of this program into a demonstration of the effectiveness of these equipment improvements.

\subsection{INTEGRATED VESSEL HEAD ASSEMBLY FOR ONE-LIFT OPERATION}

\subsubsection{Introduction}

The integrated reactor vessel head assembly combines into one package, the reactor head, lifting rig, lift columns, seismic platform, missile shield, CRDM forced air cooling system, and electrical and instrumentation cable routing. The ability to lift all of this equipment as a combined package could save considerable time during the disassembly and re-assembly of the reactor during refueling operations. Figure 5.1 shows the integrated head assembly concept.

\subsubsection{Reactor Vessel Head.}

The modified equipment required for the integrated package would be fitted onto the existing reactor vessel head.

\subsubsection{Cooling Shroud Structure}

This structure will provide support for the CRDM cooling system. The system consists of three blowers that force cooling air through openings in the shroud. The air flows down along the mechanisms, back up the shroud through the blowers and exhausts into the containment atmosphere. The shroud structure is bolted to a support ring on the reactor vessel head and is also attached to the three lift columns. Provisions are made for supporting the stud tensioner 


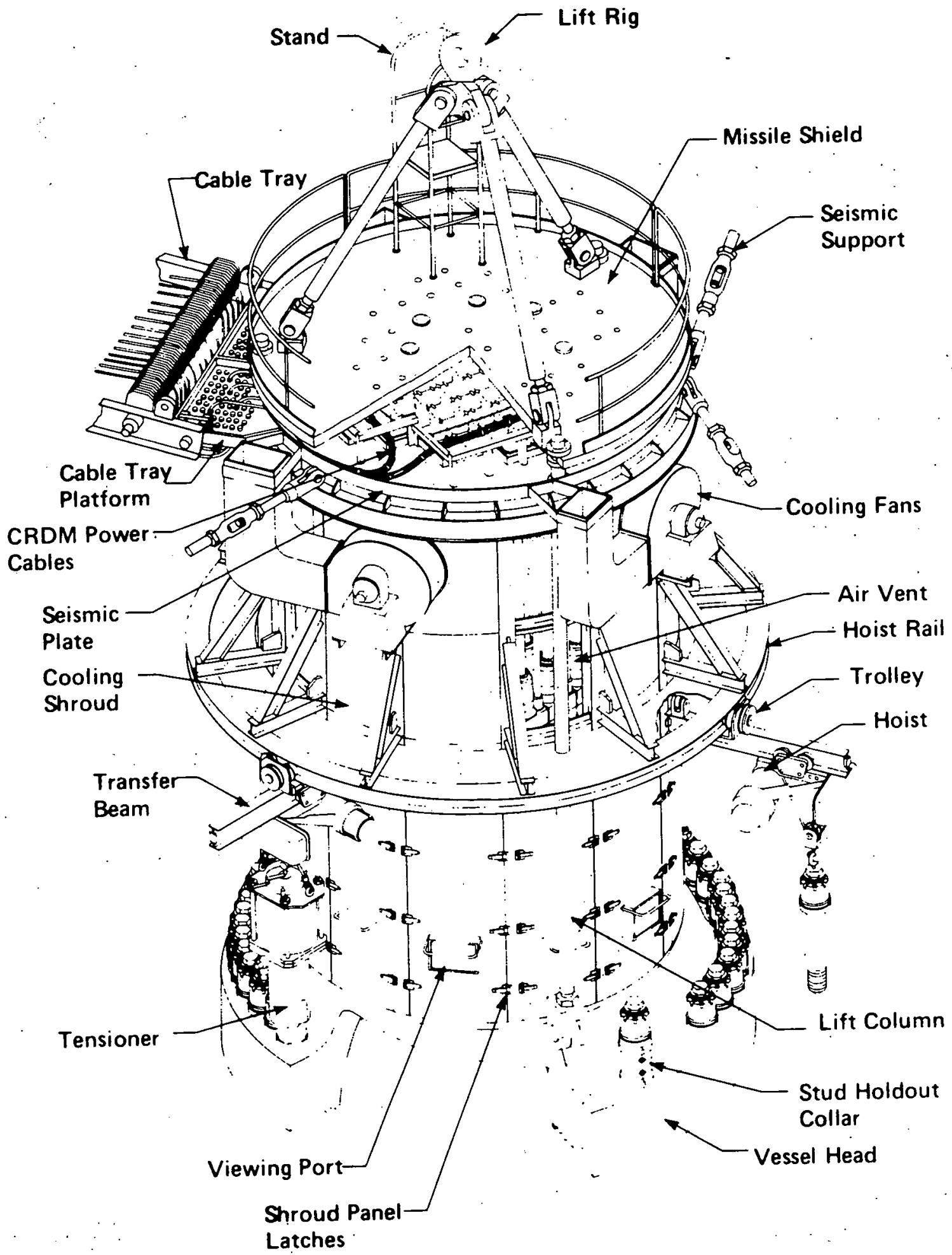

Figure 5.1 Integrated Vessel Head Package 
hoists used during the head removal and replacement operations. Access is provided through the shroud for use of a thermocouple column loading tool.

\subsubsection{Lifting Rig}

The lifting rig remains attached to the vessel head and missile shield assembly at all times, eliminating a number of separate attachment, lift and release operations. The rig is attached directly to the load cell linkage assembly for the lifting operation in the same manrier as with the standard rig presently used at the Zion Station.

\subsubsection{Missile Shield}

The missile shield remains attached to the head during movement of the assembly by three lift columns which transfer the load of the head to the lifting rig. The shield can be leveled for plant operation and can be detached to provide access to the control rod drive mechanisms if required. Unlatching of the part length control rods is done from atop the missile shield.

\subsubsection{Seismic Platform}

The existing seismic platform while continuing to provide support for the CRDM's, will also support the CRDM power and instrumentation cables, and provides a platform to which the cable tray is attached.

\subsubsection{Cable Tray}

The cable tray supports the power and instrumentation cables and provides a method for easily disassembling and storing the cables in preparation for head removal. The tray is attached to the seismic platform and pivots on the steam generator wall or another appropriate structure. Connectors are provided on the platform so the cables and the tray can be easily disconnected.

\subsubsection{Stud Handling System}

The removal, handling and replacement of the reactor vessel studs is simplified by the incorporation of monorail transfer beams that permit radial travel of the stud handling system. Each stud location can be reached without the necessity of using the polar crane or a separate jib crane. Stud holdout collars are provided so that the studs can be retained in the vessel head flange for a single lift and transport of the integrated head package. The improved stud closure system including quick disconnect tensioners described in this section is recommended as a further improvement of the stud removal and replacement process. 


\subsection{IMPROVED REACTOR VESSEL HEAD CLOSURE SYSTEM}

The time required to detension, remove, insert, and tension the reactor vessel studs could be significantly reduced by use of a fast acting tensioner and stud spinning system that is recommended by Westinghouse. (Figures 5.2, 5.3, 5.4, and 5.5)

The improved system uses three quick-disconnect/connect stud tensioner (Figure 5.2) which have quick-acting gripper devices for grasping adapters permanently attached to the studs. The lower end of each adapter is threaded onto the stud and the upper portion has concentric rings which mate with the split gripper of the tensioner (Figure 5.3). A fast acting, high capacity, hydraulic actuating system provides pressure simultaneously to the three tensioners. To replace manual threading of studs, a motor driven tool has been designed as a compliment to the quick-acting tensioners. The tool (Figure 5.4) includes the important feature of supporting the weight of the stud as it is being turned. This feature reduces the turning required and minimizes the potential for binding of the threads. (These devices function in a manner similar to those presently used at Zion.)

The proposed system could potentially save 1.5 to 2.5 days in the refueling time by reducing the time required to tension and detension the studs and to remove and insert them in the reactor vessel flange. It is expected 200 man-hours of labor could also potentially be saved.

Since the reactor vessel stud work represents one of the highest radiation exposure refueling process, significant reductions of radiation exposure can be realized. In particular, the time consuming tasks of threading and unthreading studs are reduced and in addition, the stud handling tool once attached can be operated from several feet away. Significant reduction of radiation exposure is expected.

\subsection{IMPROVED MANIPULATOR CRANE (REFUELING MACHINE)}

A number of design improvements have been developed for Westinghouse manipulator cranes that could be applied to equipment already in use at plants such as Zion Station. These modifications described in the following paragraphs should significantly reduce the time required for refueling and should also achieve an additional benefit by reducing the radiation exposure of personnel.

\subsubsection{Single Integrated Gripper Mast Assembly (SIGMA)}

As described in Section 3 the changing of thimble plugs and rod cluster control assemblies (RCCA's) from one fuel assembly to another with conventional manipulator cranes, such as those at the Zion Station, requires the fuel assemblies first be transported to the fuel transfer system upender or RCC change fixture. Removal and insertion of components is then accomplished manually with a long tool. Incorporation of the SIGMA feature on the manipulator 


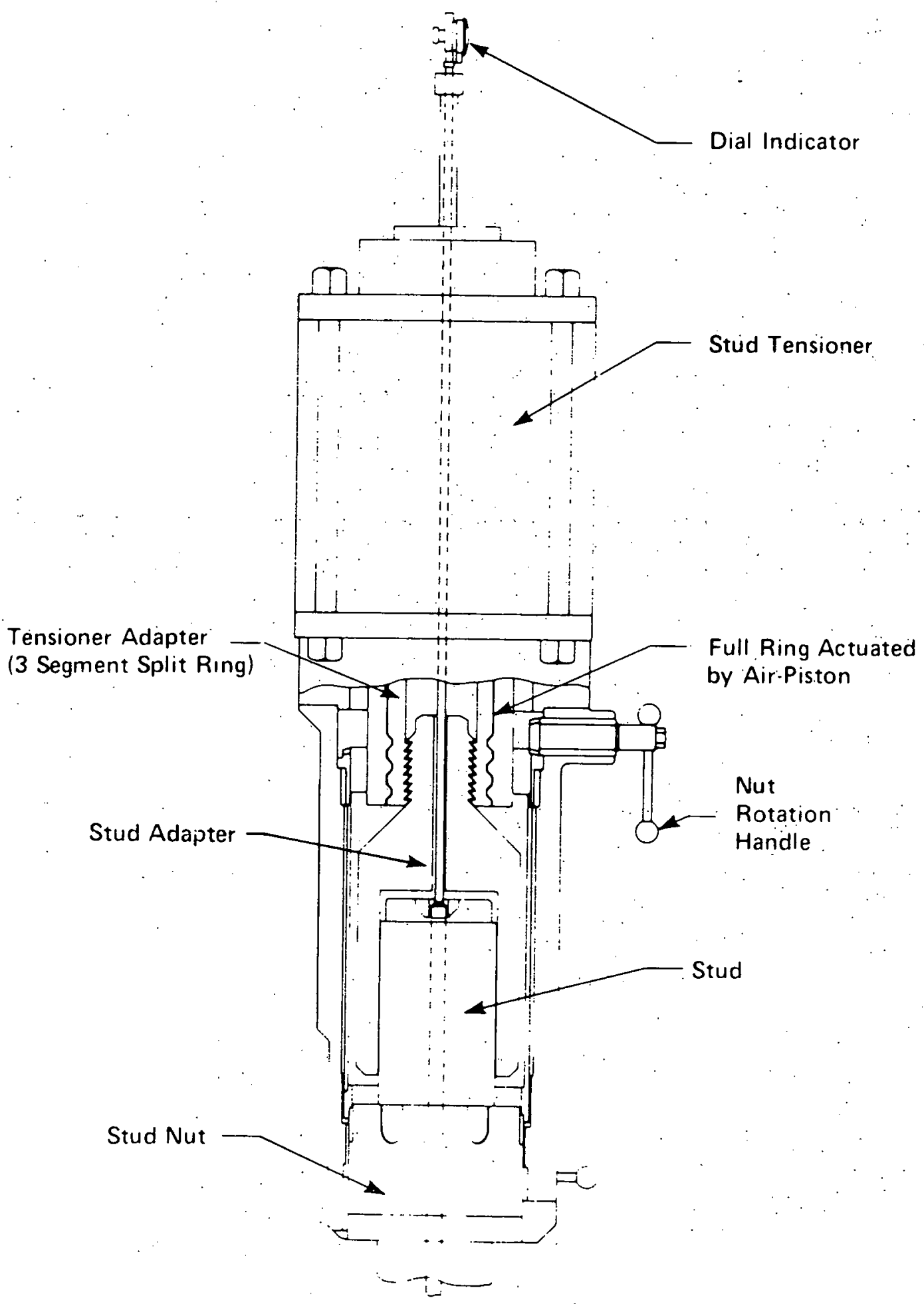

Figure 5.2 Quick-Disconnect Stud Tensioner 


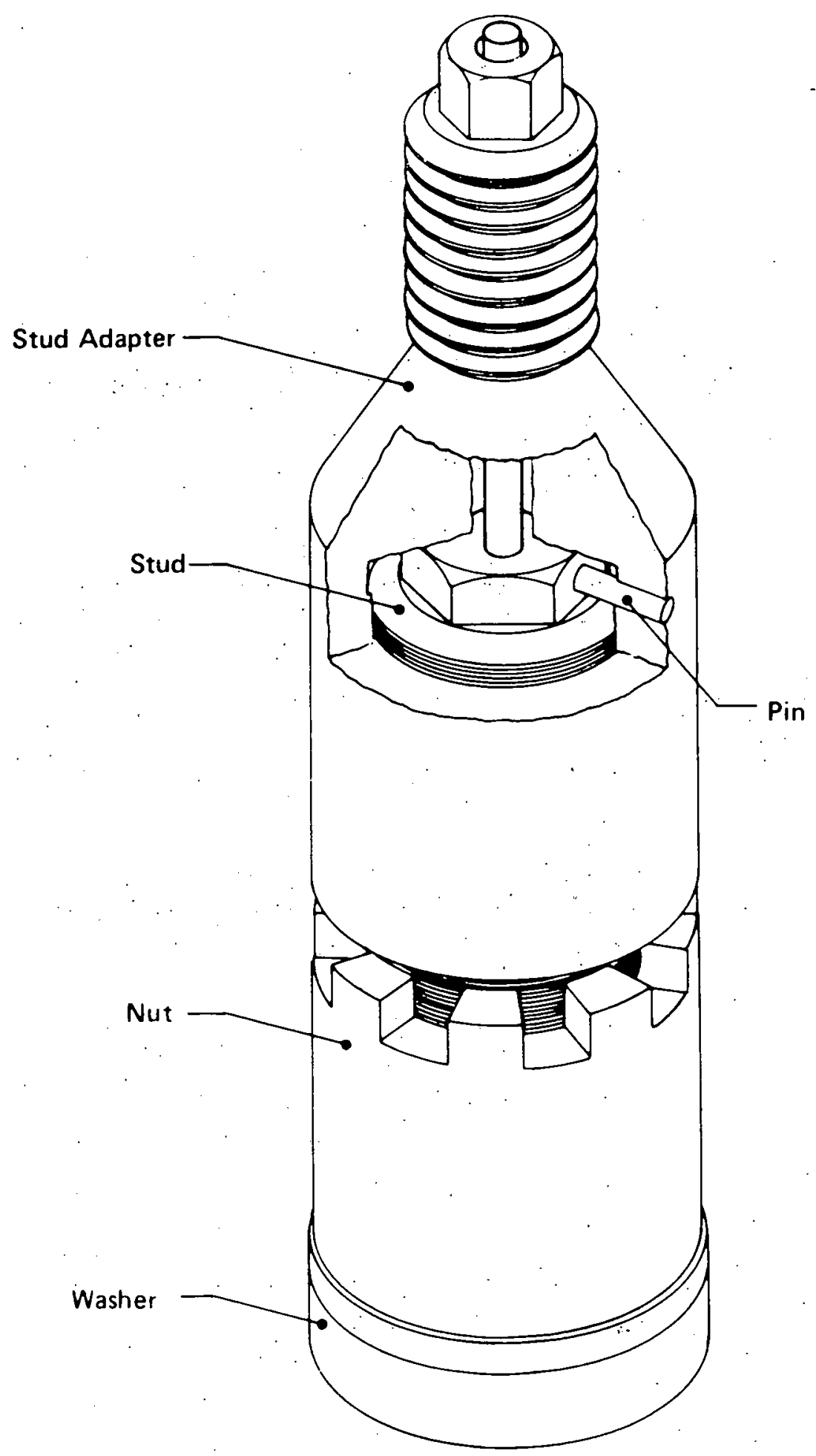

Figure 5.3 Head Stud Adapter (For Quick-Disconnect Tensioner) 


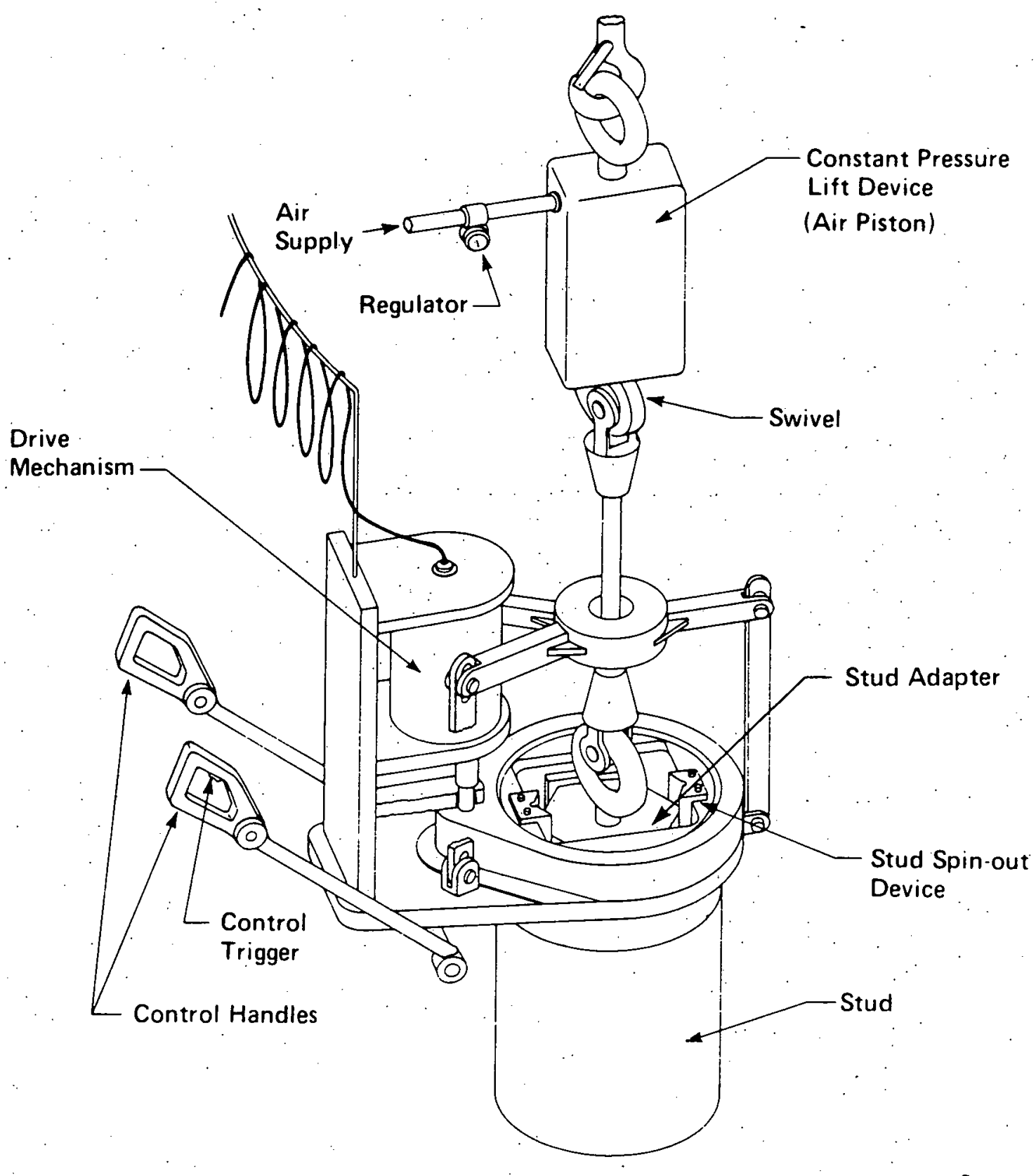

Figure 5:4 Fast Stud Spin-Out Tool 


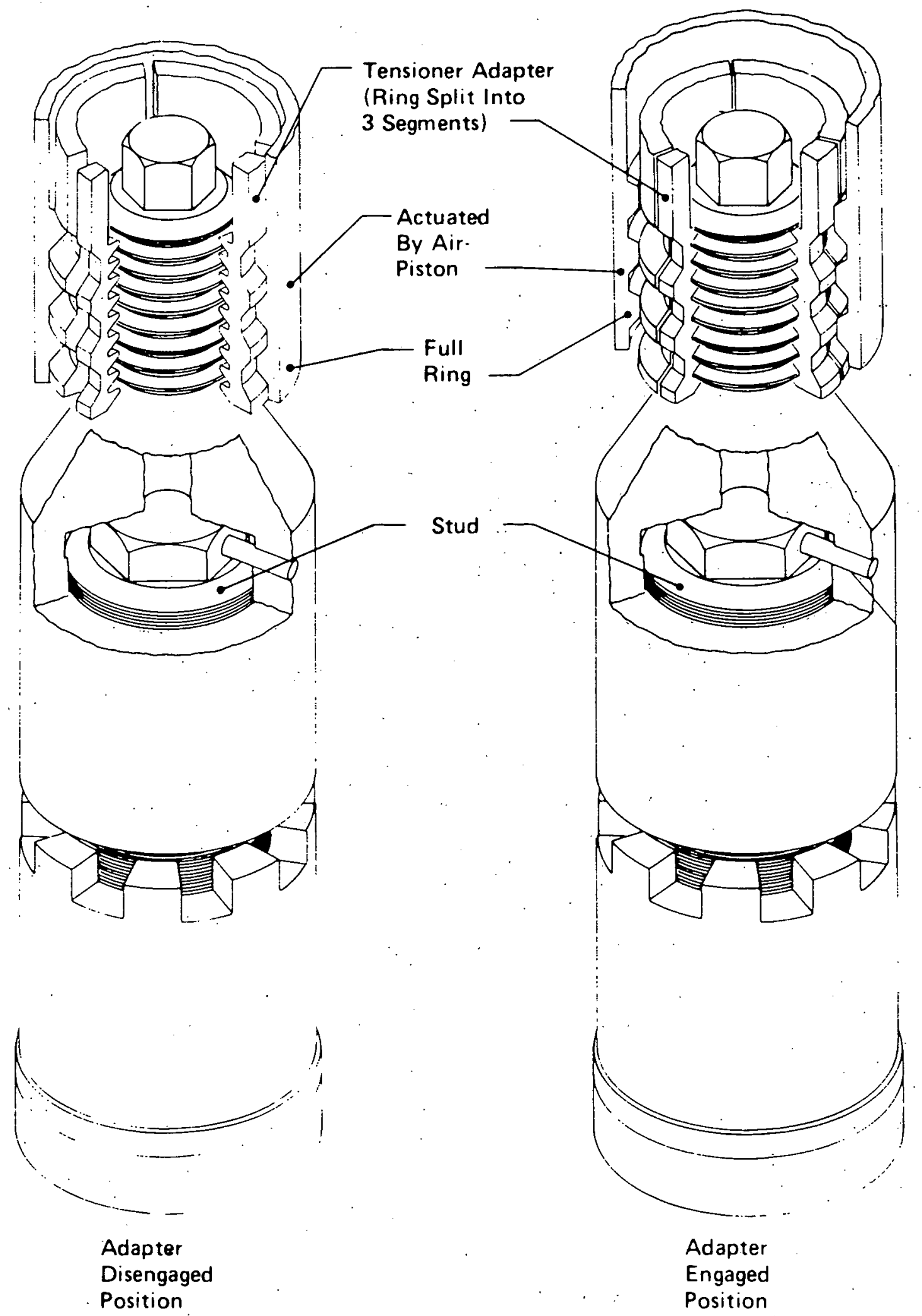

Figure 5.5 Quick-Disconnect Tensioner Gripping Operation 
crane eliminates the additional transport of the fuel assemblies from the reactor vessel and the manual exchange operations. Figure 5.6 illustrates this equipment. A conservative estimate of the resultant savings in refueling time for a 4-loop plant is approximately 42 hours which should result in a significant reduction of radiation exposure of personnel.

The SIGMA concept is based on a gripper assembly that is capable of handling thimble plugs and RCC's in addition to the fuel assemblies. The movable gripper mast is contained inside a single stationary mast extending below the trolley of the manipulator crane. The gripper mast is extended downward to latch a fuel assembly in the core and draw it upward into the stationary mast for transport to another location in the core or to the fuel transfer system. Thimble plugs and RCCA's are handled by a retractable gripper mechanism which permits withdrawal of these assemblies from the fuel assembly into the movable mast. Guide plates are intermittently spaced inside the movable mast to ensure alignment of individual RCCA rodlets as the assembly is drawn into the mast. The actuators for both the fuel assembly gripper and the combination thimble plug and RCCA gripper are operated by an air cylinder located on the top of the mast.

The SIGMA concept has considerable flexibility in the sequence of operations of moving fuel assemblies, thimble plugs and RCCA's. By careful planning of the sequence, the operations can be combined to produce a refueling of optimum efficiency. Two typical movements that are possible are described in the following example:

- When a fuel assembly, with a thimble plug inside of it, is to be sent to the spent fuel pit, the mast is lowered and the thimble plug is withdrawn into it. The mast is then used to latch the fuel assembly, lifts it from the reactor and place it in the fuel transfer system. On its return trip the manipulator crane can be used to deposit the thimble plug in a new fuel assembly, in a fuel assembly already in the reactor, or in a temporary storage fixture on the cavity floor.

- When a fuel assembly, with a RCCA inside of it, is to be moved to a position where no RCCA is required, the fuel assembly is latched and moved to its new position. After the assembly is lowered into position the RCCA is latched and raised into the mast and transported to another location.

The primary and secondary sources and the burnable poison rods will still be handled with a manual tool. The modification of these components to be compatible with the gripper design is also under consideration.

Another concept for achieving further efficiency of refueling operations would be the incorporation of an RCC Inspection Station where a RCCA could be lowered out of the manipulator crane mast and unlatched for inspection by a TV camera or a periscope. The station would permit the RCCA to be rotated while it is viewed. For plants such as Zion that have a wall mounted RCC change fixture, inspection of RCC's would still be done in the conventional manner. 


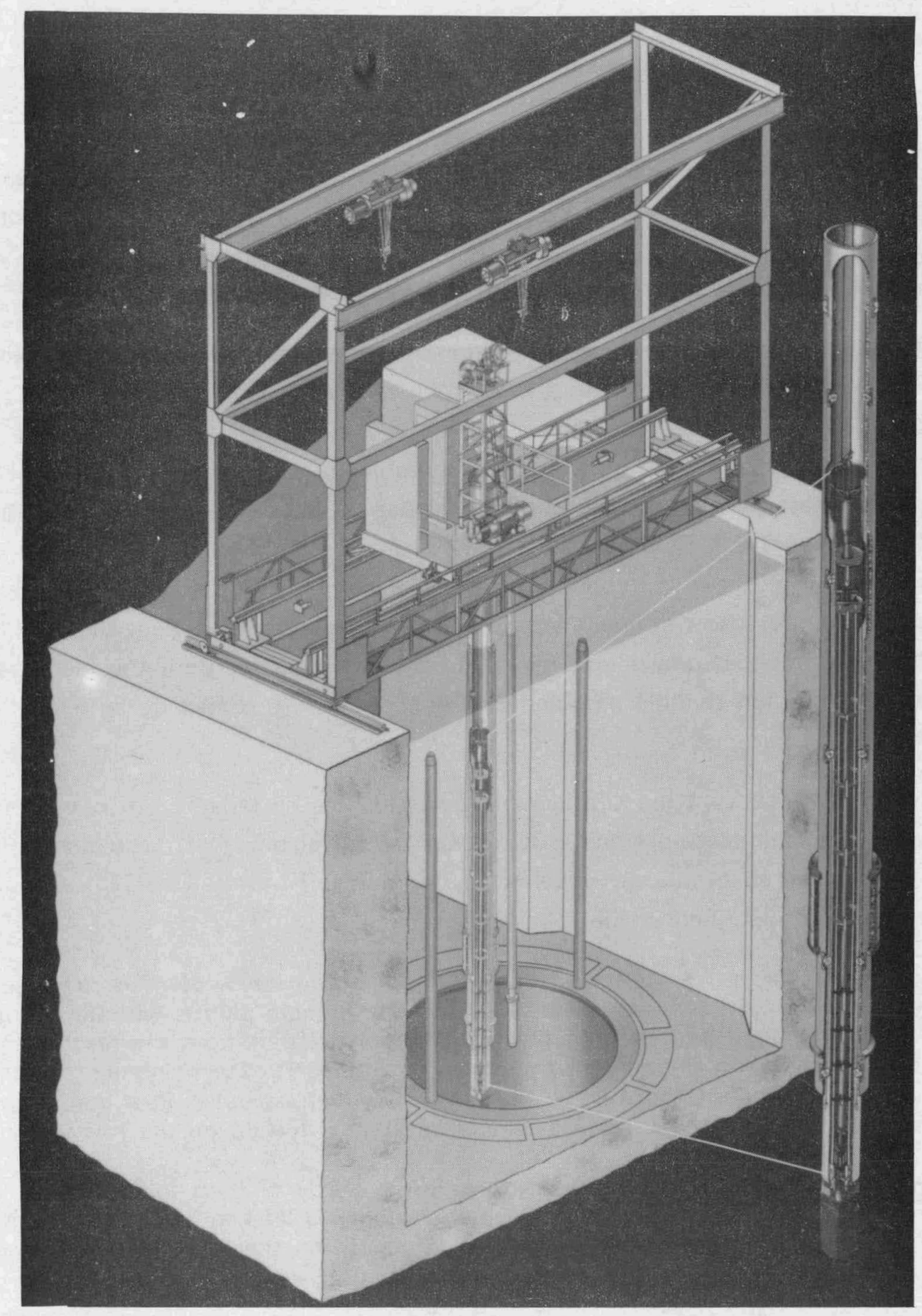

Figure 5.6 Sigma Mast Manipulator Crane 


\subsection{IMPROVED LIGHTING SYSTEM}

The efficiency and safety of fuel movement could be improved by modifications in the lighting system to enhance operator visibility. Lights mounted on the manipulator crane and on the cavity wall should be carefully selected and positioned to give optimum visibility of the underwater work areas. The portable light should be a 500 watt tungsten quartz, iodine incandescent lamp element. The fixed lights should consist of two similar 1000 watt lamps. They should be mounted on a steel bar and suspended to the proper depth. Each individual lamp should be capable of vertical and horizontal adjustment. Improved lighting would also be beneficial during core mapping and inspections of core and reactor components.

\subsection{PORTABLE UNDERWATER TV SYSTEM}

An improved portable underwater TV camera package has been developed to perform a num: ber of functions including:

- Core mapping of fuel and component positions

- Inspection of RCCAs

- Inspection of fuel assemblies

- Fuel latching (at the transfer system upender)

- General underwater viewing

The availability of an underwater TV camera that can be easily transported and positioned is especially beneficial under conditions of marginal refueling water clarity. If difficulties occur during fuel handling operations, the system is vital for determining the cause of the problem. The underwater TV system being used at Zion proved beneficial in both these areas.

The camera package incorporates a fixture which resembles a fuel nozzle to facilitate gripping and transport by the manipulator crane. The camera can be traversed and lowered to any point accessible to the manipulator crane gripper and can provide horizontal or vertical viewing with a $5 \times$ zoom magnification.

The camera package can also be attached to a pole-like fixture near the RCC change fixture where it can be used to monitor latching operations and to inspect RCCAs. The camera can also be mounted on a fixture in the spent fuel pit to perform detailed inspection of fuel assemblies. The fixture fits on top of the spent fuel racks and guides both the camera and the fuel assemblies.

A portable console houses the TV monitor, videotape and audio recorder: 


\subsection{IMPROVED REFUELING MACHINE CONTROL SYSTEM}

Westinghouse has developed a control system for automatically moving the bridge and trolley that permits manipulator crane (refueling machine) to be more quickly moved from one position to another. The refueling time could be shortened by permitting more rapid bridge and trolley traverse speeds and the delays in manual changing from bridge to trolley or trolley to bridge controls, and jogging to the final position. A conservative estimate of the potential savings in refueling work time is 26 hours. Significant reductions in labor and personnel radiation exposure are therefore expected.

The bridge and trolley control system is basically an $X-Y$ position control system much like that used on automated machines tools. The operating console will have push buttons for the $X-Y$ coordinates of the core positions, the RCC change fixture and the fuel transfer upender. Movement from one position to another will be automatically accomplished by depressing :... push buttons for the coordinates required. Movement will not start until a spring-loaded stop/ start switch is actuated. Release of the switch will stop movement. The bridge and trolley movements are one at a time with automatic fast and slow speed zones. The bridge speed is adjustable to a maximum of 60 feet per minute. The console will include position indicators and lights that display position information from. encoders, on the bridge and trolley tracks. Manual control of the raising and lowering of the gripper mast is retained since the small time savings are not sufficient to justify the greater complexity. However automatic slow zones are provided at critical elevations while working over the reactor core.

\subsection{REACTOR CAVITY FILTRATION SYSTEM}

Poor refueling water clarity is a continuing difficulty that hampers the refueling operations. The Zion Station has incorporated a filtration system for cleaning the water in the reactor cavity that has functioned satisfactorily to clean the water to provide adequate visibility. Westinghouse has developed a similar system with somewhat greater operational flexibility.

The Westinghouse reactor cavity filtration system shown in Figure 5.7 includes a $250 \mathrm{gpm}$ stainless steel pump with seals resistant to boric acid, a $7.5 \mathrm{hp}$ electric motor, four filters, suction strainer, a suction box and filter for skimming the water surface and associated valves and piping. The unit may be mounted on a skid for ease of movement in and out of containment. Permanent installation within the containment is also possible as done at Zion Unit 2.

The piping and valves are arranged so that the filters can be operated in several parallel and series combinations. Continuous system operation is possible during the changing of a filter element. Filter size selection will be based on the size of particles to be removed. 


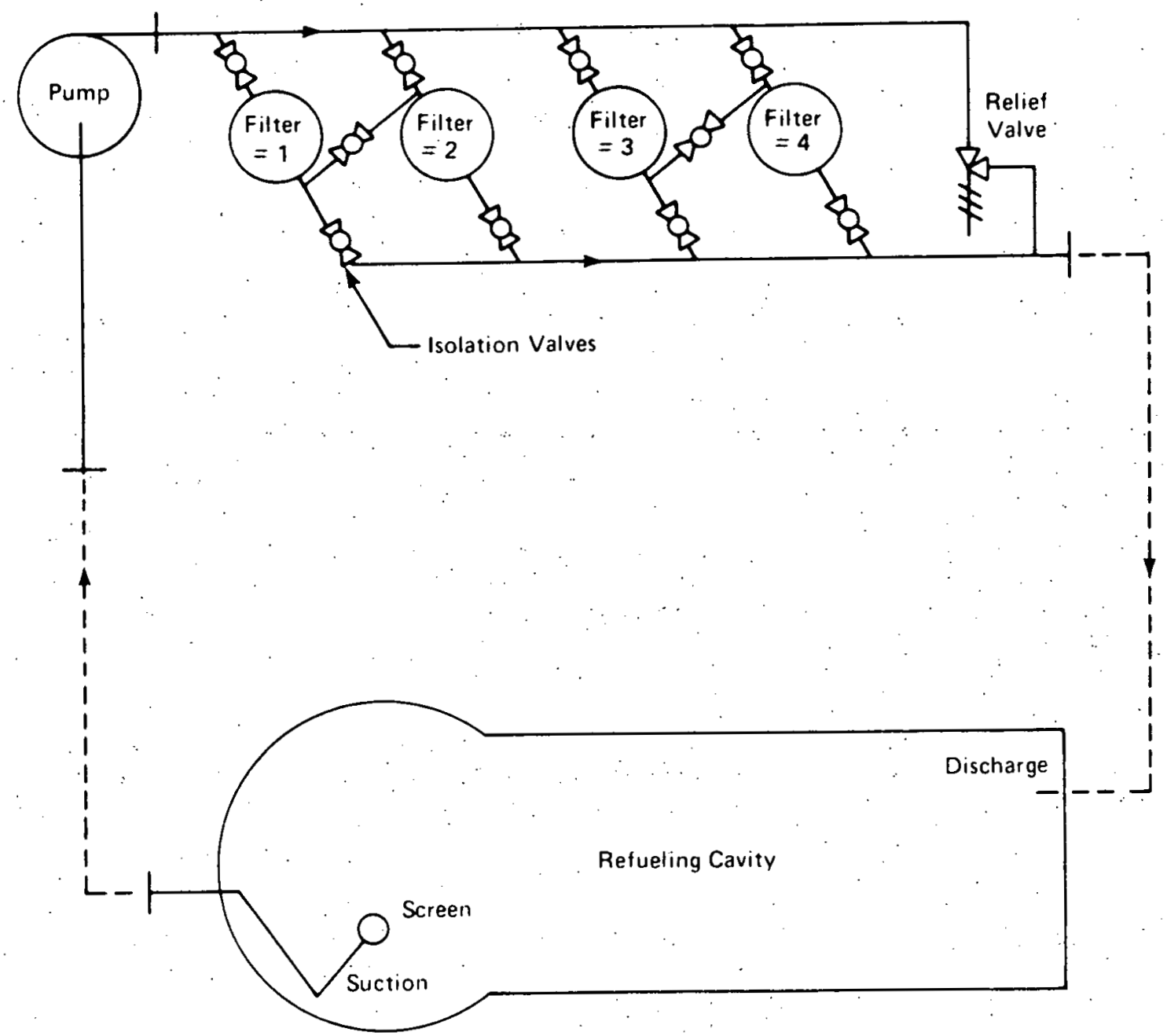

Figure 5.7 Westinghouse Reactor Cavity Filtration System 
The advantages of the system are improved visibility during refueling and reduced contamination of the refueling water. This later benefit should result in reduced personnel exposure and reduced contamination of the refueling cavity.

\subsection{REFUELING CAVITY CLEANING EQUIPMENT}

Cavity cleaning after refueling can be a costly operation in terms of time and radiation exposure. The amount of contamination that is deposited in the cavity that must be removed can be reduced by implementing several modifications: providing a No. 4 or better surface finish on the cavity liner plate, grinding the welds on the cavity walls and floor, eliminating, where possible, any protrusions and other crud traps, and incorporation of an effective filtration system including a water surface skimming feature.

A number of improvements can be made in cleaning equipment and procedures. During the 1977 refueling outage of Zion Unit 2 a high pressure water jet cleaning system was used in place of the intensive manual scrubbing previously used. This very effective system with the trade name of "Hydro-Laser" uses a multi-cylinder, positive displacement pump to produce a 6000 psi, $25 \mathrm{gpm}$ spray of demineralized water for surface cleaning. No chemical cleaning agent was required with the water spray. Proper, training of operators is important to avoid injury to personnel and damage to equipment by the high force of the jet, but the system performance was very satisfactory. Protrusions from the wall of the Zion cavity were troublesome, but were cleaned effectively. Spray cleaning of the walis requires that the R.V. head assembly be protected from splashing. This was done by the use of a prepared polyethylene wrapper completely covering the head.

Special attention should be given to the "bath tub" ring that forms on the walls at the water surface. This deposit of concentrated contamination could be removed with the high pressure water spray, but the expected result would be to spread the contamination down the walls and increase the difficulty of cleaning at lower leveis. During the Zion Unit 2 outage, the bathtub ring was effectively cleaned by manual scrubbing using a cleaning agent with the trade name of "Radiac-Wash" immediately after refueling and before the start of spray cleaning.

The Hydro-Laser or similar high pressure water systems should not be used to clean the cavity floor to avoid damage to sealing covers such as the R.V. nozzle covers and the excore detector access plates. Also, spraying the floor would tend to splash contamination onto the already cleaned walls. The floor should, therefore, be cleaned with manual or powered brushes and a suitable cleaning agent such as "Radiac-Wash."

The design of a work platform with the capability to move quickly both vertically and horizontally along the walls will maximize the potential for rapid cleaning with the high pressure water spray. The platform could be designed either for use with the polar crane (as done at 
Zion), or for use with an auxiliary cavity crane. It. should be designed to resist or balance the thrust from the high pressure water jet.

\subsection{REACTOR VESSEL O-RING GROOVE CLEANING EQUIPMENT}

Westinghouse designed PWR's utilize metal O-Rings to provide an effective seal between the reactor vessel and the closure head. Since the O-Rings function by plastic compression, they must be replaced each time the head is removed. At refueling, any dirt or foreign material present in the O-Ring groove must be removed before a new seal is installed.

The ring removal and groove cleaning operations that are performed while the reactor vessel head is on its storage pedestal on the operating floor has been troublesome at the Zion Station. Improvements of this process would not directly shorten the outage length except where time saved would free maintenance personnel to perform other work. Radiation exposure of personnel would be reduced if the close contact required by the present manual cleaning was minimized. Therefore, we recommend an O-Ring groove cleaning system be designed combining powered brushes, water rinse and vacuum collection.

\subsection{PORTABLE RCC CHANGE TOOL}

Changing RCC's between fuel assemblies must presently be done using the RCC change fixture located within the containment. If the improved manipulator crane gripper assembly described previously is incorporated, it can be used to directly perform the transfer. However, additional flexibility can be achieved by providing a portable RCC change tool (Figure 5.8 ) in the spent fuel building. RCCA's can be changed between fuel assemblies in the spent fuel building in parallel with activities in the containment. This will be particularly beneficial when the entire core must be removed as when in-service inspection of the reactor vessel is required. By reducing the number of operations that must be performed with the refueling equipment inside the containment, the length of the overall outage could be reduced.

The RCC change tool is designed to operate suspended from the spent fuel pit bridge. It consists of guide tube, a support tube, a gripper assembly and a drive mechanism. The bottom of the tool is equipped with locating pins to orient the tool with respect to the fuel assembly nozzle. Five plates in the lower end of the guide tube provide guidance for the gripper and the RCC. Four additional plates, in the upper portion of the tube, guide the gripper as an RCC is lifted from a fuel assembly. The support tube gives the same overall tool length as the spent fuel handling tool, supports the gripper actuator, and protects the lift cable. The actuator consists of a pneumatic system that engages and disengages the latch mechanism to the RCC spider. The gripper mechanism is similar to the present RCC change fixture. The tool drive mechanism consists of an electric-powered winch equipped with a variable speed. control. Two control switches are used, one for selecting up and down travel and a momentary contact 


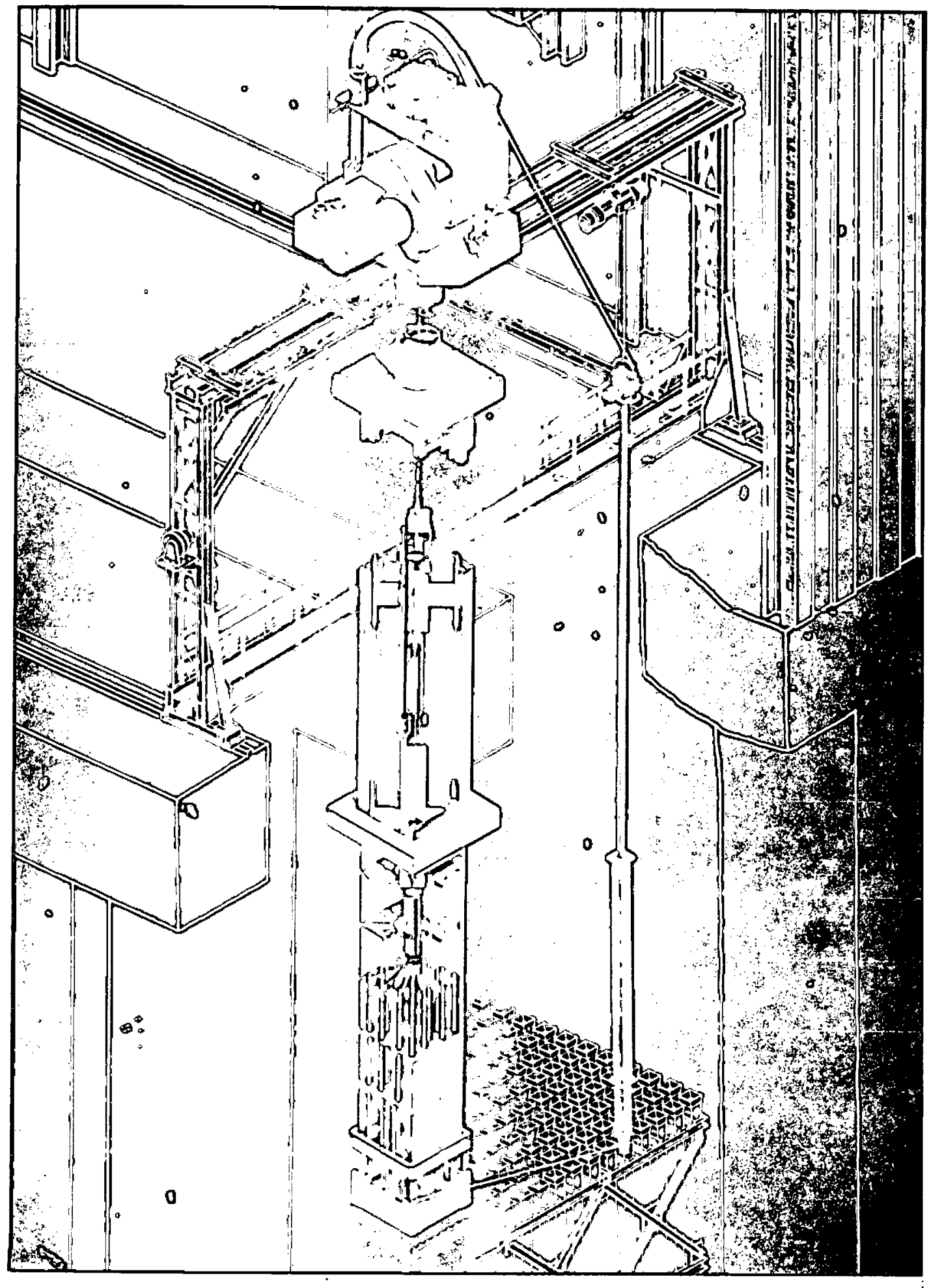

Figure 5.8 Portable RCC Change Tool 
push button to operate the motor. Two limit switches provide a stop for upward travel and an overload protection in the event of cable or RCC hang-up.

\subsection{REACTOR VESSEL STUD CLEANING}

During each refueling outage, the reactor vessel closure studs must be cleaned and lubricated prior to re-use. These operations are not on the critical path determining the length of the outage, but the cleaning is a time consuming process involving maintenance personnel who could be available for other work. Also, a temporary shelter is usually built to prevent the spread of dust and dirt from the cleaning which may be slightly radioactive.

More efficient cleaning could be provided by a portable ultrasonic cleaning system in which studs are immersed one or more at a time in an ultrasonic cleaning tank. Sonic energy would be used to excite a suitable cleaning solution causing the stud to be scrubbed clean. The solution would be continuously circulated and filtered to prevent redeposition of residue. Radioactive contamination will be concentrated in the filters and containment cleanliness would be maximized.

The unit could be used for cleaning of other components and will be designed to permit removal to the spent fuel building for use in general purpose cleaning and decontamination during normal plant operation.

\subsection{IMPROVED BURNABLE POISON ROD ASSEMBLY HANDLING TOOL}

An improved burnable poison rod (BPRA) handling tool has been developed using only mechanical actuations in place of the pneumatic cylinders used presently. This tool is used to transfer plate mounted burnable poison rods between fuel assemblies. The tool is used in the spent fuel building, suspended from the hoist on the spent fuel pit bridge and operated from the bridge walkway.

The tool includes a gripper assembly used to grasp the top of a BPRA and draw it up inside the tool. Guidance is provided for the poison rods within the tool during withdrawal and in. sertion. A manually-operated winch mounted on top of the tool is used to move the BPRA up and down within the tool during transfer from one fuel assembly to another. The value of this tool is increased reliability with expected reduction of delay time during the burnable poison transfer. operations.

\subsection{CONTAINMENT ACCESS HANDLING EQUIPMENT}

The transfer of bulky and heavy equipment into and out of the containment during refueling outages is a common problem at reactor plants. The following are examples of equipment 
that are usually moved through the personnel hatch bv manual handlina or bv the use of a removable beam gantry.

- Heavily shielded, contaminated filters

- RCP motor components and other components requiring modifications or repair

- Welding equipment and gas cylinders

- Structural and scaffolding sections.

- Work stands and fixtures

- Pipe, fictings and valves

- Large electrical and electronic equipment

- Reactor vessel stud tensioner and other heavy maintenance tools

Delays in the movement of such equipment undoubtedly has an impact on the efficiency of refueling activities. It is expected a thorough study of commercially-available, material-handling equipment such as roller conveyors, monorails, telescopic booms, etc. would identify techniques and.equipment that could be installed or provided to improve the movements of items through the personnel hatch. In addition to increasing the speed of the operations, savings would be realized in the manual efforts required, thus freeing personnel for other work. The potential for damage to the equipment would be reduced. Such a study is recommended. The steel shield on the containment side of the personnel hatch should be modified to permit im. proved access.

\subsection{CAVITY ACCESS EQUIPMENT}

During refueling, access to the reactor cavity floor is required for a multitude of tasks such as stud removal and installation, thermocouple port conoseal work, removal of reactor vessel flange insulation, nozzle cover and seal ring installation, etc. The Zion Station has used a caged ladder for personnel access. Small tools and equipment are lowered by rope. Climbing the ladder is cumbersome and dangerous for personnel double suited in plastic and carrying tools. When part of the protective railing at the cavity is removed to permit the lowering of toois and equipment, there is a hazard of personnel slipping or losing their balance. It is proposed that a light-weight, removable, self-contained power lift be designed to improve the ease and safety of cavity access.

The suggested cavity access lift would be a caged platform operating inside a light weight structural tower temporarily positioned in the cavity and supported by the cavity floor. The platform would be cable driven by a power winch, mounted at the top of the tower. 
Preliminary design parameters for the lift are: $1 / 2$ ton capacity and a speed of 100 feet per minute. The overall length of the tower would be sufficient to permit an individual to: walk on to the lift platform. Provisions would be included to permit easy removal of the assembly during fuel shuffling and prior to reactor startup.

There would be a number of expected benefits to this system in addition to improved safety. Although the speed of access is about the same, personnel fatigue would be reduced as well as the damage hazard to sensitive equipment and instruments carried into the cavity. There is also the possibility that the spread of contamination can be reduced by the use of disposable coverings on the lift platform.

With proper planning the lift could be designed as a general purpose service system capable of improving access of personnel and equipment for a number of other maintenance tasks that require temporary scaffolding and hoists such as:

- Reactor coolant pump and motor maintenance

- Steam generator inspections

- Reactor vessel head inspections and other work when the head is positioned on its storage pedestal

The lift would be available for such use when it must be removed from the cavity to permit use of the manipulator crane for fuel movement. Such general purpose capabilities would be made possible by the use of a sectionalized construction of the tower assembly.

\subsection{CRDM ELECTRICAL TEST EQUIPMENT}

Testing CRDM power and rod position indicators (RPI) coils is on the refueling critical path and is very time consuming due to the present method of making individual connections and adjustments to test instrumentation. An appreciable reduction of the time required could be achieved by the use of a test system that would include matched receptacles permitting the mating of power and instrumentation cables from each CRDM with the test meter.

A switching circuit would permit rapid selection of individual connector pins for testing. This would save time as individual pins are now connected one at a time. The test data could be read out with a conventional multirange meter. This test equipment would permit a much more rapid completion of the technical specification requirements and would also reduce the possibility of errors in the selection of leads to be tested. 


\section{SECTION 6 ANALYSIS OF POTENTIAL BENEFITS}

The most significant benefit that could be realized by the implementation of the recommendations of this report is the reduction of the number of days required for the refueling operations. Assuming that corresponding improvements are made in the balance of plant maintenance activities this can be translated directly into the shortening of the length of the outage which will have economic benefits to the utility and its customer. Industry wide realization of similar savings will achieve significant saving in terms of oil and gas consumption.

\subsection{UTILIZATION OF TIME}

The time required to perform the actual work activities required to accomplish a task was defined in Section 4 as the work time. The recommendations in this report are directed toward reducing the work time of certain tasks as much as possible. The elapsed time is the total time from when a task is begun until it is completed. A comparison of work time to elapsed time is a performance parameter indicating how efficiently time was utilized. Estimates of the savings in work time that could result from modifications in procedures or equipment can be translated into the real savings in outage time only by including a consideration of this measurement of performance efficiency.

A Time Utilization Factor can be established for work activities defined as:

$$
\tau_{u}=\frac{T_{w}}{T_{e}}=\frac{\text { Total productive work time }}{\text { Total elapsed time }}
$$

Since refueling work (and other maintenance activities) is usually not scheduled on a 24 hour basis, the time utilization factor will usually be less than 1.0 because of the work scheduling: This effect can be considered by defining a scheduled time factor as:

$$
T_{S}=\frac{T_{S}}{T_{e}}=\frac{\text { Scheduled work time }}{\text { Total elapsed time }}
$$


For the Zion refuelings two ten-hour shifts were scheduled per day with 1/2-hour lunch periods and $1 / 4$-hour breaks each half shift. The scheduled work time was therefore 18 hours per day.

$$
\tau_{S}=\frac{2[10-0.5-2(.25)]}{24}=\frac{18}{24}=0.75
$$

$\tau_{\mathrm{s}}$ can be greater for individual tasks that can be completed during one shift. For a task that. requires exactly one 10-hour shift:

$$
\tau_{\mathrm{s}}=\frac{10-0.5-2(.25)}{10}=\frac{9}{10}=0.9
$$

For tasks that require less than 3 hours and are not interrupted by lunch or other breaks, $\tau_{\mathrm{s}}$ is equal to 1.0 and $\tau_{u}$ is determined by productivity.

The time utilization factor can be expressed in terms of productivity and the schedule time factor:

$$
\tau_{\mathrm{u}}=\mathrm{p} \tau_{\mathrm{s}}
$$

where " $p$ " is a measure of the productivity of the work. The productivity is determined by a number of factors. A simplified expression can be defined as:

$$
p=p_{1} \times p_{2} \times p_{3} \times p_{4}
$$

$\mathrm{p}_{1}$, planning (a measure of the effectiveness with which the coordination and allocation of resources was accomplished)

$\mathrm{p}_{2}$. preparations (a measure of the adequacy of training procedures, tooling, spare parts)

$p_{3}$, performance (the level of the workers skills and motivation. Also included is the effectiveness of communications)

$p_{4}$, problems (this is largely a function of the other three factors.) This does include the effect of equipment problems.

Since there is a strong interrelationship between these components of productivity it is difficult to quantify them separately. Therefore productivity is considered a lumped parameter for the analysis of data observed during the Zion refueling. The individual factors should be considered when attempting to improve productivity. 


\subsection{TIME UTILIZATION FACTOR DURING ZION REFUELING}

Table 6. 1 lists the major work items required to accomplish the refueling at Zion. This list is a condensation of the 90 items observed for Unit 1 as previously described in this report.

Related work tasks are combined into major work activities. Work times, elapsed times, manpower required, and radiation field data are listed for each item for the Unit 1 outage and for those observed during the Unit 2 outage. Where data is available for both outages, the average of the two is used. In a few cases where data is inferred from another observation, work time and elapsed times are shown in parentheses but are excluded from calculation of utilization factors.

Using the work time and elapsed time data, the time utilization factor, $\tau_{u}$, was computed for each work task and included in the table. $\tau_{u}$ was found to be random and ranged from 0.04 to 1.0. The high values were possible only for short work tasks in which the schedule time factor does not affect the overall time utilization. When the work time, $T_{W^{\prime}}$ is greater than $20 \mathrm{hrs} \tau_{\mathrm{u}}$ is limited to 0.75 by the shift schedules as discussed previously. For work items of less than 10 hours $\tau_{u}$ can approach 0.90 and even greater for very short tasks. One exception is item 15, installation of cavity crane, where additional overtime may have been authorized resulting in $\tau_{u}=0.81$. Items such as 29 and 30 that required short work times demonstrate extremes of variability between the two outages.

The values of $\tau_{u}$ for the two outages were averaged to obtain indications of the overall utilization of time. Identical average time utilization factors were obtained. $\bar{\imath}_{\mathrm{u}_{1}}=0.5370$, $\left.\bar{\tau}_{u_{2}}=0.5377\right)$. This is probably coincidental but does support the use of these factors as a meaningful evaluation of work performance.

Using a time utilization factor of 0.54 , an approximate value of productivity can be inferred:

$$
\begin{aligned}
& \bar{\tau}_{\mathrm{u}}=p \tau_{\mathrm{S}} \\
& \mathrm{p}=\frac{\bar{\tau}_{\mathrm{u}}}{\tau_{\mathrm{S}}}=\frac{0.54}{0.75}=0.72
\end{aligned}
$$




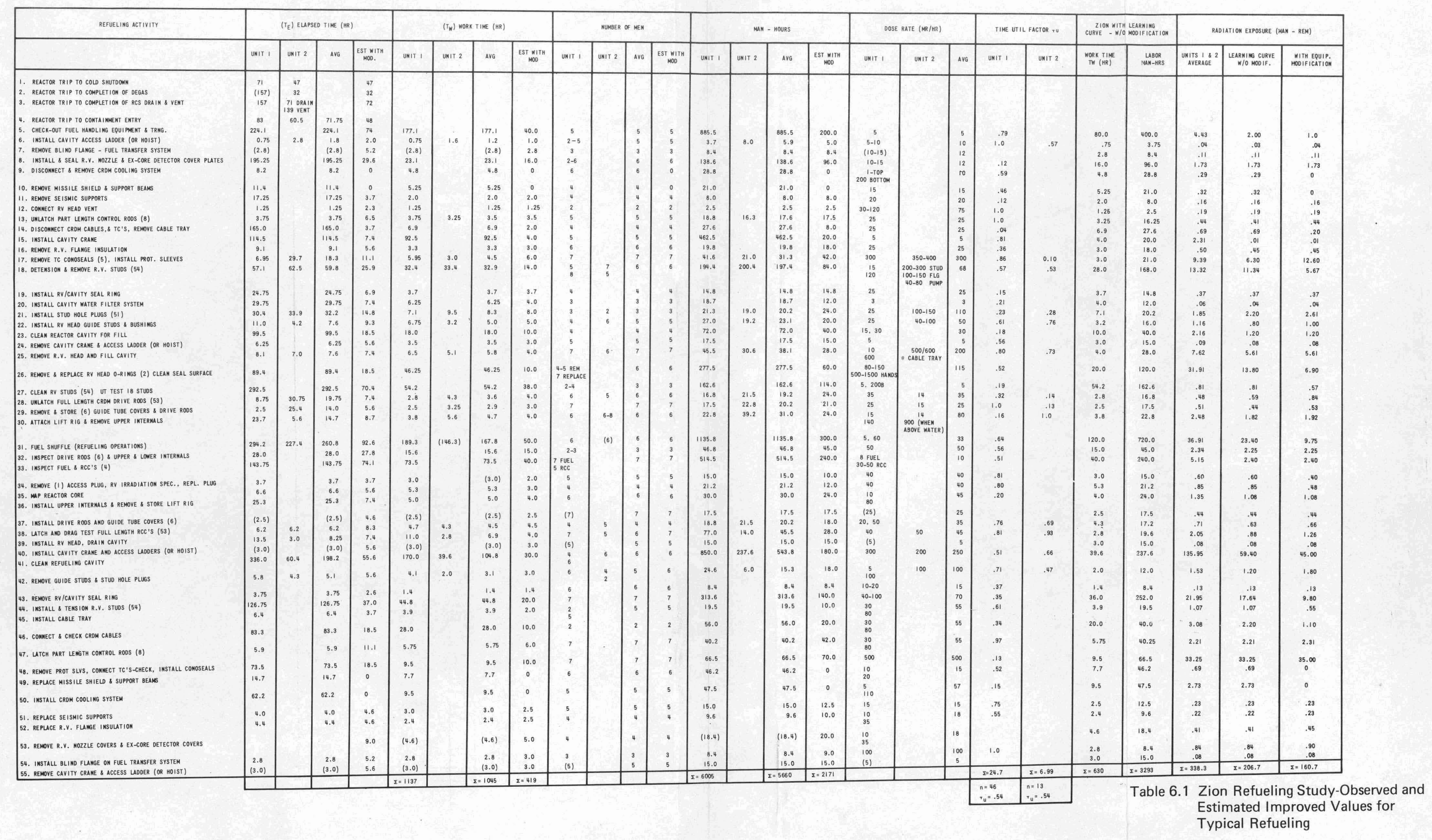




\subsection{ESTIMATED REFUELING CRITICAL PATH TIME WITH RECOMMENDED EQUIPMENT MODIFICATIONS}

An estimate of the time that should be required to perform a typical refueling at the Zion station, with the equipment improvements recommended in this report, was made using the work times observed and the foregoing analysis of the time utilization factor. The estimates of work times and elapsed times for individual tasks are shown on Table 6.1. The following assumptions were made in establishing these estimates:

- Zero time is shown for those work items that would be eliminated by implementation of the proposed equipment modifications.

- Reduced work times are estimated for the equipment modifications that will simplify the work tasks.

- For those items not affected by the equipment changes the estimated work times shown are based on:

a. Westinghouse standard values for the same task.

b. Zion average values where no Westinghouse value is available.

c. Zion average values reduced slightly where learning curve improvement is expected:

- 'The work time for each item is then transformed into a predicted elapsed time by using the average time utilization factor determined from the two refueling outages.

$$
T_{E}=\frac{T_{W}}{\tau_{u}}=\frac{T_{W}}{0.54}
$$

A bar chart of the expected elapsed times was then constructed as shown in Figure 6.1. Parallel performance of work is indicated where this was done during the first two outages. Several additional judgements that were made to establish the critical path for the refueling portion of the outage are described below:

- Time required to achieve initial entry to the containment is estimated to be 48 hours based on the experience of the Unit 2 outage. This time includes containment purge and health physics testing.

- Drain down of the reactor coolant system to the level of the vessel flange will be completed within 13 hours after containment entry. The detensioning of the reactor vessel studs can then be started.

- It is expected that the reactor vessel nozzle cover plates and the ex-core detector covers will be.placed in position prior to the start of the stud detensioning. It is also assumed that the stud hole plugs are installed in parallel with the stud removal. (Use of the auxiliary cavity crane and proposed cavity access hoist will be invaluable during these early procedures.) 


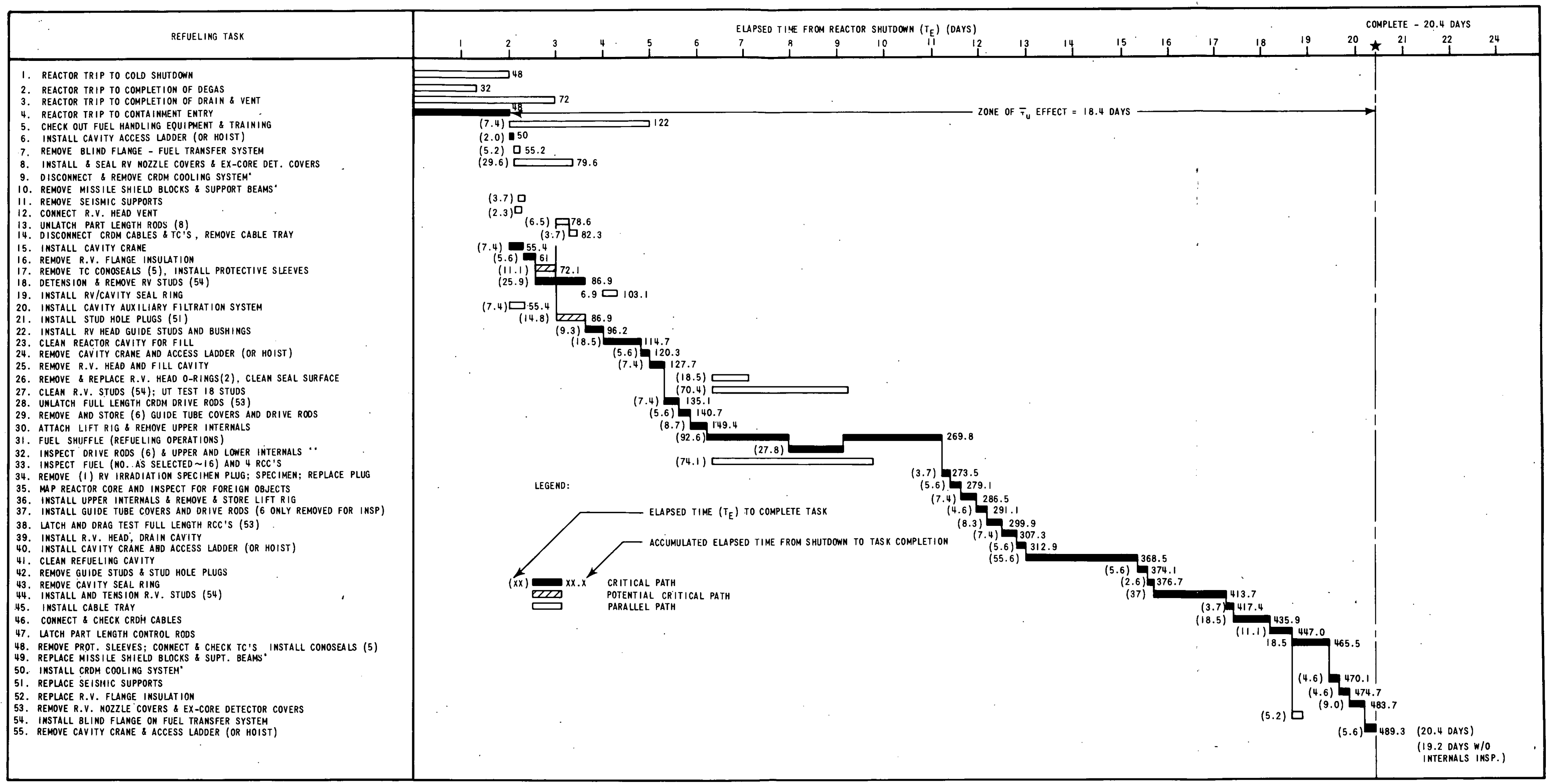

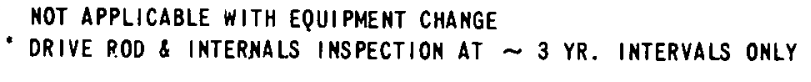

Figure 6.1. Work Path for Typical Refueling with Equipment Modification $\left(\tau_{u}=.54\right)$ 


\section{WESTINGHOUSE PROPRIETARY CLASS 2}

- The refueling operation will include the short in-service inspection of reactor internals and six drive rods that is normally performed at 3 year intervals.

- The remainder of the work path is mainly a series performance. of the individual work tasks required.

By summing the estimated elapsed times for individual work times on the refueling critical path, the total time required for the refueling portion of the outage would be 20.4 days. If the inservice inspections are not required the time would be 19.2 days.

The total refueling time for the 1976 outage of Unit 1 was 52 days. The expected improve. ment if the proposed equipment modifications are implemented is

$$
\Delta T_{E}=T_{E_{\text {Unit }}}-T_{E_{\text {Improved }}}=52-20.4=31.6 \text { days }
$$

A number of improvements were made-for the 1977 refueling of Unit 2. The time required to achieve initial entry to the containment was reduced 1 day and the fuel shuffle time was reduced approximately 3 days but modifications made to the pressurizer spray valve resulted in the total refueling time being extended to 59 days.

In making the estimate of the total refueling time that can be expected with equipment modifications, the individual work times were divided by the overall average time utilization $\bar{\tau}_{u}=$ 0.54 rather than individual factors. The validity of this can be substantiated by similarly calculating a total elapsed time from the actual work time observed in the Unit 1 and 2 outages.

Using the summation of average work times on critical path work items of $628.5^{*} \mathrm{hrs}$. and the time to entry to the containment of 3.0 days:

$$
T_{E \text { Avg }}=\frac{628.5 \mathrm{hrs}}{(.54) 24 \mathrm{hrs} / \mathrm{day}}+3.0 \text { days }-51.5 \text { days }
$$

This calculated number agrees more closely with the Unit 1 actual elapsed time for refueling, since the average data reflects the more extensive work time data that was taken during that outage. This excellent agreement verifies that use of the overall average time utilization factor can provide an accurate prediction of the refueling time.

\footnotetext{
- Work items $6,9,10,15,16,18,22,23,24,25,28,29,30,31,32,34$ through 53 , and 55 on Table $6-1$. These constitute the refueling critical work path.
} 


\section{WESTINGHOUSE PROPRIETARY CLASS 2}

Further reduction in outage time could be made by improving the scheduled work time factor, $\tau_{s}$, and the productivity, $p$. The ideal case of round the clock shifts without breaks and perfect productivity would provide a $\tau_{u}$ of 1.0 . The length of the outage based on these ideal conditions can then be calculated as a goal. It should be noted that the 2 days estimated for the time required before containment entry is not affected by shift schedules or productivity.

$$
\begin{aligned}
& T_{E}(\text { ldeal })=2+\frac{0.54}{1.0}(19.2-2)=11.3 \text { days } \\
& \text { (w/o In-Service Inspection) } \\
& T_{E} \text { (Ideal) }=2+\frac{0.54}{1.0}(20.4-2)=11.9 \text { days } \\
& \text { (with In-Service Inspection) }
\end{aligned}
$$

The full benefits of the refueling equipment modifications will be realized only if the rest of the work activities required in the plant can be performed within the reduced time period for refueling. The appendix of this report reviews the maintenance work performed on the turbines and generators during the two refueling outages. The reasons for the significant improvements in the Unit. 2 turbine outage are discussed. This evaluation concludes that the turbine generator work in a typical outage could be completed within three weeks if certain additional improvements are made. This time is consistent with the expected length of the refueling operation. Even if the refueling time becomes shorter than the length of the outage because the turbine/generator or other maintenance work require a longer period of time the other significant benefits of reduced manpower and radiation exposure as discussed in the following sections warrant implementation of the modifications suggested in this report.

\subsection{PROJECTED ZION REFUELING CRITICAL PATH TIME WITHOUT PROPOSED EQUIPMENT MODIFICATIONS}

It can be expected that as additional experience is gained, the refueling work times at Zion will be reduced to some degree even if the equipment modifications are not made. This effect can be estimated applying a learning curve adjustment on the observed data. The column at the right hand side of Table 6-1 provides the task work times estimated after the learning effect is applied. These estimates are based on analyses that have been made for a "standard" Westinghouse plant. In a few cases, the work times during the Zion refuelings are already less than the Westinghouse estimates, and these lower observed times are used without any further reductions. The summation of these times can then be used as in the preceding section to predict refueling time if the equipment modifications are not implemented. 


\section{WESTINGHOUSE PROPRIETARY CLASS 2}

The predicted improvement due to the equipment modifications and the learning curve effect is summarized in Table 6.2. The summation of critical work path average work times from the Unit 1 and 2 refuelings is 628.5 hours. ${ }^{*}$ The estimated total time for these same activities without any equipment modifications but with the maximum benefit of additional experience is 382.9 hours. It can reasonably be assumed that this improvement would be realized after 5 refuelings and that each refueling would show a linear decrease in time required due to the learning curve effect. Since the same improvement effect in work performance will also occur if the refueling modifications are made; the learning curve correction was also applied to obtain an estimate for each of the first five refuelings. The estimated time for refueling with the modified equipment was 238.4 hours, after the personnel were fully experienced. The time for the first refueling shown in Table 6.2 was obtained by using the same ratio from the first to the fifth refueling:

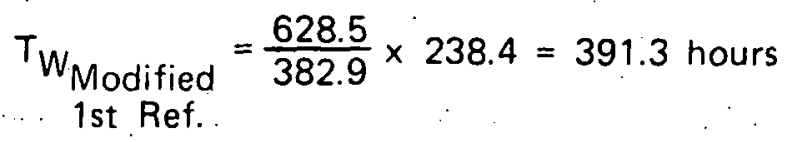

Again a linear reduction of time required was assumed to obtain the times for the $2 \mathrm{nd}, 3 \mathrm{rd}$, and 4 th refuelings.

The difference between these two columns of numbers gives the savings in work time and is used to estimate the more important savings in the time for the refueling critical path. It should be noted that the refueling considered in this table included the short time periods for partial inspections of internals and drive rods. The effect of improving the utilization of time is also shown by also computing the estimates for $\bar{\tau}_{u}=0.75$ and the ideal of $\bar{\tau}_{u}=1.0$.

The benefits of the recommended equipment modifications are greatest early in the plant life but the days savings in the refueling critical path are quite substantial even after worker experience has been maximized. The percentage savings in work time is approximately constant at 36 percent. The reduction of refueling critical path days will still be realized when there are major perturbations in the refueling schedule such as the in-service inspection of the reactor vessel which interrupts performance of the refueling critical path work.

The significant potential benefit of improving the time utilization is clearly demonstrated in the table. An increase of $\bar{\tau}_{u}$ from $0: 54$ to 0.75 that is considered possible would provide at the 5th refueling an additional savings of 5 days with the modified equipment and 8 days with the existing equipment. The benefits would be even greater as the learning process is occuring during the first 4 refuelings.

"Work tems $6,9,10,15,16,18,22,23,24,25,28,29,30,31,32,34$ through 53 , and 55 
TABLE 6.2

REFUELING TIME BENEFITS WITH PROPOSED EQUIPMENT CHANGES

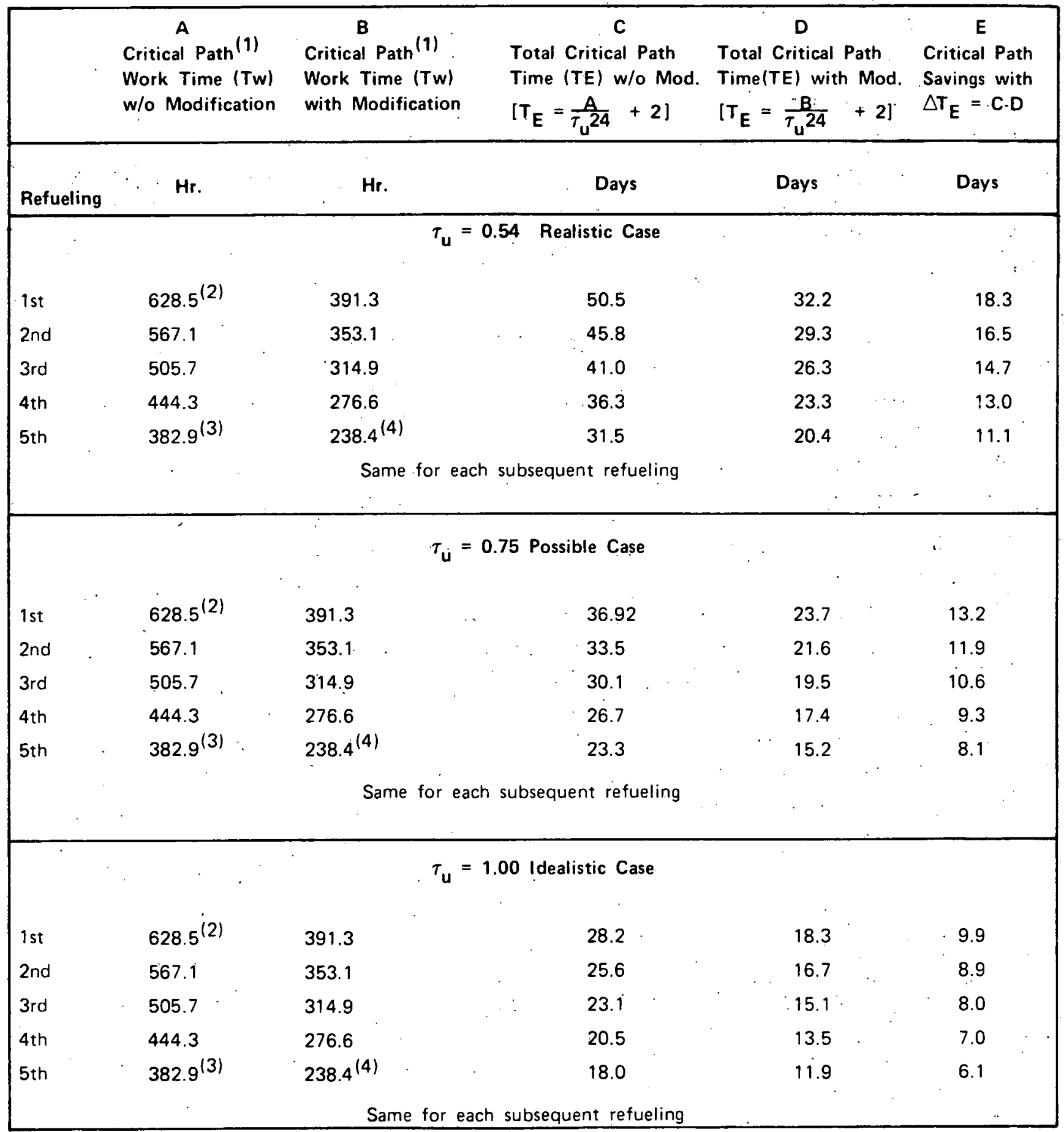

1. Critical Path Time Based on $\Sigma \dot{\mathrm{T}}_{w}$ for those tasks identified on C.P. by Figure 4.1. and table values Table 4.1: (Item Nos. $6,9,10,15,16,18,22,23,24,25,28,29,30,31,32,34$, through 53 and 551 .

2. Summation of average Tw values of Zion Unit 1 and 2 observations on critical path as above.

3. Summation of Learning Curve Tw values without modifications on critical path as above.

4. Summation of Learning Curve Tw values with modifications on critical path as above. 


\section{WESTINGHOUSE PROPRIETARY CLASS 2}

\subsection{ESTIMATED IMPROVEMENT IN LABOR EXPENDITURES}

The reduction of labor required for refueling can be estimated by multiplying the work times $\left(T_{W}\right)$ in Table 6.1 by the number of men engaged in each task. Since this study is intended to compare the total man-hours of effort required, the data is not subject to a consideration of which tasks are performed in parallel. The $T_{W}$ given for each task during Unit 1 and 2 is the observed data of the actual time spent doing productive work and is not affected by the time utilization factor. The work times given do not include support labor such as health physics and plant operations personnel whose efforts would also be reduced by a shortened refueling outage.

The total observed labor for the average of Units 1 and 2 was 5660 man-hours while the estimate for the first refueling with the proposed equipment modifications is 3731 man-hours. Applying a linear learning curve correction to these numbers gives the comparison shown in Table 6.3. As shown, it is assumed that the improvements due to the learning process would be realized by the fifth refueling.

\subsection{ESTIMATED REDUCTION IN RADIATION EXPOSURE}

The expected reduction in radiation exposure was computed using the same learning curve corrections. The exposure was estimated by multiplying the man-hour of work effort by the radiation fields measured in the area where the work was performed. The same radiation fields were assumed to exist during refueling with the modified equipment. These exposure estimates are inflated in that the personnel would not spend the entire work time in the indicated radiation field. A more accurate estimate would require careful recording of dosimeter or film badge measurements. Since comparisons are made between estimates based on the same approach, the percentage of the reductions should be valid. The comparisons are shown in Table 6.4. The computed reduction percentage is 22 percent for each year. The total reduction from the first year to the fifth year just due to increased personnel experience is 39 percent even if there were no equipment modifications. The predicted combined total improvement from the first year due to the combined effect of experience and the refueling equipment modifications is 52 percent. No further experience improvement is expected beyond the 5th year. 
TABLE 6.3

ESTIMATE OF. LABOR SAVINGS WITH PROPOSED EQUIPMENT MODIFICATIONS

\begin{tabular}{|c|c|c|c|}
\hline Refueling & $\begin{array}{l}\text { Labor } \\
\text { W/O Modifications } \\
\text { Man-hrs }\end{array}$ & $\begin{array}{l}\text { Labor } \\
\text { With Modification } \\
\text { Man-hrs }\end{array}$ & $\begin{array}{c}\text { Labor Savings } \\
\text { Man-hrs }\end{array}$ \\
\hline 1st & 5660 & 3731 & 1929 \\
2nd & 5068 & 3341 & 1727 \\
3rd & 4476 & 2951 & 1525 \\
4th & 3884 & 2561 & 1323 \\
5th & 3293 & 2171 & 1122 \\
\hline
\end{tabular}

Subsequent refuelings would have. the benefits"as the 5 th refueling. 


\section{WESTINGHOUSE PROPRIETARY CLASS 2}

\subsection{ESTIMATED IMPROVEMENTS WITH INDIVIDUAL EQUIPMENT MODIFICATIONS}

The estimates of the savings in outage duration, labor requirements, and radiation exposure described in the preceding discussion were based on all of the recommended equipment modifi. cations proposed. Since a utility might decide to make only a portion of the changes, it is useful to estimate the expected benefits of individual changes. Table 6.5 tabulates the benefits of the individual modifications.

The estimates of improvements are calculated for the case where the learning process has been completed. Other proposed equipment improvements described in this report that do not directly affect the refueling critical work path are not included in the table but are recommended because they will have indirect benefits through the improvement of the time utilization factor $\left(\tau_{\mathrm{u}}\right)$. 
TABLE 6.4

ESTIMATE OF REDUCTION OF RADIATION EXPOSURE

\begin{tabular}{|c|c|c|c|c|}
\hline Refueling & $\begin{array}{l}\text { Exposure } \\
\text { w/o } \\
\text { Modifications } \\
\text { Man-Rem }\end{array}$ & $\begin{array}{l}\text { Exposure } \\
\text { With } \\
\text { Modifications } \\
\text { Man-Rem }\end{array}$ & $\begin{array}{l}\text { Exposure } \\
\text { Reduction } \\
\text { Man-Rem }\end{array}$ & $\begin{array}{l}\text { Percent } \\
\text { Reduction }\end{array}$ \\
\hline 1st & 338.3 & 263.0 & 75.3 & 22 \\
2nd & 305.4 & 237.4 & 68.0 & 22 \\
3rd & 272.5 & 211.8 & 60.7 & 22 \\
5th & 239.6 & 186.2 & 53.7 & 22 \\
\hline
\end{tabular}

Subsequent refuelings would have the same benefits as the 5 th refueling. 
TABLE 6.5

ALLOCATION OF REFUELING BENEFITS TO EOUIPMENT IMPROVEMENTS

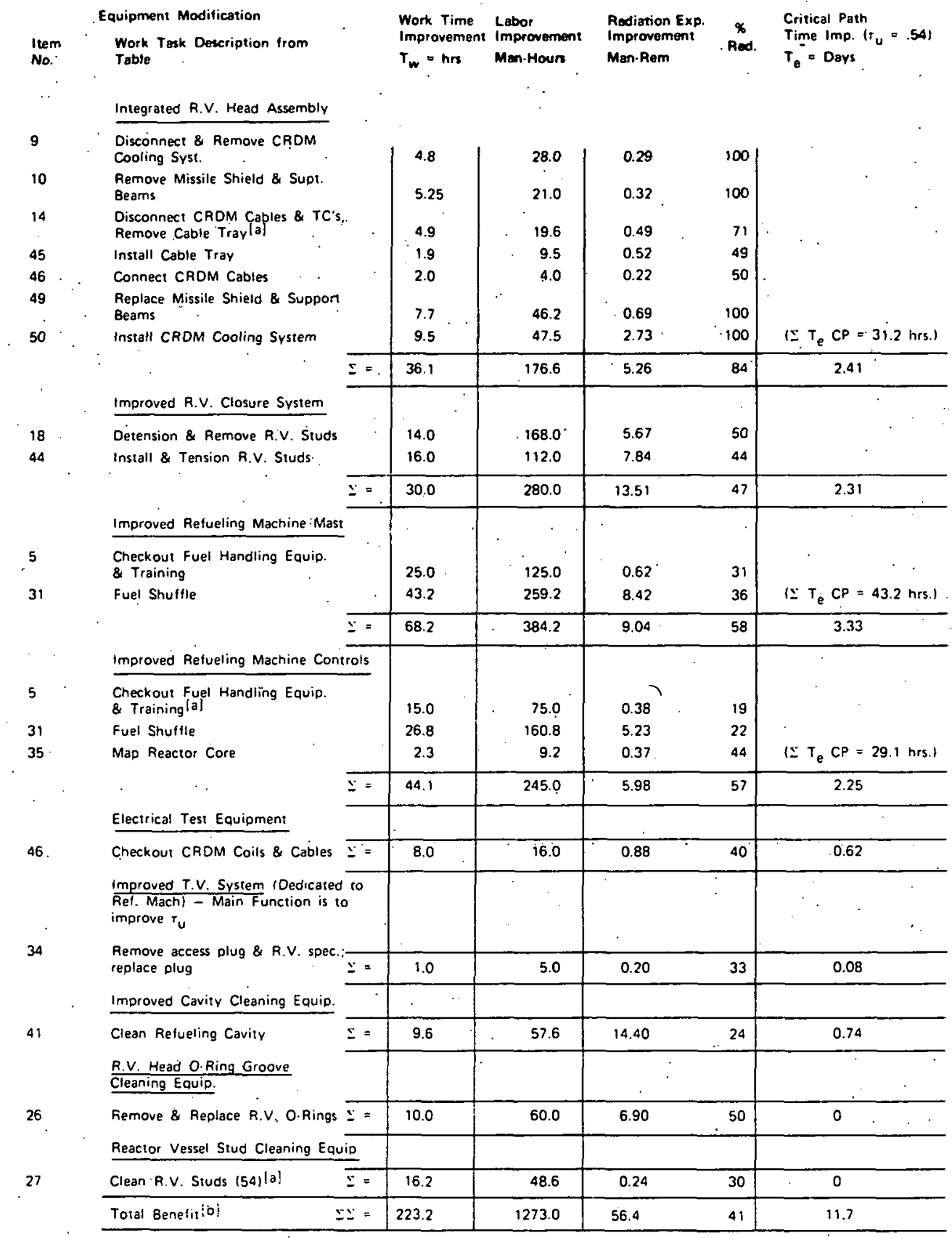

a. These tasks are not on critical path, therefore do not influence $T_{e}$ (C.P.) improvements.

b. These values are the true benefits relative to the learning curve w/o equipment improvements. They differ slightly from the benefits listed in Table 6.2 (Realistic Case, 5th Refueling) since the data in Table 6.2 includes other tasks where observed times were less than standard times and for which no equipment improvements are recommended. 


\section{SECTION 7 \\ CONCLUSIONS AND RECOMMENDATIONS}

\section{$7.1 \quad$ CONCLUSIONS}

The observations made of the Zion Unit 1 (1976) and Unit 2 (1977) refueling outages were effective in identifying or confirming areas where important improvements could be made in order to reduce refueling time. The evaluations made during the program take into consideration that these were the first refuelings and improvement can be expected due to experience gained and problem resolution.

The potential benefits of the recommended refueling equipment modifications are summarized in Table 7.1. These benefits in terms of time savings in outage length, labor man hours, and radiation exposure reduction are appreciable.

The time expended in performing any task can be shortened through elimination or simplification of work steps, improvement of tools and efficient time utilization. Analysis of most refueling equipment modifications proposed in this report shows potential for considerable benefit through the elimination and simplification of work steps. Time utilization primarily depends on planning effectiveness, training, and personnel motivation. A number of suggested equipment modifications do not have a direct impact on the refueling operation duration since they are not on the critical path. However, they should produce a vital indirect benefit upon the time utilization for critical path work activities through release of personnel for other tasks, reduction of radiation exposure of key personnel, and reduction of the total level of activity. While it is not possible to assign a numerical value to such indirect benefits, they are important.

The refueling outage length improvements of the magnitude predicted in this study must have a considerable effect on improvement of plant availability which is then an economic benefit to the utility and its customers through reduced requirements for replacement power. Implementation of similar improvements by other utilities will make an important contribution in our country's efforts to reduce the consumption of natural gas and petroleum fuels. A reduction of one day of outage duration at Zion can save Commonwealth Edison's customers approximately $\$ 250,000$ in replacement fossil fuel costs. The equivalent alternate fuel would be about 14 thousand tons of low-sulfur coal or 44 thousand barrels of residual oil. 
TABLE 7.1

SUMMARY OF BENEFITS OF REFUELING EQUIPMENT IMPROVEMENTS

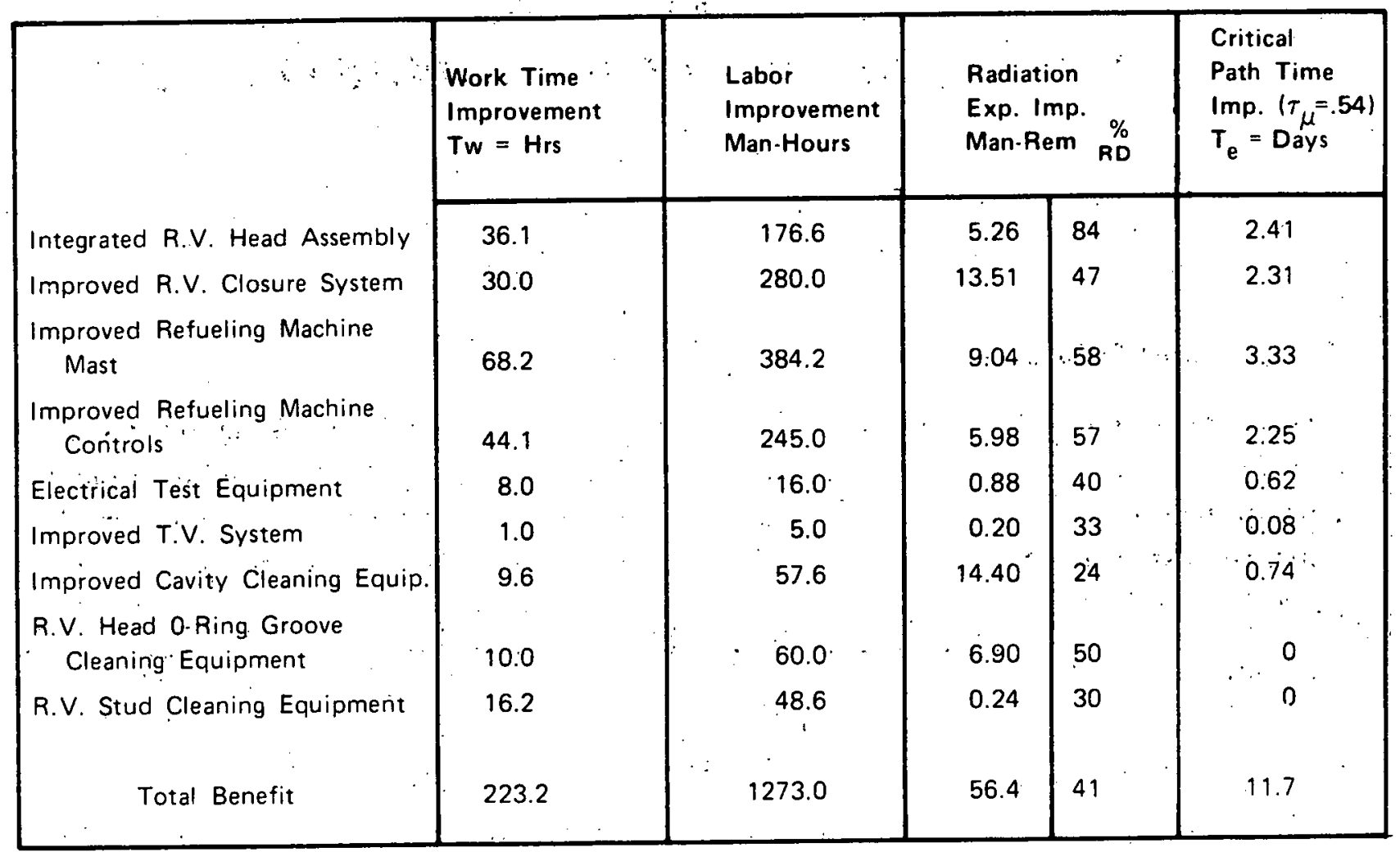




\subsection{RECOMMENDATIONS}

The applicable modifications to refueling related equipment proposed in this report should be considered for implementation at the Zion Station to demonstrate the predicted improvements in refueling time, radiation exposure, and manpower requirements. The initial step for implementation must be the development of the design concepts discussed in Section. 5 to establish:

- The activities required for installation.

- The impact on the refueling outage(s) during which installation is anticipated.

Because of the long lead time for design, fabrication and installation of the proposed equipment modifications, other utilities should also promptly consider implementation in PWR's already in operation or under construction.

A concentrated effort should be made, through additional studies and modifications of planning, procedures, and equipment, to reduce the time required for other maintenance activities performed during the refueling outage. The goal is to complete the outage work within approximately the same time period as required for refueling. The appendix describes the improvements made so far in the planning and management of turbine-generator maintenance. This work can be completed in approximately three weeks, coinciding almost exactly with the predicted refueling time of 20.4 days that would be realized with the recommended modifications with $\tau_{\mu}=.54$. It should be noted that with a refueling outage of three weeks and a two week allowance for forced outages during the year, nuclear plants could achieve an availability of 90 percent.

Time utilization can be improved by applying the following recommendations for increasing the schedule factor $\left(\tau_{\mathbf{s}}\right)$ and productivity $(p)$ :

- Schedule/Factor

Use additional overtime to complete critical path tasks.

Improved work continuity (provide shift overlap and staggered breaks and lunch hours).

Minimize interruptions (e.g. administrative personnel meetings).

- Productivity

Improve work task planning to maximize concurrent work tasks.

Continuously upgrade work procedures and tools. 
Improve preparation for the outage by training personnel in the procedures to be used and verifying that spare parts and required tools are available and have been checked for proper operation.

Ensure required support from other groups such as Quality Control, Health Physics, Engineering and craft labor. These should be available without delay when required.

Improve work task performance by continuing the work to completion without unnecessary interruptions. Begin the next task without delay, and develop an incentive system for good performance.

Prevent problems by disciplined adherence to procedures, improved communication between shifts, and prompt resolution of equipment and tooling problems prior to the next outage. 


\section{APPENDIX A}

TURBINE-GENERATOR MAINTENANCE OUTAGE EXPERIENCE AT ZION 


\section{TABLE OF CONTENTS}

1. Introduction

A.3

2. Description of 1976 Zion Unit 1 Turbine-Generator Outage

3. Description of 1977 Zion Unit 2 Turbine-Generator Outage

A.6

4. Prospect for Further Improvement in Zion Turbine Generator Outages 


\section{INTRODUCTION}

The turbine-generators at Zion are 1800 RPM four cylinder tandem compound units. These units are Westinghouse's second generation nuclear turbine design and have a High Pressure element designated as building block 296 and three Low Pressure elements designated as building block 281 . The generator is a 4-pole hydrogen cooled rotor and water cooled stator unit with a brushless exciter. Unit 1 was placed in service in June, 1973, and Unit 2 was placed in service in December, 1973. The turbine maintenance philosophy currently used by Commonwealth Edison for these units is to perform component inspection during the nuclear refueling outages. Essentially, one or two turbine elements are inspected during each annual refueling outage which results in all the turbine generator components being inspected within a five-year period. This type of maintenance program is compatible with industry. standards and Westinghouse recommendations. Commonwealth Edison has elected to contract the the turbine generator inspections. This enables station maintenance personnel to be used on the more critical nuclear plant maintenance work and provides more flexibility in manpower requirements.

Two turbine generator maintenance outages have been experienced to date; the Unit 1 outage in the spring of 1976 and the Unit 2 outage during winter of 1977... Westinghouse Power Generation Service Division (PGSD) was awarded the contract for both of these maintenance outages which were competitively bid. Considerable modification work was performed during both these outages which essentially doubled the scope of work required. The following is a discussion of each of the above outages including comments on problem areas and areas where further time reduction can be achieved.

\section{DESCRIPTION OF 1976 ZION UNIT 1 TURBINE-GENERATOR OUTAGE}

The following scope of work was included in the original outage plan for the turbine. generator:

1) Disassembly and inspection of the No. 3 low pressure turbine

2) Disassembly and inspection of the generator

3) Disassembly and inspection of the $1 \mathrm{C}$ feedpump turbine drive 
4) Inspection of all turbine valves and actuators

5) Inspection of all turbine bearings

In addition to the above, several major modifications were performed on the turbine generator equipment that was performed on a product warranty basis. These modifications will not be required on future outages. The major modification performed was the addition of bracing to the crossover and crossunder pipe turning vanes. Based on the above scope of work, an outage duration of seven weeks based on a two shift, 8 hours per day, 5 days per week schedule was established. Due to the magnitude of the turning vane modification, it was not intended to complete the entire modification during this outage.

The milestone event which completes a turbine generator outage and is required for startup and heatup of the nuclear plant, is turning gear operation. In the original plan, turning gear operation was scheduled for 4/23/76, seven weeks after the March 5 start date of the outage. Actual turning gear operation was not achieved until 5/17/76, approximately 25 days after the original plan date. The major reason for the outage extension on the turbine generator was due to the Unit 2 turbine bearing failure which occurred on April 1, 1976.

Cooling water to the Unit 2 turbine-generator lube oil system was inadvertently shut off causing the unit to be taken out of service with two wiped bearings. The incident required replacement of the two wiped bearings and inspection of the remaining 11 bearings on the unit. Westinghouse PGSD was asked to perform this work in conjunction with the outage work currently being performed on Unit 1. As there were no spare bearings on site, two of the bearings from Unit 1 were used to replace the bearings that wiped on Unit 2 . In addition to rebabbitting and refitting the two bearings for use on Unit 1, a bearing inspection also revealed several scored journals that required the refitting and rebabbitting of another bearing. In summary, the additional activity required on Unit 1 because of the bearing seriously impacted the schedule. The following additional work was required:

1) Polish No. 3 and No: 4 journals

2) Grind No. 6 journal

3) Fit and install rebabbitted bearings in No. 1, No. 5 and No. 6 locations

4) Perform a lubrication system flush

5) Realignment of all rotors due to the bearing change 
This increased activity was the main factor in delaying the turbine turning gear operation date until 5/17/76. Startup of Unit 1, after turning gear operation was achieved, required an additional 14 days until 5/31/76. A subsequent forced outage of 18 days was attributed to problems in the primary system on reactor coolant pump seals during heatup and the low power physics testing. Chart A-1 shows the effect of the above problem areas on the outage time for Zion 1.

An outage review meeting was held at the completion of the outage to discuss the problem areas and where improvements could be made on future outages. The following items were discussed:

\section{Late Award of Contract}

Commonwealth Edison issued firm price bid specifications for the outage work approximately two months prior to the outage, and the contract award was not made until approximately one week before the outage. This did not give the contractor the necessary time required for preplanning and job setup activities required to optimize the outage work.

2. Disassembly on Straight Time

The scope of work was increased by as-found conditions in several areas. For instance, blading repair work was required in the low pressure turbine. If the unit had been disassembled on overtime basis, more outage time would have been available to make corrections that were not anticipated.

3. Craft Labor Management

The PGS engineers on the second shift were not fully experienced in craft labor management. Again, this problem ties in with Item 1 in that better staffing of the job can be done if the contract is awarded at an earlier date.

4. The Effect of the Unit 2 Bearing Incident

The item was discussed in detail above and was the major cause of the outage extension. Unfortunately, contingency planining to overcome this type of problem is not practical.

5. Increased Scope of Work

Besides the bearing incident and the LP turbine blading work, considerable extra work on turbine auxiliaries was performed by the contractor which was not included in the initial plan. This work involved completion of work requisitions initiated by the station operating department on turbine auxiliaries, pumps and valves. 


\section{Startup Coordination}

As pointed out in the attached bar chart, the primary system heatup was delayed until the turbine was able to go on turning gear. An additional 18-day delay was caused by the problems encountered during the heatup and initial low power physics testing. Bypass valves have now been installed around the main steam isolation valves which will permit the primary system to be heated up isolated and independent of the balance of plant so that turning gear operation is not required. If the delays that resulted in late turning gear operation and heatup problems had been worked on simultaneously, the total outage delay would have only been seven days.

7. Spare Parts

The turning vane modification required considerable gaskets as all the crossover piping was removed to install the modification. It was felt that in future outages, precut gaskets would save the time and expense of making the gaskets at the job site.

8. Quality Assurance

Several crossover pipe flanges were not tightened properly during reassembly and resulted in steam leaks and a two-day outage of the unit. It was agreed that on future outages, a basic quality assurance program including checksheets for the scope of work would help prevent a future occurrence of this type of problem.

\section{DESCRIPTION OF 1977 ZION UNIT 2 TURBINE GENERATOR OUTAGE}

In conjunction with the outage review meeting held for the Zion Unit 1 outage, the Unit 2 outage planning was also discussed. Several improvements in the planning procedure were made. The outage was planned using the new Westinghouse Total Maintenance System (TMS) concept. TMS is a formalized outage planning program that coordinates the planning activity with the customer and all the Westinghouse Power Generation equipment divisions. The planning is done in steps or phases which include the evaluation of the unit, rationalization of customer's outage schedule with the Westinghouse recommended scope of work and a comprehensive prejob preparation program. A TMS planning manual is issued for each unit on the program and covers all aspects of the planning activities. In addition to the TMS planning, the Unit 1 outage review discussion items listed above were an integral part of the job planning to ensure that the same mistakes did not reoccur.

The following scope of work was planned for the Unit 2 turbine generator outage:

1) Disassembly of No. 2 and No. 3 low pressure turbines

2) Disassembly and inspection of the $2 B$ feedpump turbine drive 
3) Installation of Moisture Separator-Reheater vent chamber condensers

4) Inspection of all turbine generator bearings

5) A high velocity lubrication system oil flush

Considerable modification work was also planned which included crossover turning vane modification, moisture separator-reheater tube repairs and bundle bypass prevention. This work was done on a product warranty basis in conjunction with the contract work. The one major unknown that existed in the outage planning was the extent of blading repair work required in the LP turbines. Crawl-through inspections of both No. 2 and No. 3 LP turbine last row blading had been previously performed which indicated some of the blades would require replacement due to debris damage. Whether or not upstream blading was affected would not be known until the unit was disassembled. It was felt the above scope of work, excluding blade repairs, could be accomplished in a six week outage. A two week contingency was added for blading work which resulted in an eight week outage plan:

Based on the initial planned scope of work, the job was scheduled to work two 8-hour shifts, five days per week. However, it was decided that spot overtime would be used during disassembly and during the outage. This concept enabled outage costs to be minimized and to keep the turbine off the critical path resulting in schedule flexibility. Both the scope of work and schedule were finalized early in the preplanning stage, and maintenance contract bid specifications were issued four months prior to the outage. Contract award was made two months prior to the outage to Westinghouse Power Generation Service Division which enabled PGSD to start job site preparation plans in plenty of time for the outage.

After the contract award, the first area addressed was a mutually developed quality assurance program to monitor all work performed on the turbine generator, both contract and product warranty. This quality assurance and control program was administered by Commonwealth Edison and was patterned on the NRC criteria used on the primary side. In staffing the job experienced engineers were assigned to both shifts. A total of seven engineers were used to administer the job; three engineers per shift and one engineer in charge. The engineer in charge was a capable administrator who normally functions as a service assistant in the office. The lead floorman on each shift was an experienced engineer familiar with maintenance contract work on nuclear turbine generators.

The Unit 2 turbine-generator work was never on the critical path of the refueling outage: The outage work began on January 10, 1977, and the turbine-generator was on turning gear March 8, 1977, two working days over the estimated date. Primary system heatup did not being until the week of March 14, and the unit was placed on system March 29, 1977. The turbine work was paced by the critical path refueling activity. Flexibility was available to improve 
the original schedule by use of additional manpower and overtime but was not required as the turbine work remained off the critical path throughout the outage.

Areas where actual work deviated from plan were as follows:

1. Portable Balance Machine

After the blade work was performed, botn. LP. turbine rotors were low speed balanced on the PGSD portable balance machine. This work, which resulted in a two-day delay in reassembly, prevented having to balance at startup on critical path time. Some final touchup balancing was still required at a later date.

2. No.' 1 Bearing Thermocouple

This thermocouple was broken twice; once on dismantling and the second time on assembly. Failure was attributed to the way the thermocouple slot in the bearing was machined causing the wire to shear. This problem caused extra work because it was not noted until the bearing was completely reassembled. A design change has been suggested to prevent this problem from reoccurring.

3. Main Oil Pump

Inspection revealed a crack in the pump impeller, and it required considerable time to correct as a repair procedure and qualification of same was required. The repair was performed by a local service shop under Westinghouse direction.

4. Extraction Steam Isolation

A leaking valve in the high pressure turbine extraction line allowed steam to enter the MSR's. It was necessary to leave the HP cylinder exhaust crossover pipes off the unit until modification work was completed in the MSR's. This did affect the outage schedule as turning gear operation could have occurred five days earlier, if the high pressure cylinder exhausts had not been open.

5. Jackshaft Support Fixture

Only one jackshaft support fixture was provided with the turbine special tools on the original equipment contract. Because both low pressure turbine jackshafts were disassembled, considerable time was required to align and assemble the jackshaft couplings Double moves were required on each jackshaft; once for alignment and again for coupling assembly. With a second support available, alignment and coupling assembly of each jackshaft could have been accomplished as a parallel operation with only one positioning of each jackshaft support. Six shifts or three days work could have been saved with two jackshaft supports. 


\section{Crossover Piping Flange Gaskets}

The crossover piping flanges are designed for asbestos gaskets. Westinghouse procedures require that flange bolting be retorqued when piping is hot. This requires scaffolding and manpower to be available after the unit is placed in service and delays the installation of thermal blankets. The use of flexitallic gaskets would eliminate this problem and provide an easier and faster reassembly of crossover flanges.

\section{PROSPECT FOR FURTHER IMPROVEMENT IN TURBINE GENERATOR OUTAGES}

A substantial improvement was made in the execution of the 1977 turbine-generator maintenance outage over the 1976 outage. This improved performance was the result of better planning as well as administrative and procedural changes. The goal of the turbine-generator maintenance planning is to remain ahead of the refueling critical path. As previously discussed, less time should be required for future turbine generator maintenance outages since the considerable warranty work and modification work performed during this initial outages will not be required. Also, on a five-year maintenance cycle, only one major element will have to be disassembled and inspected per refueling outage. Based on a one element disassembly and some peripheral work on valves or other auxiliary equipment, typical future turbine generator outages could be performed in four weeks on the turbine elements and five weeks on the generator based on a six-day work week using two shifts with the present design and present tooling.

Further reduction in turbine generator outage time could be realized if the following areas were properly evaluated:

\section{Spare Turbine Rotors}

Once disassembled, several days are required to clean the rotating element by aluminum oxide blasting and to perform NDT evaluation. Also, distress is more likely to occur in the rotating element, rather than the stationary blade path. 'A spare rotor would enable reassembly of the turbine element to start the same day the original rotor was removed. A spare rotor could also prevent an outage extension due to unforeseen blading repair work.

\section{Improved Tooling and Fixtures}

This is an area which has not been properly evaluated. As mentioned above, an additional jackshaft alignment fixture could have saved time in the realignment of the low power turbines. One idea which originated during the outage was to redesign the jackshaft support fixture with roller barings. This would allow the 18 ton jackshaft to be rotated for coupling alignment instead of the 100 ton LP rotor. The Westinghouse PGSD 
maintenance contract tool set supplied by the PGSD tool facility to perform the work was evaluated in terms of the Zion unit. A list was made of additional tools which could reduce outage time. A thorough analysis of the tools supplied by Westinghouse Steam Turbine Division on the equipment contract could also result in reducing outage time. Another time-saver would be a customized scaffolding and work platform for the removal and reassembly of crossover piping. This would save the time and expense of purchasing material and erecting a scaffold for each outage.

3. Evaluation of Turbine-Generator Design

This is another area where improvements could shorten outage time. As with the spare rotor concept, any equipment modifications would have to withstand a cost-benefit analysis. Several design changes to improve maintainability have been incorporated on third generation nuclear turbine-generators. Design features such as crossunder steam inlets to the low pressure turbines, one low pressure inner cylinder, and generator blowers on the exciter end should save six to seven days outage time compared to the Zion units. While these designs would be difficult to retrofit, other concepts should be examined. With improvements in tooling, spare rotors and design modifications, it should be - possible to ultimately. reduce outage time to three-weeks on a "turbine-generator element. 
CHART A-1

ZION 1 REFUELING OUTAGE REVIEW 3/5/76 THROUGH 6/19/76

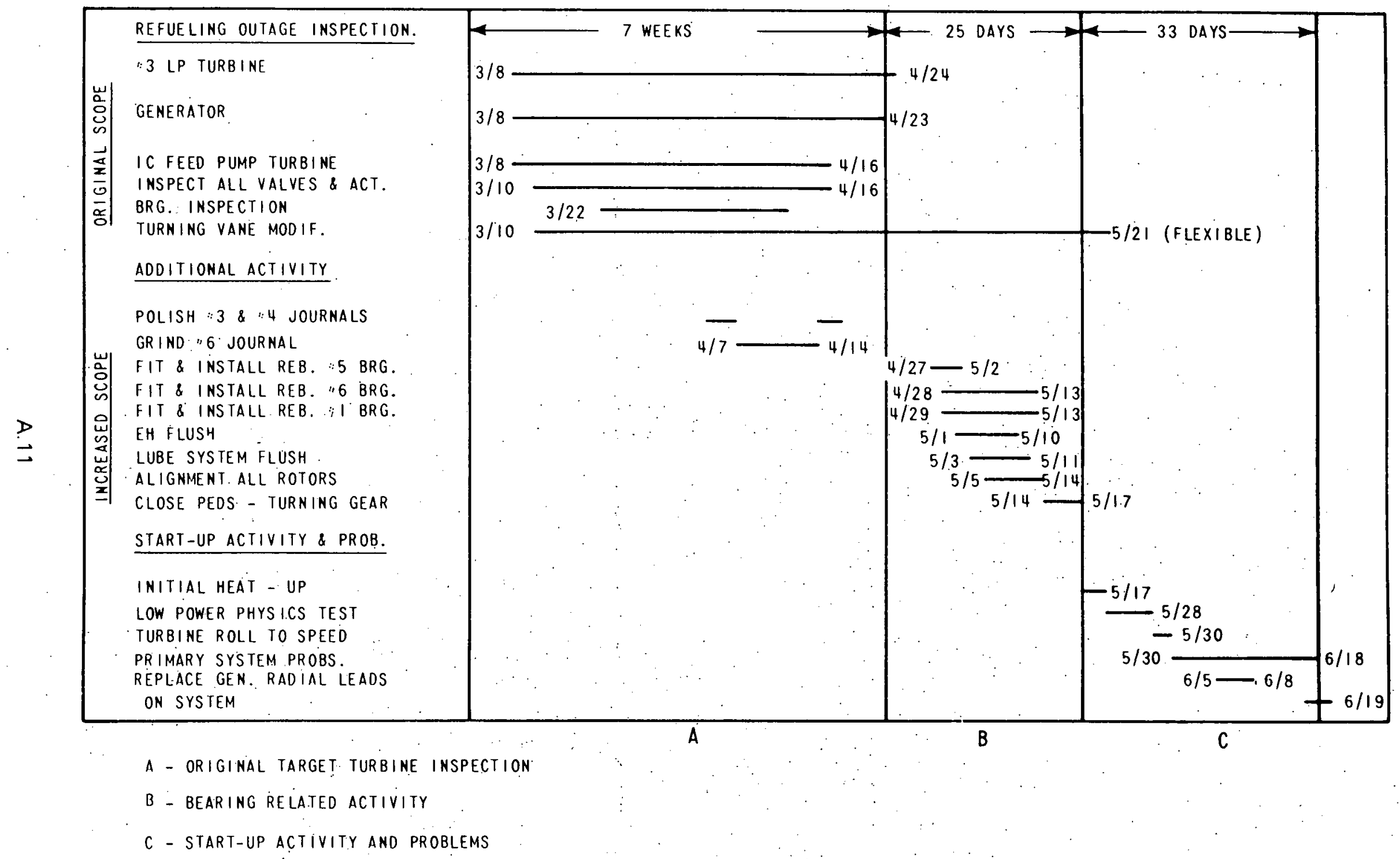


CHART A-2

ZION 2 - 1977 TURBINE OUTAGE

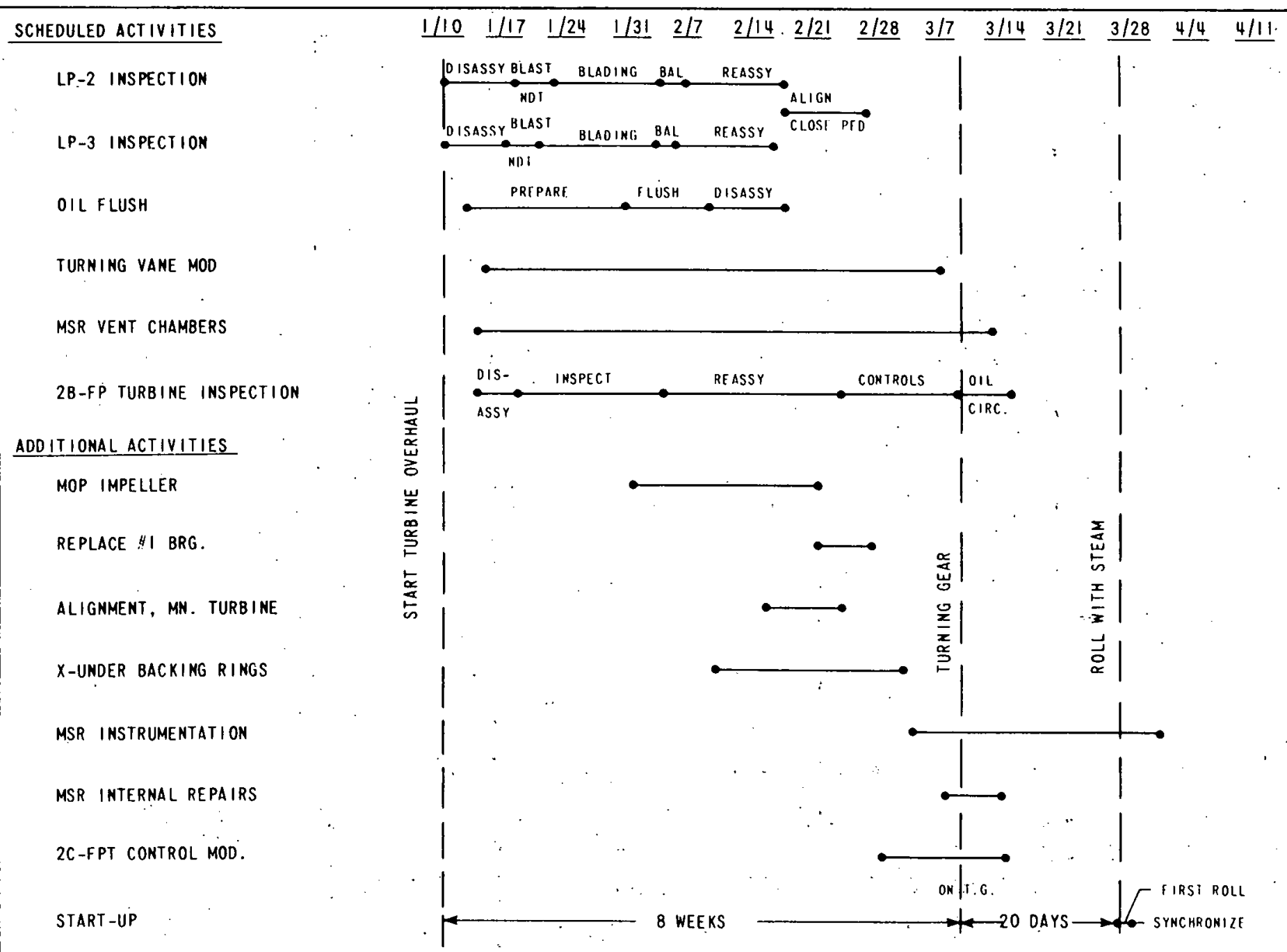




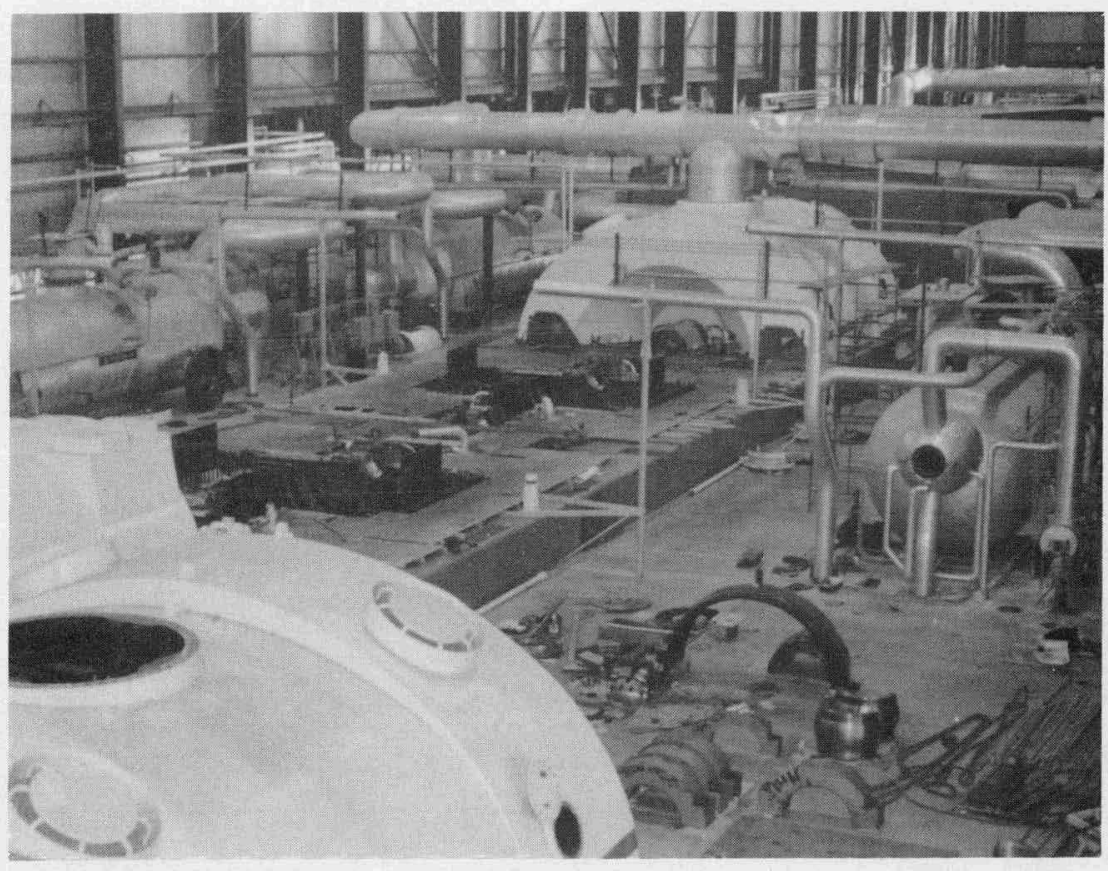

Figure A.1 Zion Unit 2 View from Generator End. LP-B and LP-C Disassembled 


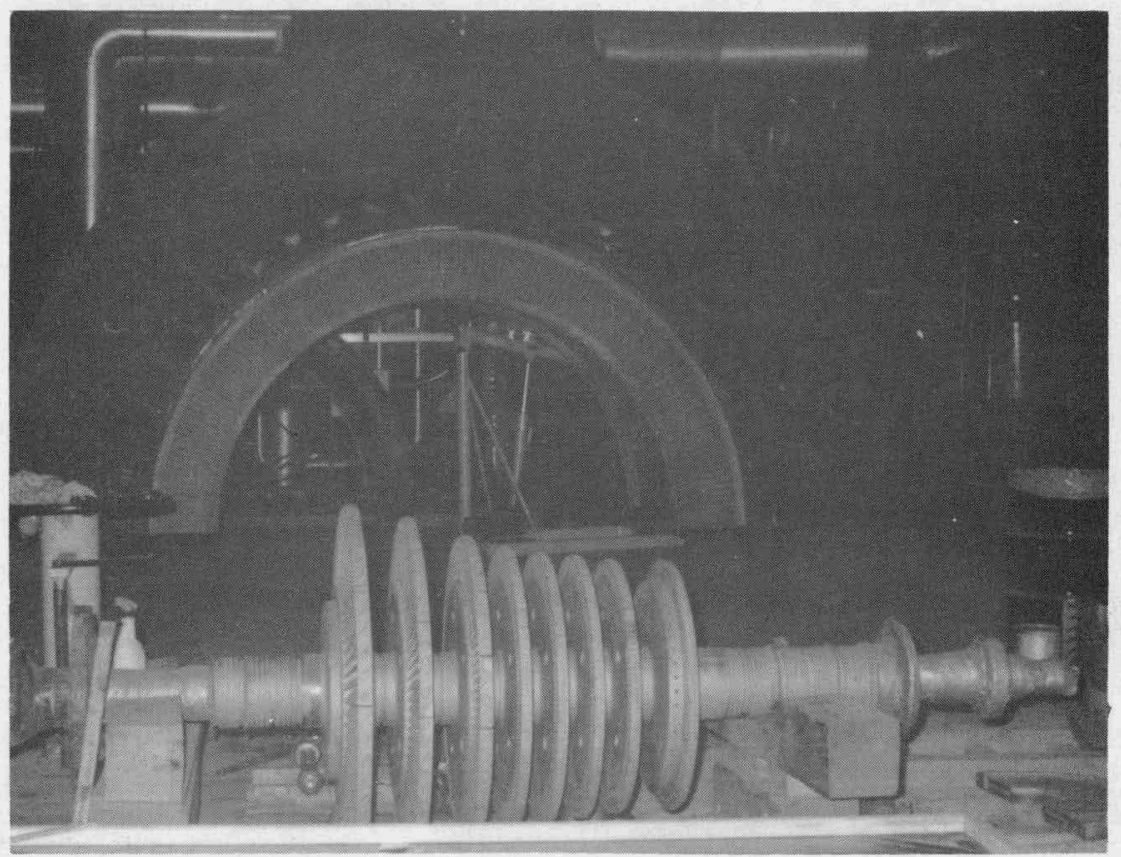

Figure A.2 Zion Unit 2 - Spindle from 2B Feed Pump Turbine. In Background is a No. 1 Inner Cylinder Cover from LP Turbine 


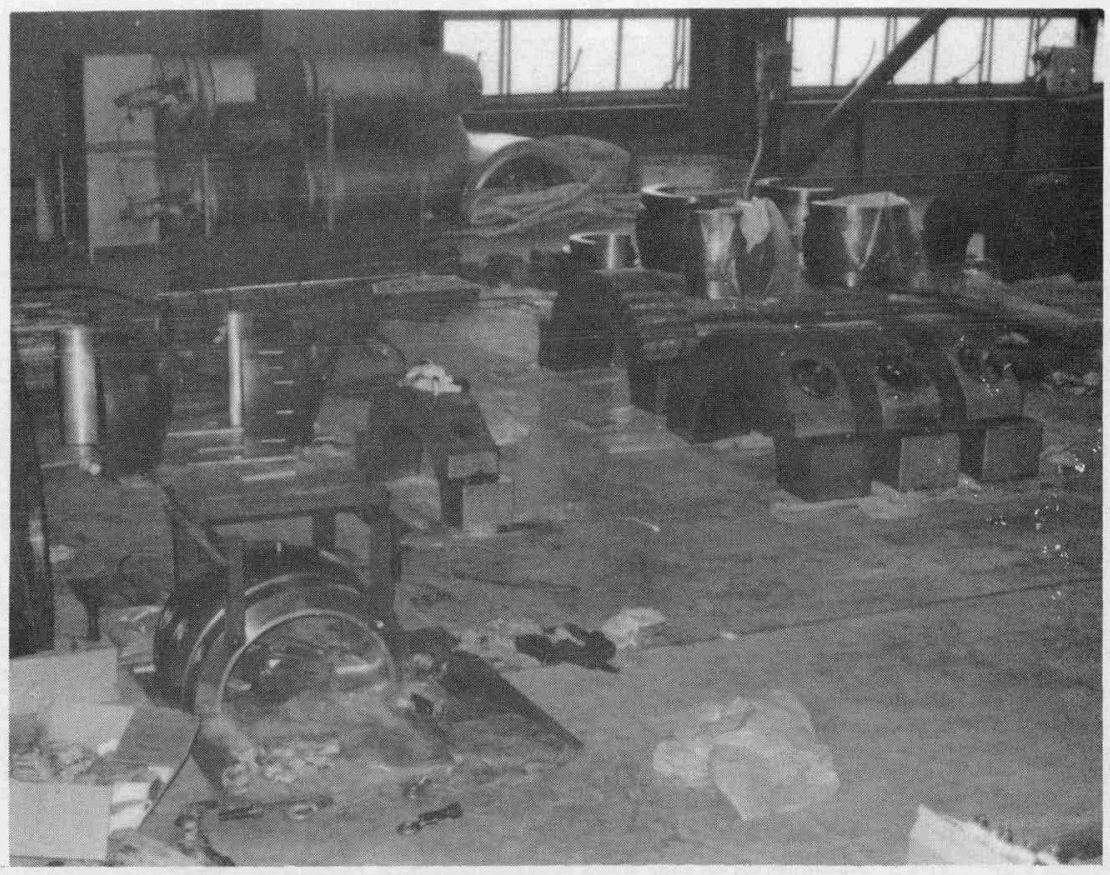

Figure A.3 LP Bearings and Saddles

A. 15 


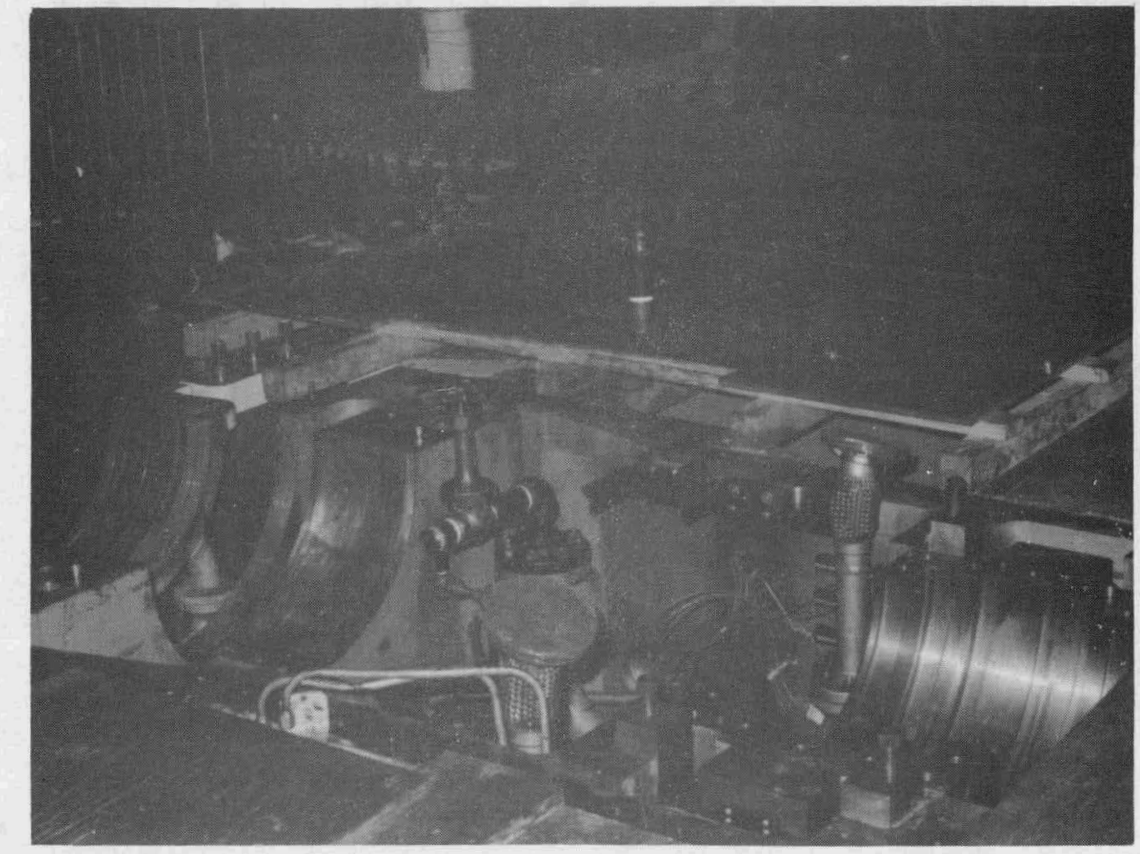

Figure A.4 View of Bearing Pedestal between LP-B and LP-A 


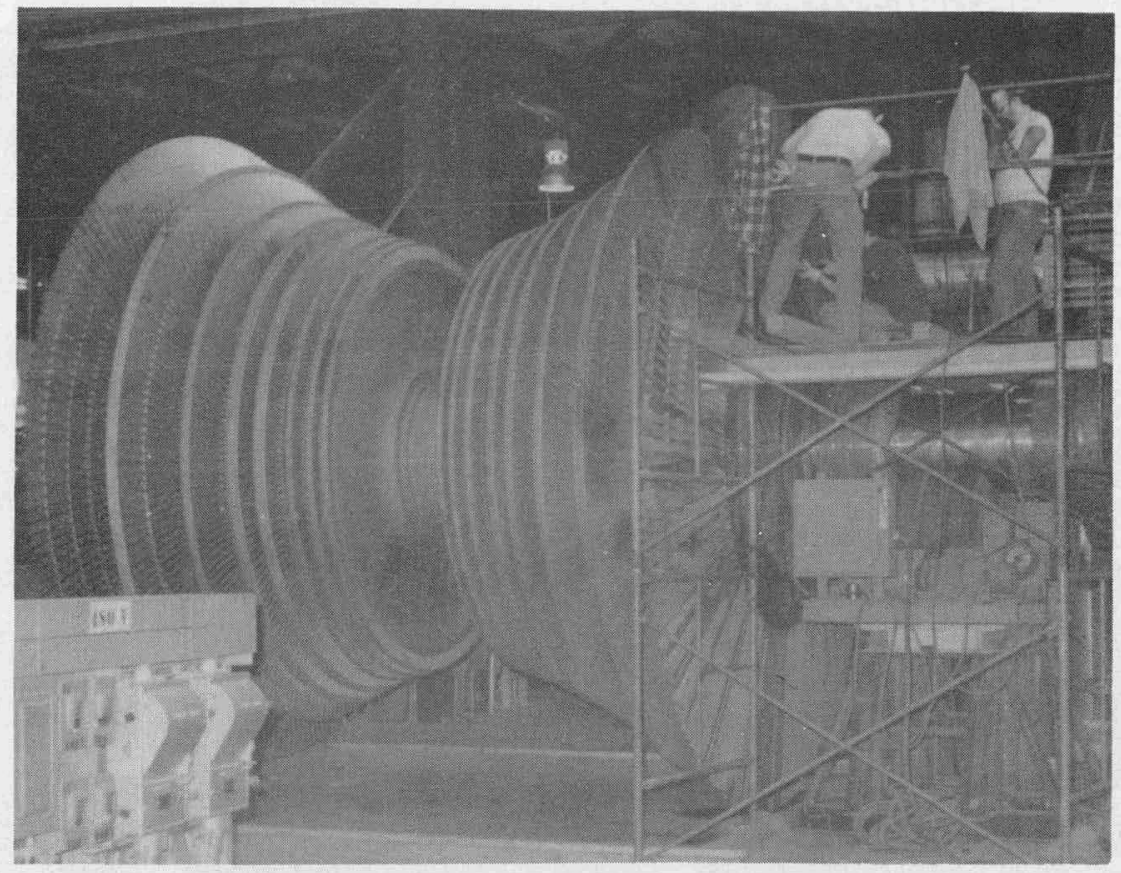

Figure A.5 LP Turbine Spindle with Last Row Blading Repairs in Progress

\section{A. 17}




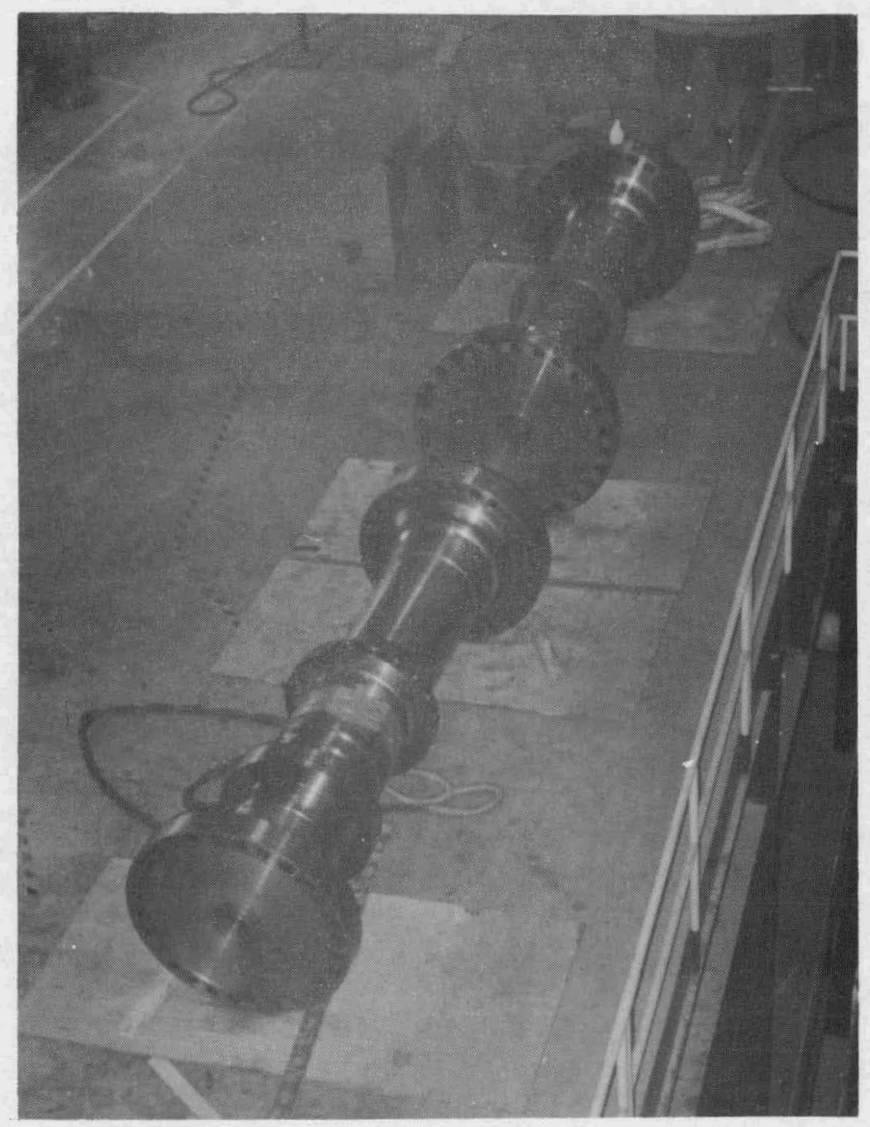

Figure A.6 Jackshafts to Connect LP-A to LP-B and LP-B to LP-C 


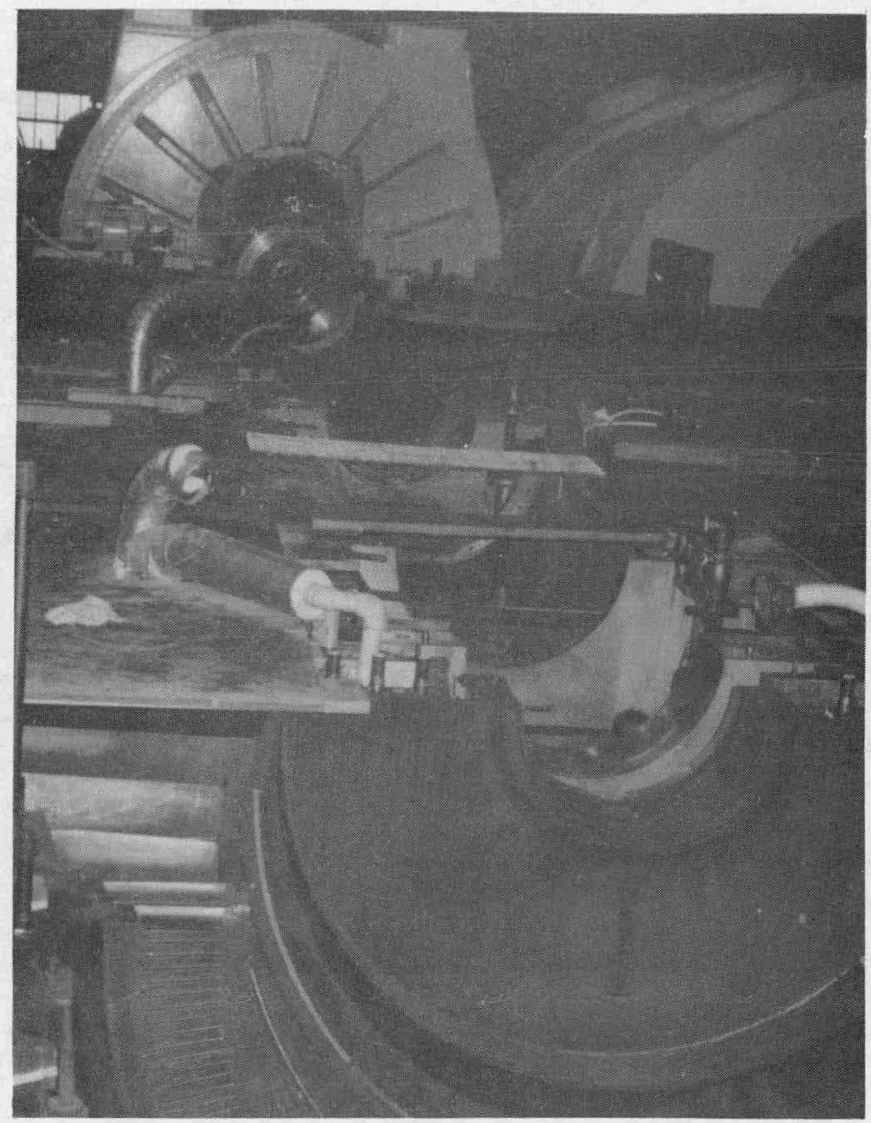

Figure A.7 View Across LP-B and LP-C Towards Generator 


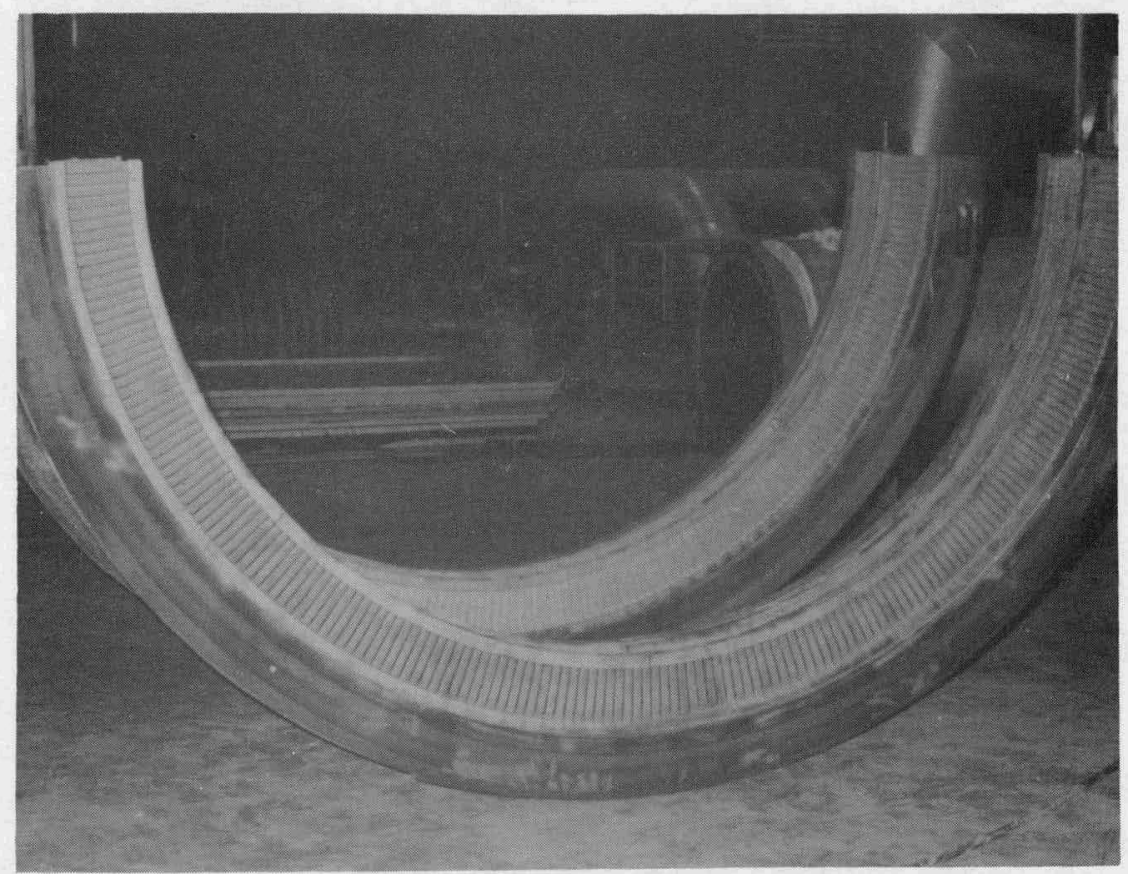

Figure A.8 Lower Half of LP Turbine with Stationary Blades 


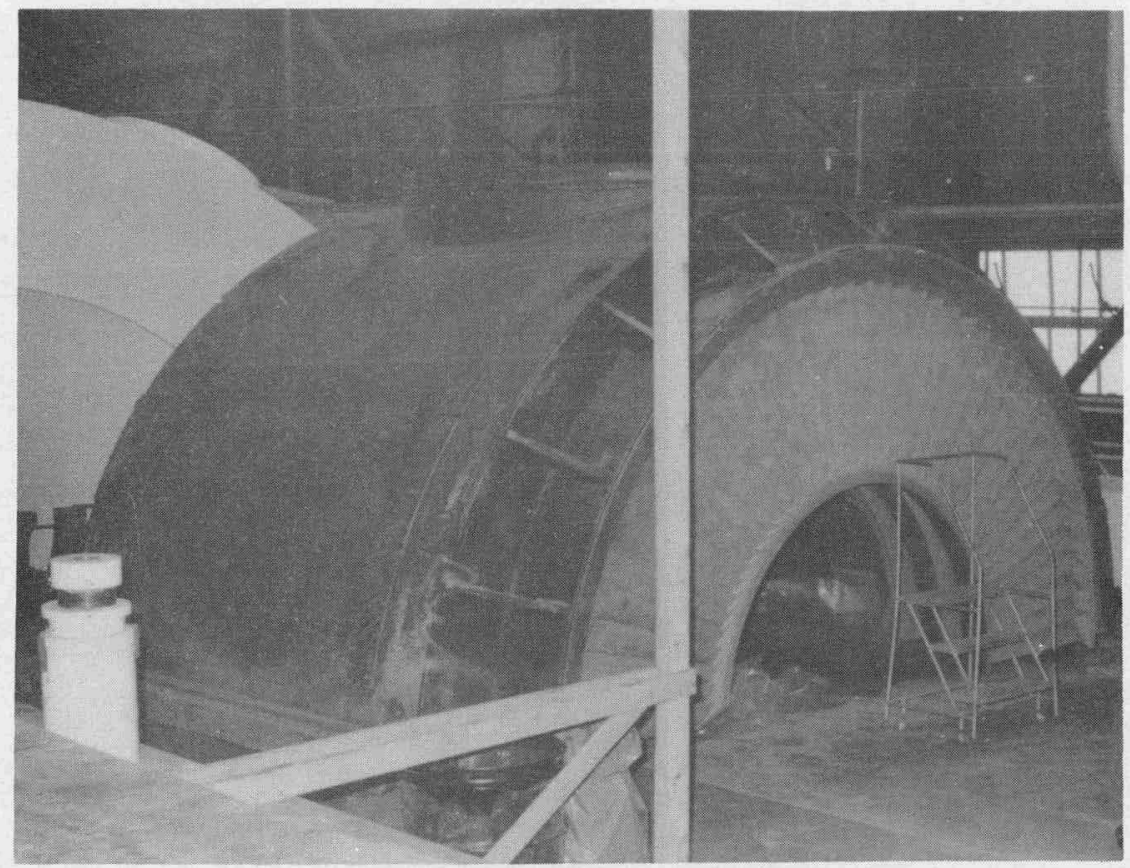

Figure A.9 LP Turbine No. 2 Inner Cylinder Cover Showing Last Row Stationary Blading 


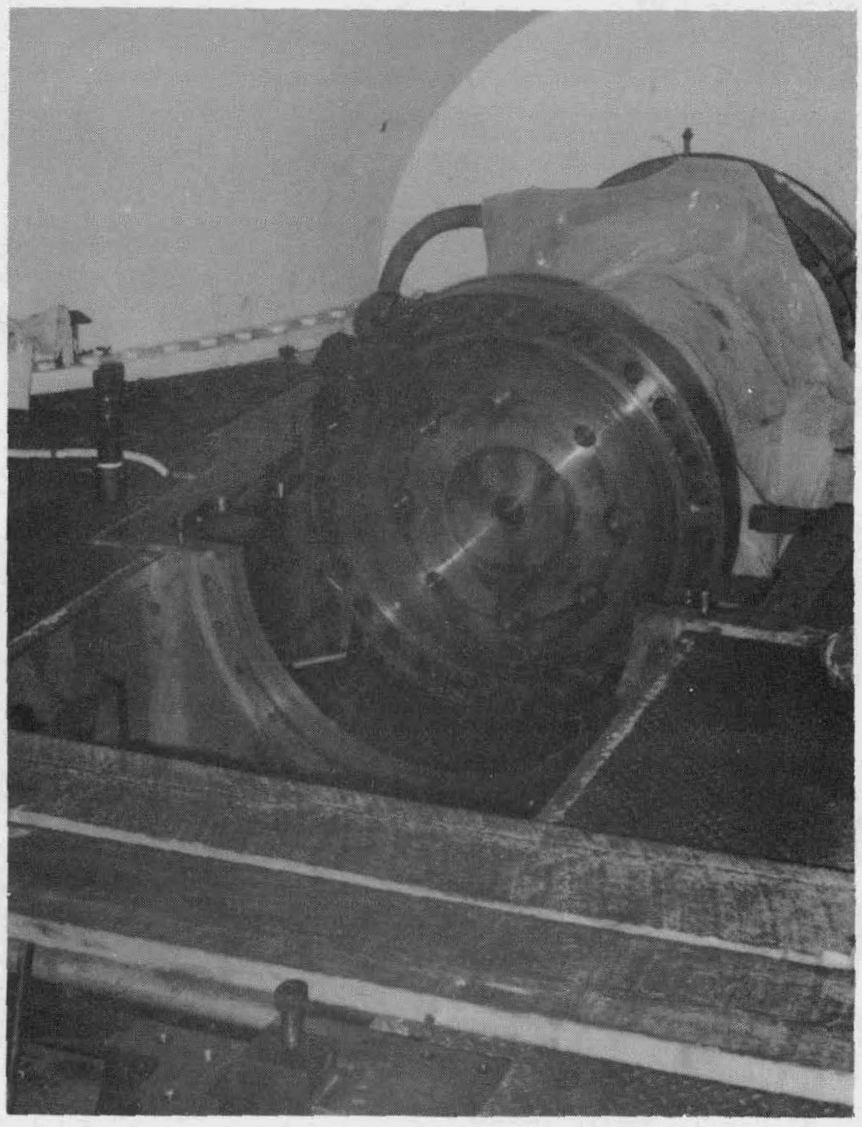

Figure A.10 Generator End Coupling on LP-A Spindle 


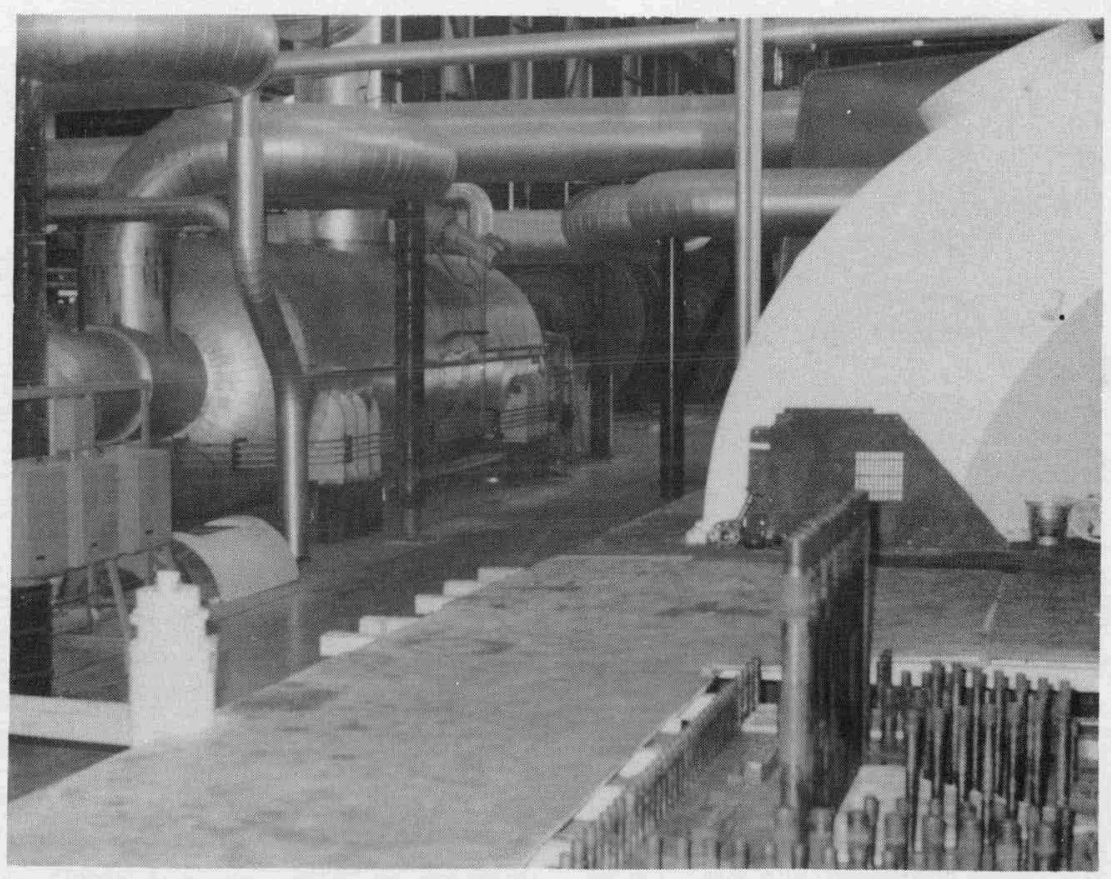

Figure A.11 View from LP-B (Disassembled) toward 2AE-MSR 